WSRC-TR-2007-00439, REVISION 0

Keywords: Hydrogen Kinetics, Hydrogen Storage Vessel Metal Hydride

Retention: Permanent

\title{
Geometry, Heat Removal and Kinetics Scoping Models for Hydrogen Storage Systems
}

Bruce J. Hardy

November 16, 2007

Washington Savannah River Company Savannah River Site

Aiken, SC 29808

Prepared for the U.S. Department of Energy

Under Contract Number DEAC09-96-SR18500

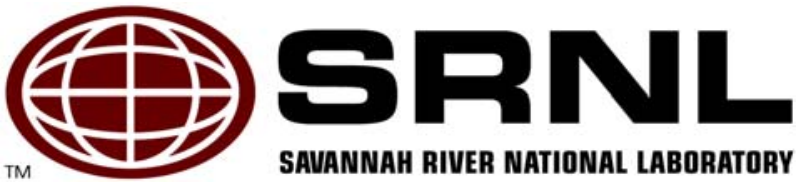




\section{DISCLAIMER}

This report was prepared for the United States Department of Energy under Contract No. DE-AC09-96SR18500 and is an account of work performed under that contract. Neither the United States Department of Energy, nor WSRC, nor any of their employees makes any warranty, expressed or implied, or assumes any legal liability or responsibility for accuracy, completeness, or usefulness, of any information, apparatus, or product or process disclosed herein or represents that its use will not infringe privately owned rights. Reference herein to any specific commercial product, process, or service by trade name, trademark, name, manufacturer or otherwise does not necessarily constitute or imply endorsement, recommendation, or favoring of same by Washington Savannah River Company or by the United States Government or any agency thereof. The views and opinions of the authors expressed herein do not necessarily state or reflect those of the United States Government or any agency thereof.

Printed in the United States of America

Prepared For the

U.S. Department of Energy 
Keywords: Hydrogen Kinetics, Hydrogen Storage Vessel Metal Hydride

Retention: Permanent

\title{
Geometry, Heat Removal and Kinetics Scoping Models for Hydrogen Storage Systems
}

\author{
Bruce J. Hardy
}

November 16, 2007

\begin{tabular}{|l|l|}
\hline Washington Savannah River Company \\
Savannah River Site \\
Aiken, SC 29808
\end{tabular}


WSRC-TR-2007-00439

Revision 0

\section{TABLE OF CONTENTS}

1.0 EXECUTIVE SUMMARY .................................................................................. 1

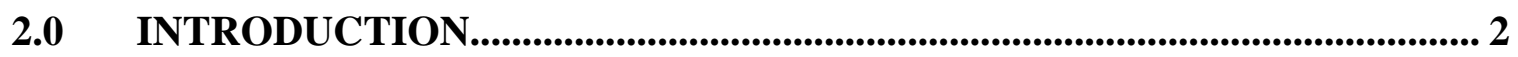

3.0 CHEMICAL KINETICS SCOPING MODEL ................................................... 2

3.1 Sodium Aluminum Hydride Reaction ............................................................... 3

3.2 Alpha Aluminum Hydride Reaction .......................................................... 6

\subsection{DESCRIPTION OF GEOMETRY AND HEAT REMOVAL SCOPING}

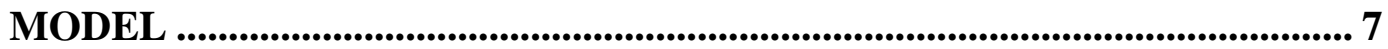

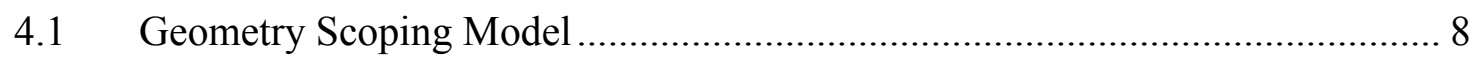

4.1.1 Radius of Outer Coolant Tube Ring ………….................................... 8

4.1.2 Length of Bed ............................................................................ 12

4.1.3 Input Parameters for System Dimensions................................................ 12

4.1.4 Bed Characteristics ........................................................................ 13

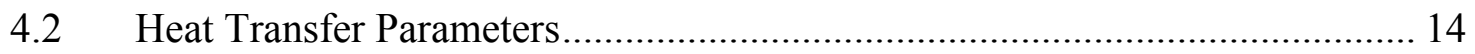

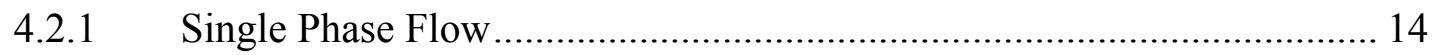

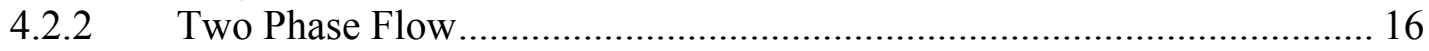

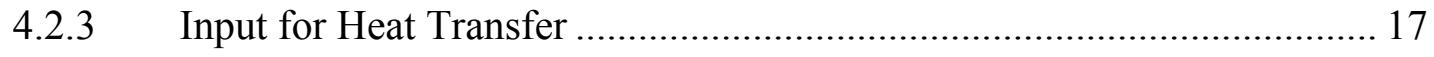

5.0 RESULTS ................................................................................................................ 18

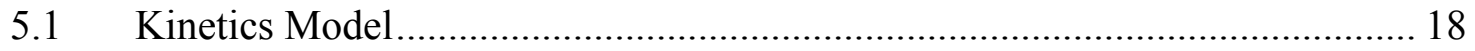

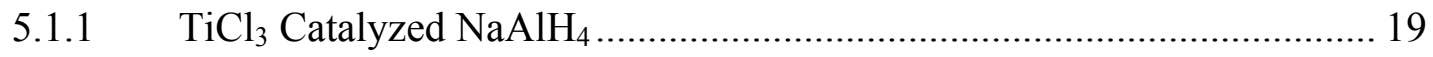

5.1.2 $\alpha-\mathrm{AlH}_{3}$ Discharge Kinetics.............................................................. 22

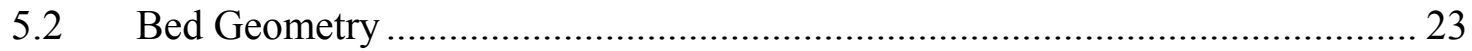

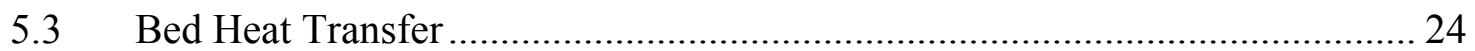

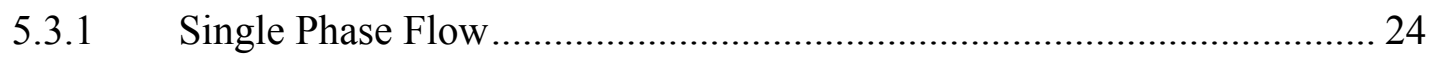

5.3.2 Two-Phase Flow .............................................................................. 24

6.0 CONCLUSIONS .................................................................................................. 25

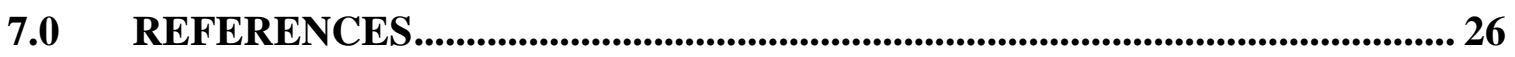

APPENDIX ….............................................................................................................. 27

\section{A.1 GEOMETRY AND HEAT REMOVAL SCOPING MODEL

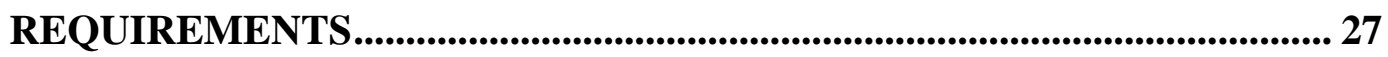

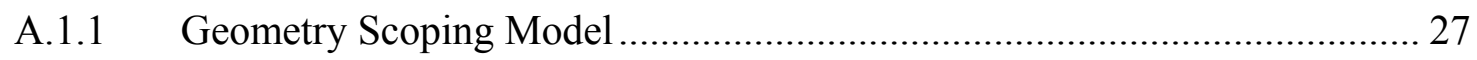

A.1.2 Heat Removal Scoping Model ................................................................. 27 
A.2 KINETICS SCOPING MODEL_........................................................... 29

A.2.1 $\mathrm{TiCl}_{3}$ Catalyzed $\mathrm{NaAlH}_{4}$ Kinetics....................................................... 29

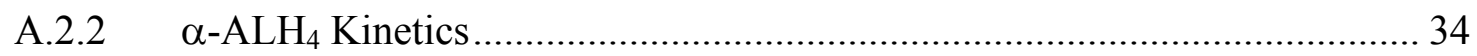

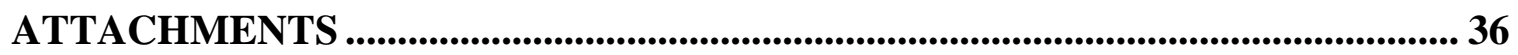

Att.1 Properties of Dowtherm $T^{\circledR}$.................................................................................... 36

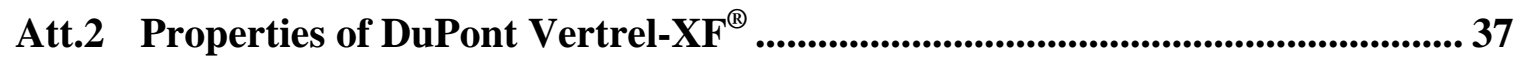

Att.3 UTRC ${ }^{\mathrm{TM}}$ Sodium Alanate Kinetics 1..................................................................... 41

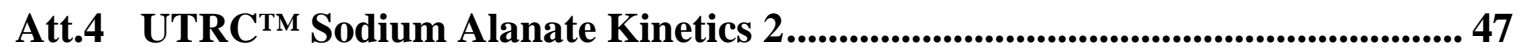


WSRC-TR-2007-00439

Revision 0

\section{LIST OF FIGURES}

Figure 2.0-1

Figure 4.1.1-1

Figure 4.1.1-2

Figure 4.1.1-3

Figure 5.1.1-1

Figure 5.1.1-2

Figure 5.1.1-3

Figure 5.1.1-4

Figure 5.1.2-1

Figure 5.1.2-2

Figure A.1.1

Figure A.2.2
Illustration of a shell, tube and fin hydride bed configuration developed by the United Technologies Research Center ${ }^{\mathrm{TM}}$, East Hartford, Connecticut.

Schematic of bed cross-section. The pressure vessel, liner and any gaps are not included. The number of coolant tubes and hydrogen feed tubes may vary.

Geometry for the partition of the cooled tube surface with respect to the inner and outer areas of the bed. Figure is not to scale.

Schematic expansion of upper half of isosceles triangles formed by the center coolant tube and outer coolant tube, and within the outer coolant tube, see Figure 4.1.1-2.

Hydrogen loading rates at 68 bar from the Mathcad ${ }^{\circledR}$ reaction kinetics model.

Hydrogen loading rates at 68 bar from the UTRCTM reaction kinetics model in Attachments 3 and 4. Solid lines represent data and dashed lines represent the model. The legend of Figure 5.3.1-1 gives the loading temperatures

Loading of hydrogen in the hydride at 50 bar and $100^{\circ} \mathrm{C}$. Storage in both $\mathrm{NaAlH}_{4}$ and $\mathrm{Na}_{3} \mathrm{AlH}_{6}$ are included.

Concentration of all species in the sodium alanate reaction. The initial concentration of $\mathrm{NaH}$ was $13,333.33 \mathrm{~mole} / \mathrm{m}^{3}$ and $0 \mathrm{~mole} / \mathrm{m}^{3}$ for the other hydrides.

Decomposition of $\alpha-\mathrm{AlH}_{3}$ in terms of relative concentration, with respect to the initial concentration of $\alpha$ $\mathrm{AlH}_{3}$.

Rate of $\mathrm{H}_{2}$ generation due to decomposition of $\alpha-\mathrm{AlH}_{3}$. The rate is expressed in terms of the rate of $\mathrm{H}_{2}$ produced relative to the initial concentration of $\alpha-\mathrm{AlH}_{3}$.

System dimensions calculated with the geometry scoping model.

System heat transfer parameters estimated with the heat removal scoping model. 
WSRC-TR-2007-00439

Revision 0

\section{LIST OF TABLES}

Table 3.1-1 Constants for the Rate and Equilibrium Expressions

Table 3.1-2

Values for $\mathrm{wf}_{\text {iso }}^{\text {sat }}(\mathrm{T})$

Table 4.1.3-1

Input for Calculation of System Dimensions

Table 4.2.3-1

Input for Calculation of Heat Transfer Parameters

Table 5.2-1

Calculated Bed and Vessel Parameters

Table 5.3.1-1

Bed Heat Removal Parameters for a Single Coolant Tube

\section{LIST OF ACRONYMS}

$\begin{array}{ll}\text { DOE } & \text { Department of Energy } \\ \text { UTRC } & \text { United Technologies Research Center }\end{array}$ 
WSRC-TR-2007-00439

Revision 0

\section{NOMENCLATURE}

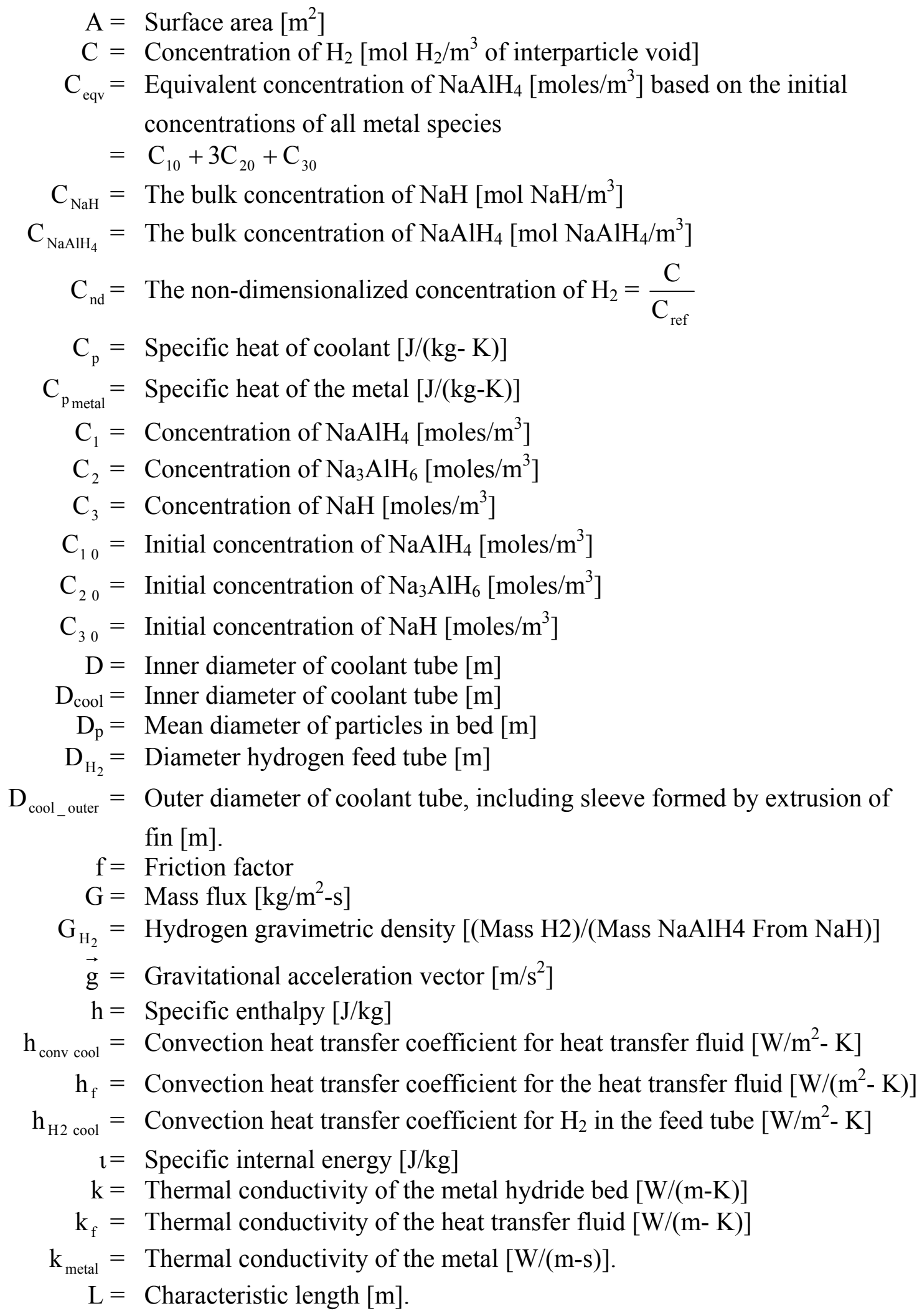


WSRC-TR-2007-00439

Revision 0

$$
\begin{aligned}
& \mathrm{m}_{\mathrm{H}_{2}}=\text { Mass of recoverable hydrogen sorbed in the bed [kg] } \\
& \mathrm{m}_{\text {system }}=\text { Total mass of loaded storage tank, including the bed loaded with } \mathrm{H}_{2} \text {, } \\
& \text { fins, liner gaps and pressure vessel. The mass of the heat transfer fluid } \\
& \text { is not included. } \\
& \mathrm{P}=\text { Pressure }[\mathrm{Pa}] \\
& \mathrm{M}_{\mathrm{i}}=\text { Molecular weight of species i per mole }[\mathrm{kg} / \mathrm{g}-\mathrm{mole}] \\
& \mathrm{M}_{\mathrm{H}_{2}}=\text { Gram molecular weight of } \mathrm{H}_{2}[\mathrm{~kg} / \mathrm{g}-\mathrm{mol}]=0.002016 \mathrm{~kg} / \mathrm{g}-\mathrm{mole} \\
& \mathrm{M}_{\mathrm{NaH}}=\text { Gram molecular weight of } \mathrm{NaH}[\mathrm{kg} / \mathrm{g}-\mathrm{mol}] \\
& \mathrm{M}_{\mathrm{NaAlH}_{4}}=\text { Gram molecular weight of } \mathrm{NaAlH}_{4}[\mathrm{~kg} / \mathrm{g}-\mathrm{mol}]=0.054 \mathrm{~kg} / \mathrm{g} \text {-mole } \\
& \mathrm{M}_{\mathrm{Na}_{3} \mathrm{AlH}_{6}}=\text { Gram molecular weight of } \mathrm{Na}_{3} \mathrm{AlH}_{6} \\
& \hat{\mathrm{n}}=\text { Outward normal to surface } \\
& \mathrm{n}_{\mathrm{NaH}}=\text { Number of moles of } \mathrm{NaH} \\
& \mathrm{n}_{\mathrm{NaAlH}_{4}}=\text { Number of moles of } \mathrm{NaAlH}_{4} \\
& \mathrm{n}_{\mathrm{Na}_{3} \mathrm{AlH}_{6}}=\text { Number of moles of } \mathrm{Na}_{3} \mathrm{AlH}_{6} \\
& \mathrm{n}_{\mathrm{H}_{2}}=\text { Total number hydrogen feed tubes } \\
& \mathrm{Nu}_{\mathrm{D}}=\frac{\mathrm{hD}}{\mathrm{k}}=\text { Nusselt number based on diameter, } \mathrm{D} \\
& \mathrm{P}=\text { Pressure }[\mathrm{Pa}] \\
& \mathrm{P}_{\mathrm{nd}}=\frac{\mathrm{P}}{\mathrm{P}_{\mathrm{ref}}}=\text { Non-dimensional pressure } \\
& \mathrm{P}_{\text {ref }}=\text { Reference pressure }[\mathrm{Pa}] \\
& \operatorname{Pr}=\frac{v}{\alpha}=\text { Prandtl number } \\
& \overrightarrow{\mathrm{q}}^{\prime \prime}=\text { Heat flux vector }\left[\mathrm{W} / \mathrm{m}^{2}\right] \\
& \mathrm{q} "=\text { Heat flux }\left[\mathrm{W} / \mathrm{m}^{2}\right] \\
& \mathrm{R}=\text { Gas constant } \\
& \mathrm{Re}_{\mathrm{D}}=\frac{\mathrm{GD}}{\mu}=\text { Reynolds number based on diameter, } \mathrm{D} \\
& \mathrm{S}=\text { Arc length }[\mathrm{m}] \\
& \mathrm{S}_{\mathrm{H}_{2}}=\text { Rate of } \mathrm{H}_{2} \text { generation per volume of bed from all chemical reactions } \\
& {\left[\mathrm{mol} \mathrm{H}_{2} /\left(\mathrm{m}^{3}-\mathrm{s}\right)\right] \text {, }} \\
& \mathrm{S}_{\mathrm{H}_{2}}>0 \text { if } \mathrm{H}_{2} \text { is produced } \\
& \mathrm{S}_{\mathrm{H}_{2}}<0 \text { if } \mathrm{H}_{2} \text { is removed } \\
& \mathrm{S}_{1}=\text { The arc length of tubes in contact with coolant, lying within area } \mathrm{A}_{1}[\mathrm{~m}] \\
& \mathrm{S}_{2}=\text { The arc length of tubes in contact with coolant, lying within area } A_{2}[\mathrm{~m}] \\
& \mathrm{T}_{\text {coolant bulk }}=\text { Bulk temperature of the heat transfer fluid }[\mathrm{K}] \\
& \mathrm{T}_{\mathrm{nd}}=\frac{\mathrm{T}}{\mathrm{T}_{\mathrm{ref}}}=\text { Non-dimensional temperature }
\end{aligned}
$$


WSRC-TR-2007-00439

Revision 0

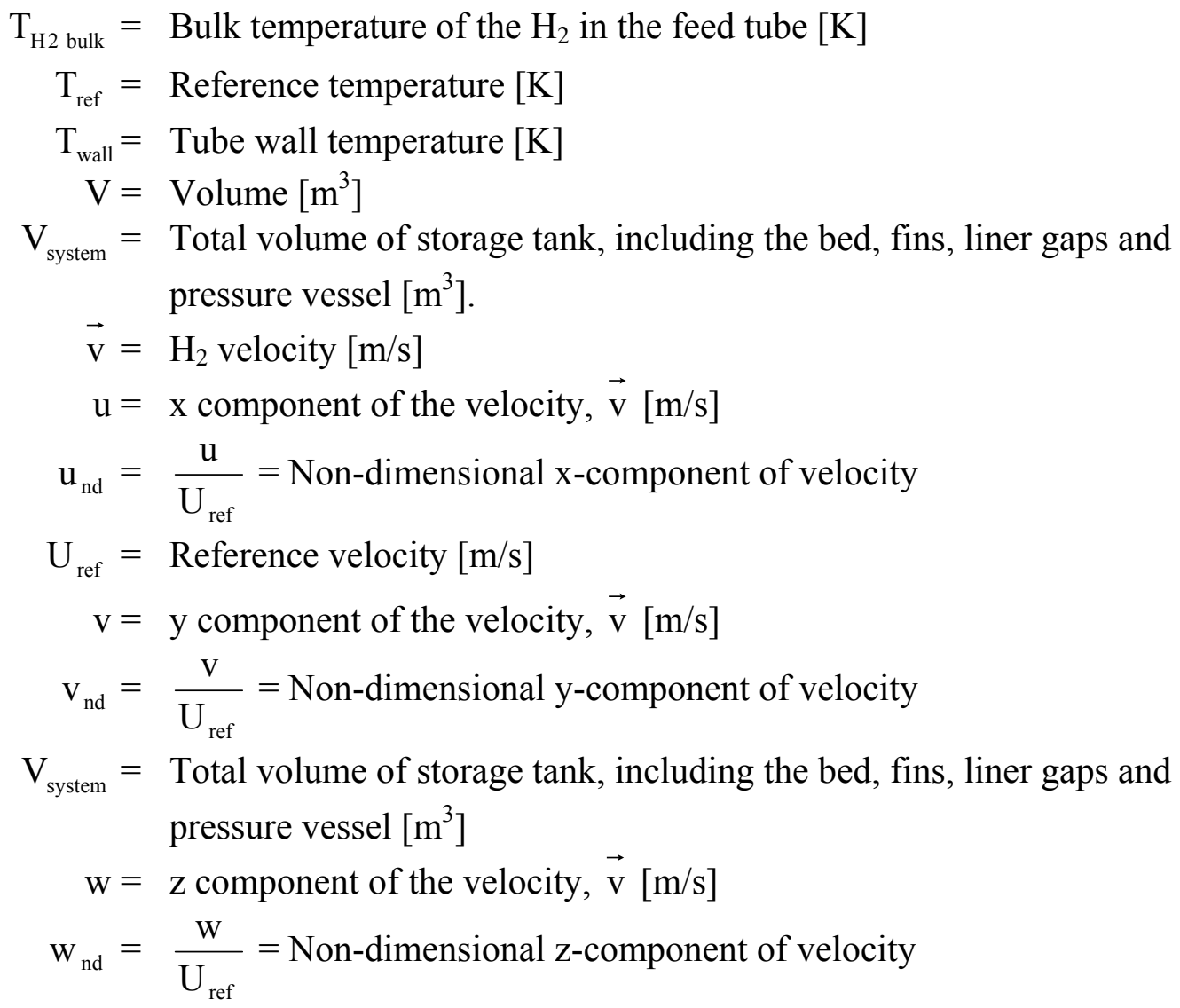

\section{Greek}

$\alpha=$ Thermal diffusivity of coolant $\left[\mathrm{m}^{2} / \mathrm{s}\right]$.

$\Delta \mathrm{C}_{\mathrm{H}_{2}}=$ Change in the concentration of $\mathrm{H}_{2}\left[\mathrm{~mole} / \mathrm{m}^{3}\right]$

$\Delta \mathrm{C}_{\mathrm{NaAlH}_{4}}=$ Change in the concentration of $\mathrm{NaAlH}_{4}\left[\mathrm{~mole} / \mathrm{m}^{3}\right]$

$\Delta \mathrm{H}_{\mathrm{i}}=$ Enthalpy of reaction on a molar basis of species $\mathrm{i}[\mathrm{J} /(\mathrm{mol}$ of $\mathrm{i})]$

$\Delta \mathrm{H}_{\mathrm{rx}}=$ Overall heat of reaction for uptake of $\mathrm{H}_{2}$ by the hydride [J/g-mol].

$\Delta \mathrm{H}_{\mathrm{rxn} \mathrm{1}}=$ Heat of per mole of $\mathrm{H}_{2}$ consumed going to left for reaction 1

$=-37 \mathrm{~kJ} /\left(\mathrm{mol} \mathrm{H}_{2}\right)$

$\Delta \mathrm{H}_{\mathrm{rxn} 2}=$ Heat of per mole of $\mathrm{H}_{2}$ consumed going to left for reaction 2

$=-47 \mathrm{~kJ} /\left(\mathrm{mol} \mathrm{H}_{2}\right)$

$\Delta \mathrm{n}_{\mathrm{H}_{2}}=$ Number of moles of $\mathrm{H}_{2}$ consumed in going form $\mathrm{NaH}$ to $\mathrm{NaAlH}_{4}$ [mole]

$\Delta \mathrm{n}_{\mathrm{NaAlH}_{4}}=$ Number of moles of $\mathrm{NaAlH}_{4}$ produced from $\mathrm{NaH}$ [mole]

$\Delta \mathrm{P}=$ Pressure drop across the length of the tube $[\mathrm{Pa}]$

$\Delta \mathrm{T}=$ Change in bulk temperature of coolant over the heated length of the cooling tube $\left[{ }^{\circ} \mathrm{C}\right]$

$\varepsilon=$ Void between particles in bed

$v=$ Kinematic viscosity of coolant $\left[\mathrm{m}^{2} / \mathrm{s}\right]$ 
WSRC-TR-2007-00439

Revision 0

$$
\begin{aligned}
\rho & =\text { Mass density }\left[\mathrm{kg} / \mathrm{m}^{3}\right] \\
\rho_{\mathrm{i}} & =\text { Mass density of species } \mathrm{i}\left[\mathrm{kg} / \mathrm{m}^{3}\right] \\
\rho_{\text {metal }} & =\text { Density of the metal }\left[\mathrm{kg} / \mathrm{m}^{3}\right] . \\
\mu & =\text { Viscosity }[\mathrm{Pa}-\mathrm{s}] \\
\tau & =\text { Stress tensor, having components } \tau_{\mathrm{ij}}\left[\mathrm{N} / \mathrm{m}^{2}\right] \\
\tau & =\text { Time required for } \mathrm{H}_{2} \text { loading }[\mathrm{s}] .
\end{aligned}
$$

\section{Symbols and Operators}

$$
\begin{aligned}
& \left.\frac{v_{\mathrm{H}_{2}}}{v_{\mathrm{NaH}}}\right|_{\mathrm{Rxn} 2}=\text { Ratio of the stoichiometric coefficient of } \mathrm{H}_{2} \text { to } \mathrm{NaH} \text { in reaction } 2=0.5 \\
& \left.\frac{v_{\mathrm{H}_{2}}}{v_{\mathrm{NaAHH}_{4}}}\right|_{\mathrm{Rxn1}}=\text { Ratio of the stoichiometric coefficient of } \mathrm{H}_{2} \text { to } \mathrm{NaAlH}_{4} \text { in reaction } 1=1 \\
& ()_{\mathrm{H}_{2}}=\text { For } \mathrm{H}_{2} \text { gas } \\
& ()_{\mathrm{R}}=\text { For solid phase reactants } \\
& ()_{\mathrm{P}}=\text { For solid phase products } \\
& ()_{\mathrm{I}}=\text { For inert (non-reacting) material, such as metal foam }
\end{aligned}
$$


WSRC-TR-2007-00439

Revision 0

\subsection{EXECUTIVE SUMMARY}

It is recognized that detailed models of proposed hydrogen storage systems are essential to gain insight into the complex processes occurring during the charging and discharging processes. Such insight is an invaluable asset for both assessing the viability of a particular system and/or for improving its design. The detailed models, however, require time to develop and run. Clearly, it is much more efficient to begin a modeling effort with a good system design and to progress from that point. To facilitate this approach, it is useful to have simplified models that can quickly estimate optimal loading and discharge kinetics, effective hydrogen capacities, system dimensions and heat removal requirements. Parameters obtained from these models can then be input to the detailed models to obtain an accurate assessment of system performance that includes more complete integration of the physical processes.

This report describes three scoping models that assess preliminary system design prior to invoking a more detailed finite element analysis. The three models address the kinetics, the scaling and heat removal parameters of the system, respectively. The kinetics model is used to evaluate the effect of temperature and hydrogen pressure on the loading and discharge kinetics. As part of the kinetics calculations, the model also determines the mass of stored hydrogen per mass of hydride (in a particular reference form). As such, the model can determine the optimal loading and discharge rates for a particular hydride and the maximum achievable loading (over an infinite period of time). The kinetics model developed with the Mathcad ${ }^{\circledR}$ solver, runs in a mater of seconds and can quickly be used to identify the optimal temperature and pressure for either the loading or discharge processes. The geometry scoping model is used to calculate the size of the system, the optimal placement of heat transfer elements, and the gravimetric and volumetric capacities for a particular geometric configuration and hydride. This scoping model is developed in Microsoft Excel ${ }^{\circledR}$ and inputs the mass of hydrogen to be stored, mass of stored hydrogen to mass of hydride (from the kinetics model), component densities, etc. The heat removal scoping model is used to calculate coolant flowrates, pressure drops and temperature increases over the length of the cooling channels. The model also calculates the convection heat transfer coefficient required to remove the heat of reaction associated with hydrogen uptake. The heat removal model inputs dimensions and the mass of hydrogen to be stored directly from the geometry scoping model. Additionally, the model inputs the heats of reaction, the thermal properties of the coolant and the time required to charge the bed. 
WSRC-TR-2007-00439

Revision 0

\subsection{INTRODUCTION}

Detailed models for hydrogen storage systems provide essential information about flow and temperature distributions and the utilization of the bed. However, before constructing a detailed model it is necessary to know the geometry and dimensions of the system, along with its heat transfer requirements, which depend on the limiting reaction kinetics. This document describes scoping models that were developed to estimate system dimensions required to store a given mass of hydrogen, determine coolant flowrates and temperatures required to remove heat generated by uptake or discharge reactions, evaluate the reaction kinetics models and, within the context of these models, determine limiting bed loading rates.

The system of scoping models is general and can be applied to any storage material and bed configuration. In this document, the system of models are applied to $\mathrm{TiCl}_{3}$ catalyzed $\mathrm{NaAlH}_{4}$ storage media in a cylindrical shell and tube storage configuration that has axially spaced fins, that extend in the radial direction; similar to that in Figure 2.0-1. Additionally, the kinetics scoping model is applied to $\alpha-\mathrm{AlH}_{3}$.

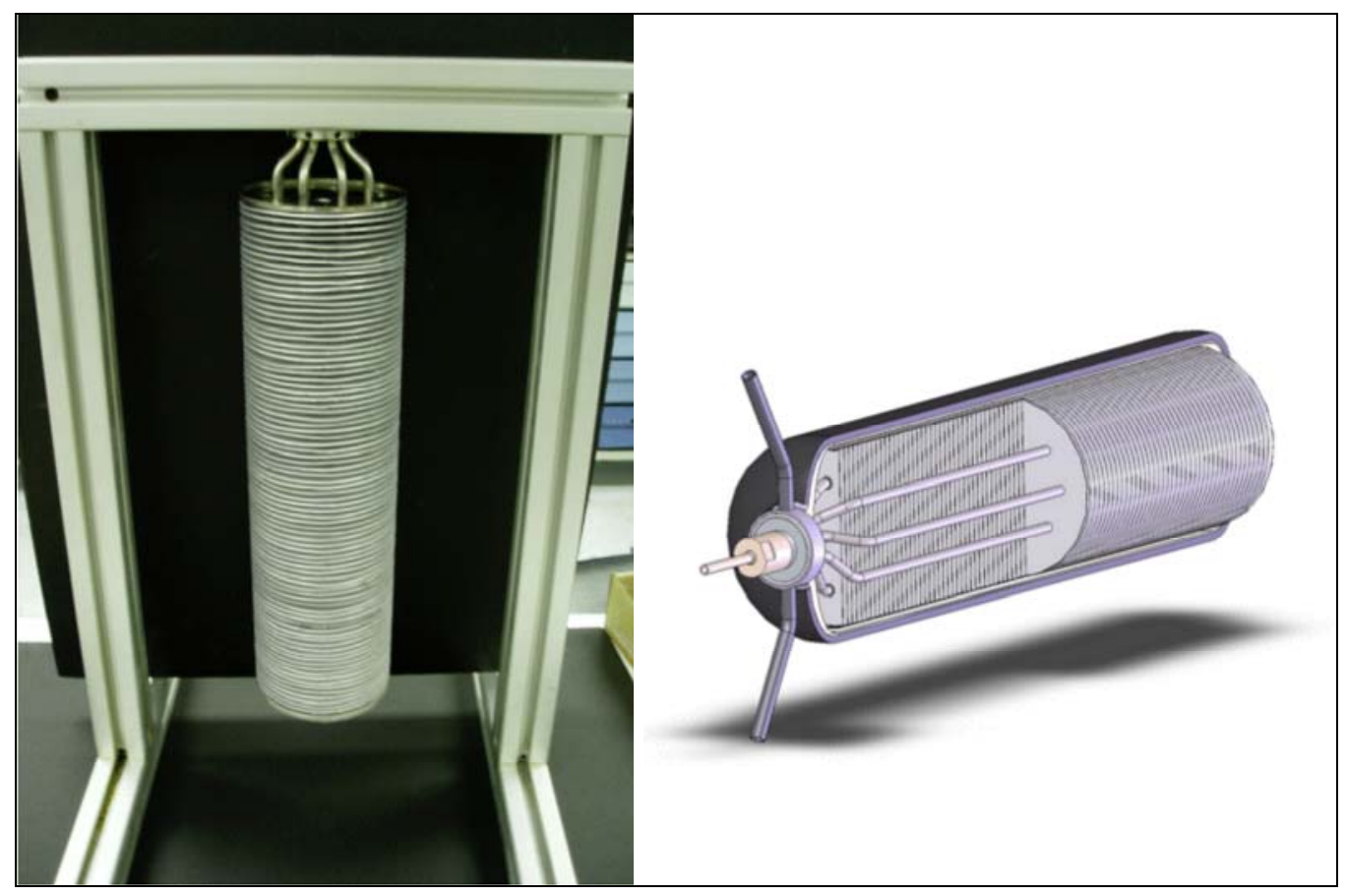

Figure 2.0-1 Illustration of a shell, tube and fin hydride bed configuration developed by the United Technologies Research Center ${ }^{\mathrm{TM}}$, East Hartford, Connecticut.

\subsection{CHEMICAL KINETICS SCOPING MODEL}

The effect of chemical kinetics on the hydrogen loading and discharge rates from a particular hydrogen storage material are evaluated using the chemical kinetics scoping 
model, which is based on the Mathcad ${ }^{\circledR}$, version 14.0.0.163, software. The model, which considers the dependence of reaction kinetics on temperature and pressure, is used to identify potential discrepancies in kinetics data, predict loading rates, and determine the gravimetric and volumetric capacities of the bed.

The equations governing reaction rates for hydrogen with the metal hydrides are dependent on the hydride and its reaction mechanism. In this document, the reactions for hydrogen uptake by $\mathrm{TiCl}_{3}$ catalyzed sodium alanate, $\mathrm{NaAlH}_{4}$, and by alpha aluminum hydride, $\alpha-\mathrm{AlH}_{3}$, are specifically addressed in Sections 3.1 and 3.2. The Mathcad ${ }^{\circledR}$ based model, however, may be applied to any metal hydride once its kinetics have been characterized.

\subsection{Sodium Aluminum Hydride Reaction}

The United Technologies Research CenterTM (UTRC) developed an empirical kinetics model for hydrogen uptake and discharge reactions in $\mathrm{TiCl}_{3}$ catalyzed $\mathrm{NaAlH}_{4}$, see Attachments 3 and 4 . The chemical balance equation for the reaction is

$$
\underbrace{\mathrm{NaAlH}_{4}}_{\text {Species1 }} \underbrace{\leftrightarrow}_{\text {Re action 1 }} \underbrace{\frac{1}{3} \mathrm{Na}_{3} \mathrm{AlH}_{6}}_{\text {Species 2 }}+\frac{2}{3} \mathrm{Al}+\mathrm{H}_{2} \underbrace{\leftrightarrow}_{\text {Re action 2 }} \underbrace{\mathrm{NaH}}_{\text {Species3 }}+\mathrm{Al}+\frac{3}{2} \mathrm{H}_{2}
$$

To use the UTRC kinetics model, define the expressions:

$$
\begin{gathered}
\left.r_{1 F} \equiv C_{\text {eqv }} A_{1 F} \exp \left[-\frac{E_{1 F}}{R T}\right]\left[\frac{P(C, T)-P_{\text {eq } 1}(T)}{P_{\text {eq1 }}(T)}\right]\right] \\
r_{1 B} \equiv-C_{\text {eqv }} A_{1 B} \exp \left[-\frac{E_{1 B}}{R T}\right]\left[\frac{P_{\text {eq1 }}(T)-P(C, T)}{P_{\text {eq1 }}(T)}\right] \\
r_{2 F} \equiv-C_{\text {eqv }} A_{2 F} \exp \left[-\frac{E_{2 F}}{R T}\right]\left[\frac{P(C, T)-P_{\text {eq2 }}(T)}{P_{\text {eq } 2}(T)}\right] \\
r_{2 B} \equiv C_{\text {eqv }} A_{2 B} \exp \left[-\frac{E_{2 B}}{R T}\right]\left[\frac{P_{\text {eq2 }}(T)-P(C, T)}{P_{\text {eq } 2}(T)}\right]
\end{gathered}
$$

where: $\quad r_{1 F}=$ Hydriding (forward) reaction rate coefficient for reaction $1\left[\mathrm{~mole} /\left(\mathrm{m}^{3} \mathrm{~s}\right)\right]$, see Eq. 3.1-1

$\mathrm{r}_{1 \mathrm{~B}}=$ Deydriding (backward) reaction rate coefficient for reaction 1 [mole/( $\left.\mathrm{m}^{3} \mathrm{~s}\right)$ ], see Eq. 3.1-1

$r_{2 \mathrm{~F}}=$ Hydriding (forward) reaction rate coefficient for reaction 2 [mole $\left./\left(\mathrm{m}^{3} \mathrm{~s}\right)\right]$, see Eq. 3.1-1

$\mathrm{r}_{2 \mathrm{~B}}=$ Deydriding (backward) reaction rate coefficient for reaction 2 [mole $\left./\left(\mathrm{m}^{3} \mathrm{~s}\right)\right]$, see Eq. 3.1-1

$\mathrm{C}=$ Concentration of $\mathrm{H}_{2}\left[\mathrm{~mole} / \mathrm{m}^{3}\right]$ 
WSRC-TR-2007-00439

Revision 0

$\mathrm{C}_{\text {eqv }}=$ Equivalent concentration of $\mathrm{NaAlH}_{4}\left[\mathrm{~mole} / \mathrm{m}^{3}\right]$ based on the initial concentrations of all metal species

$=\mathrm{C}_{10}+3 \mathrm{C}_{20}+\mathrm{C}_{30}$

$\mathrm{C}_{10}=$ Initial concentration of $\mathrm{NaAlH}_{4}\left[\mathrm{~mole} / \mathrm{m}^{3}\right]$

$\mathrm{C}_{20}=$ Initial concentration of $\mathrm{Na}_{3} \mathrm{AlH}_{6}\left[\mathrm{~mole} / \mathrm{m}^{3}\right]$

$\mathrm{C}_{30}=$ Initial concentration of $\mathrm{NaH}\left[\mathrm{mole} / \mathrm{m}^{3}\right]$

$\mathrm{P}_{\text {eq1 }}(\mathrm{T})$ and $\mathrm{P}_{\text {eq } 2}(\mathrm{~T})$ are the $\mathrm{H}_{2}$ pressures, in $\mathrm{Pa}$, in equilibrium with the $\mathrm{NaAlH}_{4}$ and the $\mathrm{Na}_{3} \mathrm{AlH}_{6}$ metal hydrides, respectively, at temperature $\mathrm{T}$, in $[\mathrm{K}]$. These equilibrium pressures are given by the van't Hoff equations:

$\mathrm{P}_{\text {eq } 1}(\mathrm{~T})=10^{5} \exp \left[\frac{\Delta \mathrm{H}_{4}}{\mathrm{RT}}-\frac{\Delta \mathrm{S}_{4}}{\mathrm{R}}\right]$

$\mathrm{P}_{\mathrm{eq} 2}(\mathrm{~T})=10^{5} \exp \left[\frac{\Delta \mathrm{H}_{2}}{\mathrm{RT}}-\frac{\Delta \mathrm{S}_{2}}{\mathrm{R}}\right]$

Values for the constants used in Eqs. 3.1-2a-d, and 3.1-3a-b are listed in Table 3.1-1

Table 3.1-1

Constants for the Rate and Equilibrium Expressions

\begin{tabular}{|c|c|}
\hline Constant & Value \\
\hline $\mathrm{A}_{1 \mathrm{~F}}$ & $10^{8}$ \\
\hline $\mathrm{A}_{1 \mathrm{~B}}$ & $4 \times 10^{5}$ \\
\hline $\mathrm{A}_{2 \mathrm{~F}}$ & $1.5 \times 10^{5}$ \\
\hline $\mathrm{A}_{2 \mathrm{~B}}$ & $6 \times 10^{12}$ \\
\hline $\mathrm{E}_{1 \mathrm{~F}}$ & $80.0 \mathrm{~kJ} / \mathrm{mol}$ \\
\hline $\mathrm{E}_{1 \mathrm{~B}}$ & $110.0 \mathrm{~kJ} / \mathrm{mol}$ \\
\hline $\mathrm{E}_{2 \mathrm{~F}}$ & $70.0 \mathrm{~kJ} / \mathrm{mol}$ \\
\hline $\mathrm{E}_{2 \mathrm{~B}}$ & $110.0 \mathrm{~kJ} / \mathrm{mol}$ \\
\hline$\chi_{1 \mathrm{~F}}$ & 2.0 \\
\hline$\chi_{1 \mathrm{~B}}$ & 2.0 \\
\hline$\chi_{2 \mathrm{~F}}$ & 1.0 \\
\hline$\chi_{2 \mathrm{~B}}$ & 1.0 \\
\hline$\frac{\Delta \mathrm{H}_{1}}{\mathrm{R}}$ & -4475 \\
\hline$\frac{\Delta \mathrm{S}_{1}}{\mathrm{R}}$ & -14.83 \\
\hline$\frac{\Delta \mathrm{H}_{2}}{\mathrm{R}}$ & -6150 \\
\hline$\frac{\Delta \mathrm{S}_{2}}{\mathrm{R}}$ & -16.22 \\
\hline
\end{tabular}


WSRC-TR-2007-00439

Revision 0

The reference for this model, contained in Attachment A-1, proposes the kinetics equations

$\frac{\mathrm{dC}_{1}}{\mathrm{dt}}= \begin{cases}\mathrm{r}_{1 \mathrm{~F}}\left[\frac{3 \mathrm{C}_{2}(\mathrm{t})}{\mathrm{C}_{\text {eqv }}}-\mathrm{C}_{2 \text { sat }}(\mathrm{T})\right]^{\chi_{1 \mathrm{~F}}} & \text { if } \mathrm{P} \geq \mathrm{P}_{\text {eq } 1}(\mathrm{~T}) \\ \mathrm{r}_{1 \mathrm{~B}}\left[\frac{\mathrm{C}_{1}(\mathrm{t})}{\mathrm{C}_{\text {eqv }}}\right]^{\chi_{1 \mathrm{~B}}} & \text { if } \mathrm{P}<\mathrm{P}_{\text {eq } 1}(\mathrm{~T}) \text { and } \mathrm{C}_{1}(\mathrm{t}) \geq 0\end{cases}$

and

$\frac{\mathrm{dC}_{3}}{\mathrm{dt}}= \begin{cases}\mathrm{r}_{2 \mathrm{~F}}\left[\frac{\mathrm{C}_{3}(\mathrm{t})}{\mathrm{C}_{\text {eqv }}}-\mathrm{C}_{3 \mathrm{sat}}(\mathrm{T})\right]^{\chi_{2 \mathrm{~F}}} & \text { if } \mathrm{P} \geq \mathrm{P}_{\mathrm{eq} 2}(\mathrm{~T}) \\ \mathrm{r}_{2 \mathrm{~B}}\left[\frac{3 \mathrm{C}_{2}(\mathrm{t})}{\mathrm{C}_{\text {eqv }}}\right]^{\chi_{2 \mathrm{~B}}} & \text { if } \mathrm{P}<\mathrm{P}_{\mathrm{eq} 2}(\mathrm{~T}) \text { and } \mathrm{C}_{2}(\mathrm{t}) \geq 0\end{cases}$

By Eq. 3.1-1

$\frac{\mathrm{dC}_{2}}{\mathrm{dt}}=-\frac{1}{3}\left(\frac{\mathrm{dC}_{1}}{\mathrm{dt}}+\frac{\mathrm{dC}_{3}}{\mathrm{dt}}\right)$ or $\mathrm{C}_{2}=\mathrm{C}_{20}-\frac{1}{3}\left[\left(\mathrm{C}_{1}-\mathrm{C}_{10}\right)+\left(\mathrm{C}_{3}-\mathrm{C}_{30}\right)\right]$

where: $\quad \mathrm{C}_{1}=$ Concentration of $\mathrm{NaAlH}_{4}\left[\mathrm{~mole} / \mathrm{m}^{3}\right]$

$\mathrm{C}_{2}=$ Concentration of $\mathrm{Na}_{3} \mathrm{AlH}_{6}\left[\mathrm{~mole} / \mathrm{m}^{3}\right]$

$\mathrm{C}_{3}=$ Concentration of $\mathrm{NaH}\left[\mathrm{mole} / \mathrm{m}^{3}\right]$

Based on data for the loading of $\mathrm{NaH}$, expressions for $\mathrm{C}_{2 \text { sat }}(\mathrm{T})$ and $\mathrm{C}_{3 \text { sat }}(\mathrm{T})$, in

$\left[\mathrm{mole} / \mathrm{m}^{3}\right]$, were estimated by UTRC in Attachment 1 as

$\mathrm{C}_{2 \text { sat }}(\mathrm{T})=0$

$\mathrm{C}_{3 \text { sat }}(\mathrm{T})=\mathrm{r}_{\text {sat }}\left(1-\frac{\mathrm{wf}_{\text {iso }}^{\mathrm{sat}}(\mathrm{T})}{0.056}\right)$

where: $\quad r_{\text {sat }}=\operatorname{Max}\left[1,\left(1-\frac{0.0373}{0.056-\mathrm{wf}_{\text {iso }}^{\text {sat }}(\mathrm{T})}\right)\right]$

The values for $\mathrm{wf}_{\mathrm{iso}}^{\mathrm{sat}}(\mathrm{T})$, the saturation hydrogen weight fraction for loading at a fixed temperature T, are listed in Table 3.1-2. Both the Mathcad ${ }^{\circledR}$ kinetics scoping model, and the $\mathrm{COMSOL}^{\circledR}$ two and three-dimensional system models, Hardy [2007], use a spline fit to this data with extrapolated values fixed at the endpoints. 
WSRC-TR-2007-00439

Revision 0

Table 3.1-2

Values for $\mathrm{wf}_{\text {iso }}^{\text {sat }}(\mathrm{T})$

\begin{tabular}{|c|c|}
\hline $\mathbf{T}(\mathbf{K})$ & $\mathrm{wf}_{\text {iso }}^{\text {sat }}(\mathrm{T})$ \\
\hline \hline 353.15 & 0.021 \\
\hline 363.15 & 0.023 \\
\hline 373.15 & 0.029 \\
\hline 393.15 & 0.022 \\
\hline 413.15 & 0.018 \\
\hline
\end{tabular}

The weight fraction of $\mathrm{H}_{2}$ contained in the sodium alanate metal, based on Eq. 3.1-1, is defined as

$$
\begin{aligned}
\text { wf } & =\frac{\text { Mass of } \mathrm{H}_{2} \text { in Metal }}{\text { Equivalent Mass of } \mathrm{NaAlH}_{4}} \\
= & \frac{\left(1.5 \mathrm{n}_{\mathrm{NaAlH}_{4}}+0.5 \mathrm{n}_{\mathrm{Na}_{3} \mathrm{AlH}_{6}}\right) \mathrm{M}_{\mathrm{H}_{2}}}{\mathrm{n}_{\mathrm{NaAlH}_{4}} \mathrm{M}_{\mathrm{NaALH}_{4}}+3 \mathrm{n}_{\mathrm{Na}_{3} \mathrm{AlH}_{6}} \mathrm{M}_{\mathrm{Na}_{3} \mathrm{AlH}_{6}}+\mathrm{n}_{\mathrm{NaH}} \mathrm{M}_{\mathrm{NaH}}} \\
& =\frac{1.5 \mathrm{C}_{1}+0.5 \mathrm{C}_{2}}{\mathrm{C}_{\text {eqv }}} \frac{\mathrm{M}_{\mathrm{H}_{2}}}{\mathrm{M}_{\mathrm{NaAlH}_{4}}}
\end{aligned}
$$

where: $\quad \mathrm{n}_{\mathrm{NaAlH}_{4}}=$ Number of moles of $\mathrm{NaAlH}_{4}$

$\mathrm{n}_{\mathrm{Na}_{3} \mathrm{AlH}_{6}}=$ Number of moles of $\mathrm{Na}_{3} \mathrm{AlH}_{6}$

$\mathrm{n}_{\mathrm{NaH}}=$ Number of moles of $\mathrm{NaH}$

$\mathrm{M}_{\mathrm{NaAlH}_{4}}=$ Gram molecular weight of $\mathrm{NaAlH}_{4}[\mathrm{~kg} / \mathrm{g}-\mathrm{mole}]$

$\mathrm{M}_{\mathrm{Na}_{3} \mathrm{AlH}_{6}}=$ Gram molecular weight of $\mathrm{Na}_{3} \mathrm{AlH}_{6}[\mathrm{~kg} / \mathrm{g}-\mathrm{mole}]$

$\mathrm{M}_{\mathrm{NaH}}=$ Gram molecular weight of $\mathrm{NaH}[\mathrm{kg} / \mathrm{g}-\mathrm{mole}]$

$\mathrm{M}_{\mathrm{H}_{2}}=$ Gram molecular weight of $\mathrm{H}_{2}[\mathrm{~kg} / \mathrm{g}-\mathrm{mole}]$.

\subsection{Alpha Aluminum Hydride Reaction}

The reaction kinetics model for discharge of hydrogen from $\alpha-\mathrm{AlH}_{3}$ is based on Graetz and Reilly [2005]. Data was used to fit the constants $\mathrm{E}_{\mathrm{a}}$ and $\mathrm{A}$ in the reaction rate $\mathrm{k}(\mathrm{T})$, which is given by

$\mathrm{k}(\mathrm{T})=\mathrm{A} \exp \left(-\frac{\mathrm{E}_{\mathrm{a}}}{\mathrm{RT}}\right)$

where: $\quad \mathrm{A}=$ Constant $[1 / \mathrm{s}]$

$\mathrm{R}=$ Gas constant $=8.314 \frac{\mathrm{J}}{\mathrm{mol} \mathrm{K}}$

$\mathrm{E}_{\mathrm{a}}=$ Activation energy $[\mathrm{J} / \mathrm{mol}]$

$\mathrm{T}=$ Temperature $[\mathrm{K}]$. 
WSRC-TR-2007-00439

Revision 0

The rate of decomposition of $\alpha-\mathrm{AlH}_{3}$ is obtained in terms of the fractional decomposition, $\alpha$, where

$\alpha \equiv \frac{\mathrm{n}_{\mathrm{AlH}_{3} 0}-\mathrm{n}_{\mathrm{AlH}_{3}}(\mathrm{t})}{\mathrm{n}_{\mathrm{AlH}_{3} 0}}$

So that,

$\frac{\mathrm{d} \alpha}{\mathrm{dt}} \equiv \frac{\mathrm{d}}{\mathrm{dt}}\left[\frac{\mathrm{n}_{\mathrm{AlH}_{3} 0}-\mathrm{n}_{\mathrm{AlH}_{3}}(\mathrm{t})}{\mathrm{n}_{\mathrm{AlH}_{3} 0} 0}\right]=-\frac{\mathrm{d}}{\mathrm{dt}}\left[\frac{\mathrm{n}_{\mathrm{AlH}_{3}}(\mathrm{t})}{\mathrm{n}_{\mathrm{AlH}_{3} 0}}\right]$

where: $\quad \mathrm{n}_{\mathrm{AlH}_{3} 0}=$ Initial number of moles of $\mathrm{AlH}_{3}$

$n_{\mathrm{AlH}_{3}}(\mathrm{t})=$ Number of moles of $\mathrm{AlH}_{3}$ at time $\mathrm{t}$.

$\alpha$ is expressed as

$\alpha=1-\exp \left(-\mathrm{Bt}^{\mathrm{n}}\right)$

where: $\mathrm{k}(\mathrm{T}) \equiv \mathrm{B}^{1 / \mathrm{n}} \quad$ or $\quad \mathrm{B}=\mathrm{k}(\mathrm{T})^{\mathrm{n}}$

Then, from Equations 3.2-4 and 3.2-5

$\alpha=1-\exp \left(-[\mathrm{k}(\mathrm{T}) \mathrm{t}]^{\mathrm{n}}\right)$

Graetz and Reilly found that $\mathrm{n} \approx 2$ and for $\alpha-\mathrm{AlH}_{3}, \mathrm{~A}=1.2 \times 10^{10}\left(\mathrm{~s}^{-1}\right)$

and $\mathrm{E}_{\mathrm{a}}=102.2 \times 10^{3} \mathrm{~J} / \mathrm{mol}$.

Hence, from Equations 3.2-3 and 3.2-6

$\frac{\mathrm{d}}{\mathrm{dt}} \mathrm{n}_{\mathrm{AlH}_{3}}(\mathrm{t})=2 \mathrm{n}_{\mathrm{AlH}_{3} 0}\left(\mathrm{k}(\mathrm{T})^{2} \mathrm{t}\right) \exp \left[-(\mathrm{k}(\mathrm{T}) \mathrm{t})^{2}\right]$

Equation 3.2-1, along with the values for $\mathrm{A}$ and $\mathrm{E}_{\mathrm{a}}$, is used to provide an explicit expression for $\mathrm{k}(\mathrm{T})$.

\subsection{DESCRIPTION OF GEOMETRY AND HEAT REMOVAL SCOPING MODEL}

The size of a hydrogen storage system, the location of particular components and it gravimetric and volumetric capacities are calculated with the geometry scoping model. Operating parameters for the heat removal system are calculated with the heat removal parameter scoping model. The heat transfer scoping model inputs data from the geometry scoping model and is therefore run afterwards. Although the two scoping models are distinct, they are both incorporated in to the same Microsoft Excel ${ }^{\circledR}$ 
WSRC-TR-2007-00439

Revision 0

workbook, using the workbook format to transfer necessary data from the geometry scoping model to the heat transfer scoping model.

\subsection{Geometry Scoping Model}

The storage system modeled in this report consists of a cylindrical bed with a circular array of axial coolant tubes and a central axial coolant tube, see Figure 4.1.1-1. Fins used to enhance heat transfer, are positioned normal to the vessel axis. The arrangement of fins is similar to that of the UTRC ${ }^{\text {TM }}$ storage vessel shown in Figure 2.0-1. The storage media $\left(\mathrm{TiCl}_{3}\right.$ catalyzed $\left.\mathrm{NaAlH}_{4}\right)$ is layered between the fins. Hydrogen is assumed to be introduced to the bed by a circular array of axial tubes that could be filled with an inert porous metal. The pressure vessel wall is assumed to have a cylindrical midsection with hemispherical end caps.

\subsubsection{Radius of Outer Coolant Tube Ring}

Consider a cylindrical bed having a cross-sectional geometry similar to that in Figure 4.1.1-1, but with a variable number of coolant and hydrogen feed tubes. Figure 4.1.1-1 represents a cross-section of the hydride bed only; the pressure vessel, liner and gaps are not included in the drawing. Area $\mathrm{A}_{1}\left[\mathrm{~m}^{2}\right]$ in the figure represents the cross-sectional surface area extending from the center of the bed to the circle passing through the centers of the coolant tubes. Area $\mathrm{A}_{2}\left[\mathrm{~m}^{2}\right]$ represents the area of the bed extending from the circle passing through the centers of the coolant tubes to the outer edge of the bed.

Let

$\mathrm{S}_{1}=$ The arc length of tubes in contact with coolant, lying within area $\mathrm{A}_{1}$.

$\mathrm{S}_{2}=$ The arc length of tubes in contact with coolant, lying within area $A_{2}$.

To obtain similar rates of heat removal for the inner and outer volumes of the bed (which are the volumes formed by projecting areas $A_{1}$ and $A_{2}$ along the axis of the bed) it is desirable to have

$$
\frac{\mathrm{A}_{1}}{\mathrm{~S}_{1}}=\frac{\mathrm{A}_{2}}{\mathrm{~S}_{2}}
$$

Equation 4.1.1-1, which gives the radius, $\mathrm{r}$ of the ring of outer coolant tubes is equivalent to requiring the ratio of volume to cooled surface area to be the same for both regions. This can easily be seen by multiplying the numerator and denominator of both sides of the equation by the bed length, $\mathrm{L}_{\text {bed }}$. 
WSRC-TR-2007-00439

Revision 0

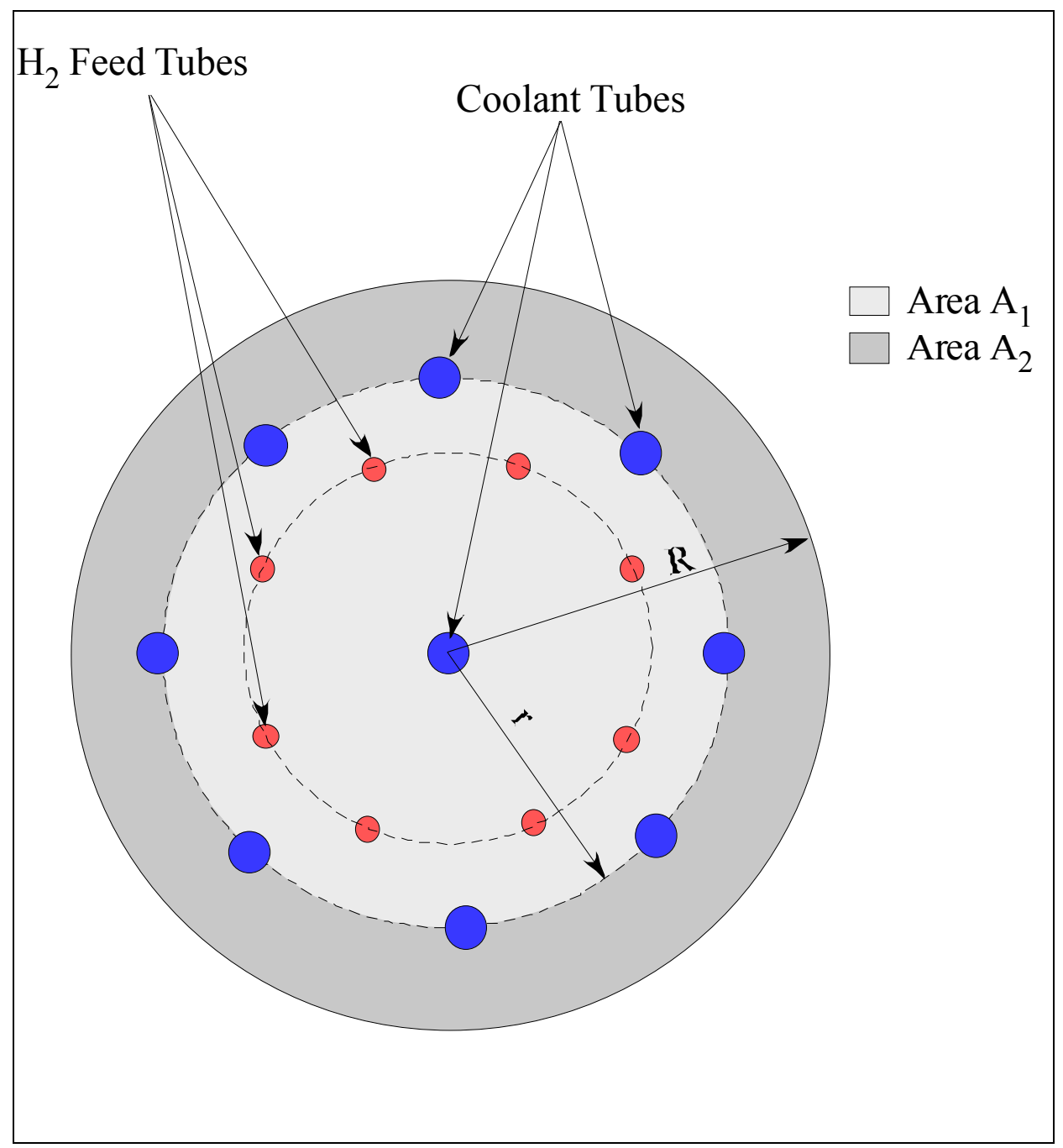

Figure 4.1.1-1 Schematic of bed cross-section. The pressure vessel, liner and any gaps are not included. The number of coolant tubes and hydrogen feed tubes may vary.

The arc lengths of the surfaces in contact with the coolant, $S_{1}$ and $S_{2}$, in $[\mathrm{m}]$, are calculated by considering the geometries shown in Figure 4.1.1-2 and Figure 4.1.1-3. 
WSRC-TR-2007-00439

Revision 0

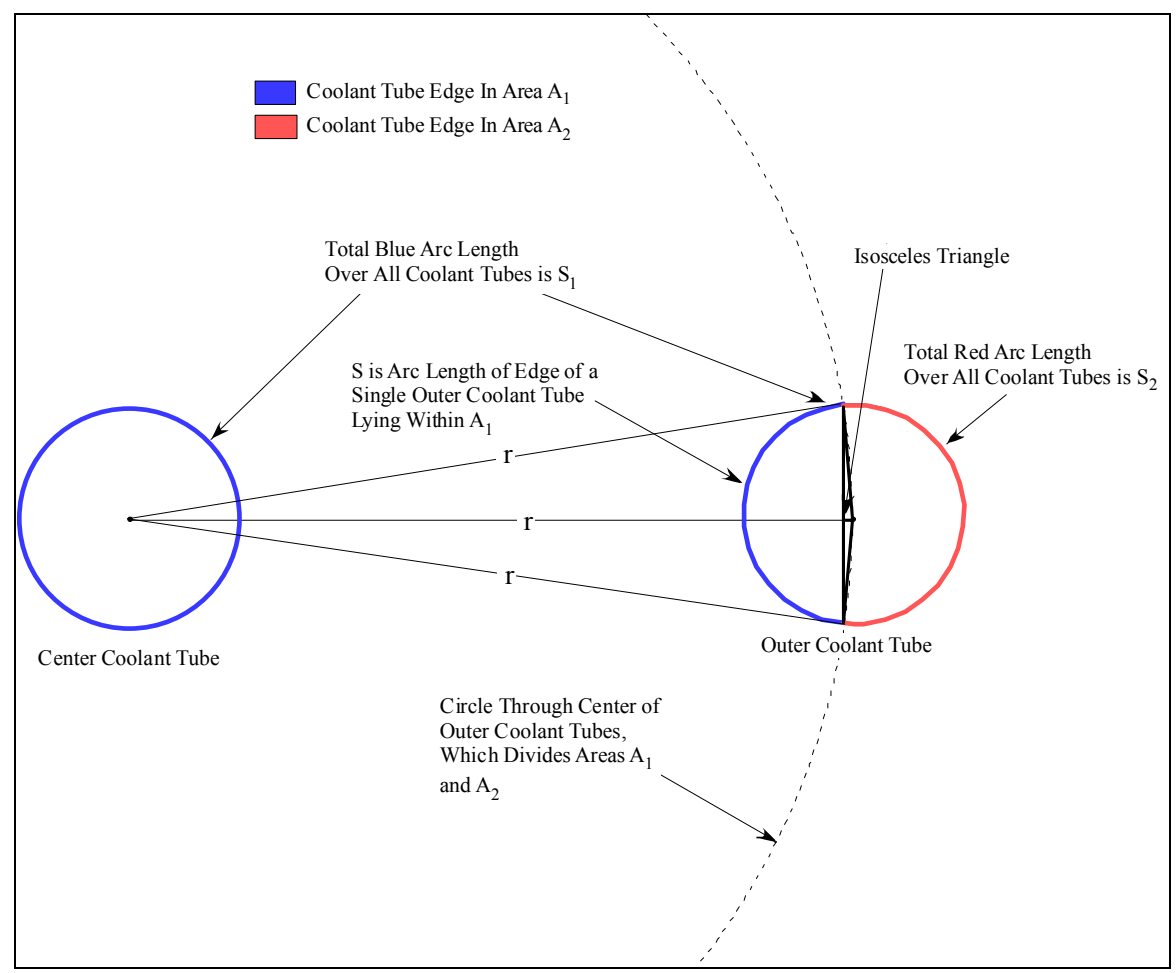

Figure 4.1.1-2 Geometry for the partition of the cooled tube surface with respect to the inner and outer areas of the bed. Figure is not to scale.

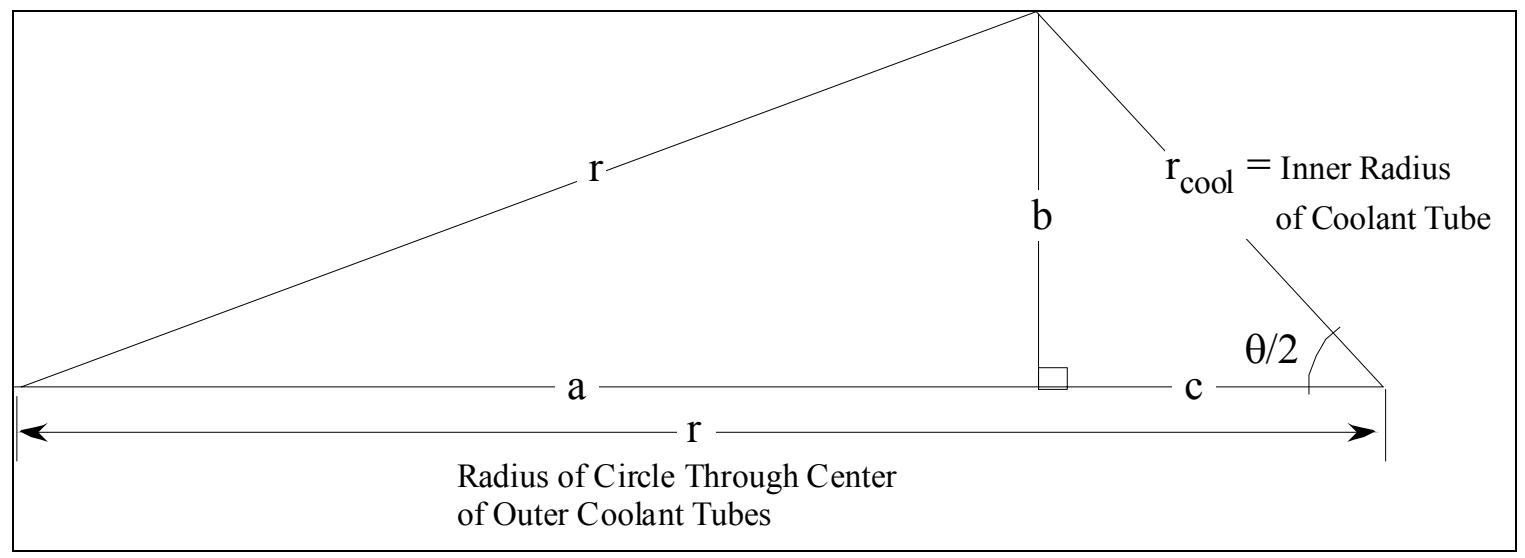

Figure 4.1.1-3 Schematic expansion of upper half of isosceles triangles formed by the center coolant tube and outer coolant tube, and within the outer coolant tube, see Figure 4.1.1-2. 
From Figures 4.1.1-2 and 4.1.1-3

$$
\begin{aligned}
& r^{2}=a^{2}+b^{2} \\
& r_{\text {cool }}^{2}=c^{2}+b^{2} \\
& r=a+c
\end{aligned}
$$

Solve for a from Equations 4.1.1-2 through 4.1.1-4

$\mathrm{a}=\frac{2 \mathrm{r}^{2}-\mathrm{r}_{\text {cool }}^{2}}{2 \mathrm{r}}$

So, from Equation 4.1.1-2

$$
\mathrm{b}=\frac{\mathrm{r}_{\text {cool }}}{2} \sqrt{\left(4 \mathrm{r}^{2}-\mathrm{r}_{\text {cool }}^{2}\right)}
$$

Now, $\theta$ (in radians), shown in Figure 4.1.1-3, is

$$
\theta=2 \arcsin \left(\frac{b}{r_{\text {cool }}}\right)=2 \arcsin \left(\frac{1}{2 r} \sqrt{\left(4 r^{2}-r_{\text {cool }}^{2}\right)}\right)
$$

The arc length, $\mathrm{S}[\mathrm{m}]$, of the edge of a single outer coolant tube lying within area $\mathrm{A}_{1}$, see Figure 4.1.1-2, is

$$
\mathrm{S}=\mathrm{r}_{\text {cool }} \theta=2 \mathrm{r}_{\text {cool }} \arcsin \left(\frac{1}{2 \mathrm{r}} \sqrt{\left(4 \mathrm{r}^{2}-\mathrm{r}_{\text {cool }}^{2}\right)}\right)
$$

The total arc length, $S_{1}[\mathrm{~m}]$, of the edges of all coolant tubes lying within area $A_{1}$ is $\mathrm{S}_{1}=\left(\mathrm{n}_{\text {cool }}-1\right) \mathrm{S}+\pi \mathrm{D}_{\text {cool }}$

The total arc length, $S_{2}[\mathrm{~m}]$, of the edges of all coolant tubes lying within area $A_{2}$ is $\mathrm{S}_{2}=\left(\mathrm{n}_{\text {cool }}-1\right)\left(\pi \mathrm{D}_{\text {cool }}-\mathrm{S}\right)$

where: $\mathrm{n}_{\mathrm{cool}}=$ Total number coolant tubes

$$
\mathrm{D}_{\mathrm{cool}}=\text { Inner diameter of coolant tube }[\mathrm{m}] \text {. }
$$

The areas $A_{1}$ and $A_{2}$ are given by

$$
\begin{aligned}
& \mathrm{A}_{1}=\pi \mathrm{r}^{2}-\pi\left(\frac{\mathrm{D}_{\text {cool_outer }}}{2}\right)^{2}-\mathrm{n}_{\mathrm{H}_{2}} \pi\left(\frac{\mathrm{D}_{\mathrm{H}_{2}}}{2}\right)^{2}-\left(\mathrm{n}_{\text {cool }}-1\right) \frac{\theta}{2}\left(\frac{\mathrm{D}_{\text {cool_outer }}}{2}\right)^{2} \\
& \mathrm{~A}_{2}=\pi\left(\mathrm{R}^{2}-\mathrm{r}^{2}\right)-\left(\mathrm{n}_{\text {cool }}-1\right)\left(\frac{\mathrm{D}_{\text {cool_outer }}}{2}\right)^{2}\left(\pi-\frac{\theta}{2}\right)
\end{aligned}
$$

where: $\quad \mathrm{n}_{\mathrm{H}_{2}}=$ Total number hydrogen feed tubes

$\mathrm{D}_{\mathrm{H}_{2}}=$ Inner diameter hydrogen feed tube [m] 
WSRC-TR-2007-00439

Revision 0

$$
\begin{aligned}
\mathrm{D}_{\text {cool_outer }}= & \text { Outer diameter of coolant tube, including sleeve formed by extrusion of } \\
& \text { fin }[\mathrm{m}] .
\end{aligned}
$$

To satisfy Equation 4.1.1-1 the following must be valid, with substitutions from Equations 4.1.1-9 through 4.1.1-12

$$
\frac{\mathrm{A}_{1}}{\mathrm{~S}_{1}}-\frac{\mathrm{A}_{2}}{\mathrm{~S}_{2}}=0
$$

Given the total number of coolant and hydrogen feed tubes, along with their associated dimensions, Equation 4.1.1-13 is used as an objective function in the Excel ${ }^{\circledR}$ spreadsheet to obtain a value for $r$.

\subsubsection{Length of Bed}

The required length, $\mathrm{L}_{\text {hyd }}$, of the hydride alone, without vessel walls, liners or fins, is

$$
\mathrm{L}_{\text {hyd }}=\frac{\mathrm{V}_{\text {hyd }}}{\pi\left[\mathrm{R}^{2}-\mathrm{n}_{\text {cool }}\left(\frac{\mathrm{D}_{\text {cool_outer }}}{2}\right)^{2}-\mathrm{n}_{\mathrm{H}_{2}}\left(\frac{\mathrm{D}_{\mathrm{H}_{2}}}{2}\right)^{2}\right]}
$$

where: $V_{\text {hyd }}=$ Total volume of hydride (in a reference chemical form) $\left[\mathrm{m}^{3}\right]$. Depends on hydride density, mass of hydrogen to be stored and moles of recoverable hydrogen to the moles of $\mathrm{NaAlH}_{4}$.

For a bed with fins bounding the end surfaces, having a thickness $\mathrm{t}$ [m], and approximate spacing $\delta_{\text {approx }}[\mathrm{m}]$, the number of plate fins, $\mathrm{n}_{\text {plate }}$, is given by

$\mathrm{n}_{\text {plate }}=\operatorname{Roundup}\left(\frac{\mathrm{L}_{\text {hyd }}}{\delta_{\text {approx }}}, 0\right)+1$

Here, the operator $\operatorname{Roundup}(x, 0)$ in $\operatorname{Excel}^{\circledR}$ rounds $\mathrm{x}$ up to the next highest integer.

Given this number of fins, the total length of the bed, including hydride and fins, is

$\mathrm{L}_{\text {hyd\&fins }}=\mathrm{L}_{\text {hyd }}+\mathrm{tn}_{\text {plate }}$

The actual spacing between the fins, $\delta[\mathrm{m}]$, (which is the axial distance between the surfaces of the fins bounding the metal hydride layer) is

$\delta=\frac{\mathrm{L}_{\text {hyd\&fins }}-\mathrm{tn} \text { plate }}{\mathrm{n}_{\text {plate }}-1}$

\subsubsection{Input Parameters for System Dimensions}

The input parameters required to calculate the dimensions of the storage vessel are list in Table 4.1.3-1. 
WSRC-TR-2007-00439

Revision 0

Table 4.1.3-1 Input for Calculation of System Dimensions

\begin{tabular}{|c|c|}
\hline Parameter & Value \\
\hline Mass of recoverable $\mathrm{H}_{2}$ to be stored in vessel & $1000.00 \mathrm{~g}$ \\
\hline $\begin{array}{l}\text { Practical ratio of moles } \mathrm{H}_{2} \text { to moles } \mathrm{NaAlH}_{4} \text { that can } \\
\text { be stored }\end{array}$ & 1.500 \\
\hline Bulk density of $\mathrm{NaAlH}_{4}$ powder & $0.72 \mathrm{~g} / \mathrm{cm}^{3}$ \\
\hline Hydride bed diameter, no walls & $23.00 \mathrm{~cm}$ \\
\hline Diameter of coolant tubes & $1.91 \mathrm{~cm}$ \\
\hline Diameter of $\mathrm{H}_{2}$ injection tubes & $1.27 \mathrm{~cm}$ \\
\hline Number of coolant tubes & 9 \\
\hline Number of $\mathrm{H}_{2}$ injection tubes & 8 \\
\hline Thickness of fin plates & $0.0313 \mathrm{~cm}$ \\
\hline Approximate spacing between fin plates & $0.64 \mathrm{~cm}$ \\
\hline Tube wall thickness & $0.12 \mathrm{~cm}$ \\
\hline $\begin{array}{l}\text { Density of tube material (6061-T6 Al from table on pg } \\
\text { 6-11 of Avallone and Baumeister [1987]) }\end{array}$ & $2.70 \mathrm{~g} / \mathrm{cm}^{3}$ \\
\hline $\begin{array}{l}\text { Density of fin material (6061-T6 Al from table on pg } \\
\text { 6-11 of Avallone and Baumeister [1987]) }\end{array}$ & $2.70 \mathrm{~g} / \mathrm{cm}^{3}$ \\
\hline $\begin{array}{l}\text { Material density of porous insert for } \mathrm{H}_{2} \text { delivery } \\
\text { (6061-T6 Al from table on pg 6-11 of Avallone and } \\
\text { Baumeister [1987]) }\end{array}$ & $2.70 \mathrm{~g} / \mathrm{cm}^{3}$ \\
\hline Void fraction of porous insert for $\mathrm{H}_{2}$ delivery & 0.70 \\
\hline $\begin{array}{l}\text { Density of tank material (Composite @ } \\
\left.0.054191 \mathrm{bm} / \mathrm{in}^{3}\right)\end{array}$ & $1.50 \mathrm{~g} / \mathrm{cm}^{3}$ \\
\hline $\begin{array}{l}\text { Density of liner material (6061-T6 Al from table on } \\
\text { pg 6-11 of Avallone and Baumeister [1987]) }\end{array}$ & $2.70 \mathrm{~g} / \mathrm{cm}^{3}$ \\
\hline Assume $1 / 16$ in gap between bed $\&$ liner & $0.159 \mathrm{~cm}$ \\
\hline Assume $1 / 32$ in thick liner & $0.079 \mathrm{~cm}$ \\
\hline Tank wall thickness at 50 bar w/ safety factor & $0.132 \mathrm{~cm}$ \\
\hline
\end{tabular}

\subsubsection{Bed Characteristics}

The Department of Energy has set goals for the system volumetric capacity, $\mathrm{V}_{\text {cap }}$, and the system gravimetric capacity, $\mathrm{G}_{\text {cap }}$, which are respectively defined as

$$
\mathrm{V}_{\text {cap }} \equiv \frac{\mathrm{m}_{\mathrm{H}_{2}}}{\mathrm{~V}_{\text {system }}}
$$

and

$$
\mathrm{G}_{\text {cap }} \equiv \frac{\mathrm{m}_{\mathrm{H}_{2}}}{\mathrm{~m}_{\text {system }}}
$$

where: $\mathrm{m}_{\mathrm{H}_{2}}=$ Mass of recoverable hydrogen reacted in the bed $[\mathrm{kg}]$.

$\mathrm{V}_{\text {system }}=$ Total volume of storage tank, including the bed, fins, liner gaps and pressure vessel $\left[\mathrm{m}^{3}\right]$. 
WSRC-TR-2007-00439

Revision 0

$\mathrm{m}_{\text {system }}=$ Total mass of loaded storage tank, including the bed loaded with $\mathrm{H}_{2}$, fins, liner gaps and pressure vessel. The mass of the heat transfer fluid is not included $[\mathrm{kg}]$.

$\mathrm{V}_{\text {cap }}$ and $\mathrm{G}_{\text {cap }}$ are calculated in the scoping spreadsheet.

\subsection{Heat Transfer Parameters}

The exothermic chemical reactions occurring during the loading of the bed and the requirement that the bed be heated to release hydrogen necessitate the use of a heat management system. Since a shell and tube heat transfer system is assumed for the storage system, the principal heat transfer parameters are those related to convective exchange within the coolant tubes.

In the spreadsheet model, the required rate of heat removal is determined by dividing the total heat generated during the charging of the bed by amount of time required for charging to occur. In this calculation, it is tacitly assumed that heat transfer to the coolant tubes is instantaneous and that the bed uptakes the full charge of hydrogen over the time allotted for charging. The system modeled in this report was evaluated for Dowtherm $\mathrm{T}^{\circledR}$ heat transfer fluid for single phase cooling and DuPont Vertrel-XF ${ }^{\circledR}$ heat transfer fluid for two phase cooling. Data sheets, from the respective vendors are listed in Attachments 1 and 2.

\subsubsection{Single Phase Flow}

For coolant in single phase flow the Dittus-Boelter correlation was used to predict the mass flowrate required to remove the heat of reaction. From Holman [1976] the DittusBoelter correlation is

$\mathrm{Nu}_{\mathrm{D}}=0.023 \operatorname{Re}^{0.8} \operatorname{Pr}^{0.4}$

where: $\mathrm{Nu}_{\mathrm{D}}=\frac{\mathrm{h}_{\mathrm{DB}} \mathrm{D}}{\mathrm{k}_{\mathrm{f}}}=$ Nusselt number based on diameter, $\mathrm{D}$

$\mathrm{D}=$ Inner diameter of coolant tube $[\mathrm{m}]$

$\mathrm{h}_{\mathrm{DB}}=$ Dittus-Boelter convection heat transfer coefficient for the heat transfer fluid $\left[\mathrm{W} /\left(\mathrm{m}^{2}-\mathrm{K}\right)\right]$

$\mathrm{k}_{\mathrm{f}}=$ Thermal conductivity of the heat transfer fluid [W/(m- K)]

$\mathrm{Re}_{\mathrm{D}}=\frac{\mathrm{GD}}{\mu}=$ Reynolds number based on diameter, $\mathrm{D}$

$\mathrm{G}=$ Coolant mass flux $\left[\mathrm{kg} /\left(\mathrm{m}^{2}-\mathrm{s}\right)\right]$

$\mu=$ Viscosity $[\mathrm{Pa}-\mathrm{s}]$

$\operatorname{Pr}=\frac{v}{\alpha}=$ Prandtl number

$v=$ Kinematic viscosity of coolant $\left[\mathrm{m}^{2} / \mathrm{s}\right]$

$\alpha=$ Thermal diffusivity of coolant $\left[\mathrm{m}^{2} / \mathrm{s}\right]$. 
WSRC-TR-2007-00439

Revision 0

Therefore, the single phase convection heat transfer coefficient, $\mathrm{h}_{\mathrm{f}}$, is that obtained from the Dittus-Boelter correlation, $\mathrm{h}_{\mathrm{DB}}$, which is

$\mathrm{h}_{\mathrm{DB}}=0.023\left(\frac{\mathrm{GD}}{\mu}\right)^{0.8} \operatorname{Pr}^{0.4} \frac{\mathrm{k}}{\mathrm{D}}$

The average heat flux, q", from the wall of the coolant tube is then

$\mathrm{q}^{\prime \prime}=\mathrm{h}_{\mathrm{DB}}\left(\mathrm{T}_{\text {wall }}-\mathrm{T}_{\text {bulk }}\right)=\left(0.023\left(\frac{\mathrm{GD}}{\mu}\right)^{0.8} \operatorname{Pr}^{0.4} \frac{\mathrm{k}}{\mathrm{D}}\right)\left(\mathrm{T}_{\text {wall }}-\mathrm{T}_{\text {bulk }}\right)$

where: $T_{\text {wall }}=$ Tube wall temperature $(K)$.

$\mathrm{T}_{\text {bulk }}=$ Bulk coolant temperature $(\mathrm{K})$.

Based on the stored mass of hydrogen, $\mathrm{m}_{\mathrm{H}_{2}}$, and the time, $\tau$, for the loading process, the average heat flux is

$\mathrm{q}^{\prime \prime}=\frac{\left(\mathrm{m}_{\mathrm{H}_{2}} / \mathrm{M}_{\mathrm{H}_{2}}\right) \Delta \mathrm{H}_{\mathrm{rx}}}{\tau}$

where: $\mathrm{m}_{\mathrm{H}_{2}}=$ Mass of hydrogen stored in the bed $(\mathrm{kg})$.

$\mathrm{M}_{\mathrm{H}_{2}}=$ Molecular weight of $\mathrm{H}_{2}[\mathrm{~kg} / \mathrm{g}-\mathrm{mol}]$.

$\Delta \mathrm{H}_{\mathrm{rx}}=$ Overall heat of reaction for uptake of $\mathrm{H}_{2}$ by the hydride [J/g-mol].

$\tau=$ Time required for $\mathrm{H}_{2}$ loading $[\mathrm{s}]$.

Use Equations 4.2.1-3 and 4.2.1-4 to obtain the mass flux, G, required to remove the heat generated during loading.

$\mathrm{G}=\frac{\left(\mathrm{q}^{\prime \prime}\right)^{1 / 0.8}}{\left[0.023 \frac{\mathrm{k}}{\mathrm{D}} \operatorname{Pr}^{0.4}\left(\frac{\mathrm{D}}{\mu}\right)^{0.8}\left(\mathrm{~T}_{\text {wall }}-\mathrm{T}_{\text {bulk }}\right)\right]^{1 / 0.8}}$

The pressure drop over the length of a coolant tube (length of the bed), required to drive coolant through the tube at a mass flux $\mathrm{G}$, is

$\Delta \mathrm{P}=\mathrm{f} \frac{\mathrm{L}_{\text {hyd\&fins }}}{\mathrm{D}} \frac{\mathrm{G}^{2}}{2 \rho}$

where: $\quad f=$ Friction factor for the tube

$\Delta \mathrm{P}=$ Pressure drop across the length of the tube [Pa]

$\mathrm{L}_{\text {hyd\&fins }}=$ Length of the bed, including hydride and fins $[\mathrm{m}]$.

The rise in the bulk coolant temperature over the length of a coolant tube (length of the bed) is approximated as 
WSRC-TR-2007-00439

Revision 0

$\Delta \mathrm{T} \approx 4 \frac{\mathrm{q}^{\prime \prime} \mathrm{L}_{\text {hyd\&fins }}}{\mathrm{DGC}_{\mathrm{p}}}$

where: $\quad \mathrm{C}_{\mathrm{p}}=$ Specific heat of coolant $[\mathrm{J} /(\mathrm{kg}-\mathrm{K})]$, assumed approximately constant

$\Delta \mathrm{T}=$ Change in bulk temperature of coolant over the length of the bed $[\mathrm{K}]$.

\subsubsection{Two Phase Flow}

If the coolant is allowed to boil at the inner wall of the coolant tube, and the critical heat flux is not exceeded, the rate of wall heat transfer will be greater than if the coolant remained in the liquid state. However, the chemical kinetics of the bed are dependent on temperature. Thus, the coolant must be selected to have a saturation temperature that is consistent with optimal reaction rates in the bed.

Gungor and Winterton [1986] adapted their correlation for the convection heat transfer coefficient in vertical two-phase flow to horizontal flows by identifying a liquid Froude number dependent threshold between stratified and non-stratified flows. The liquid Froude number, $\mathrm{Fr}_{\mathrm{L}}$, is defined as

$$
\mathrm{Fr}_{\mathrm{L}}=\frac{\mathrm{G}^{2}}{\rho_{\mathrm{L}}^{2} \mathrm{gD}}(1-\mathrm{x})^{2}
$$

where: $\quad \mathrm{G}=$ Mass flux of liquid and gas phases of coolant, $\left[\mathrm{kg} / \mathrm{m}^{2}-\mathrm{s}\right]$

$$
\begin{aligned}
\mathrm{g} & =\text { Gravitational acceleration }\left[\mathrm{m} / \mathrm{s}^{2}\right] \\
\mathrm{D} & =\text { Inner diameter of coolant tube }[\mathrm{m}] \\
\rho_{\mathrm{L}} & =\text { Density of saturated liquid coolant }\left[\mathrm{kg} / \mathrm{m}^{3}\right] \\
\mathrm{x} & =\text { Quality of coolant }\left[\frac{\text { Mass of Gas Phase of Coolant }}{\text { Mass of Coolant }}\right]
\end{aligned}
$$

When $\mathrm{Fr}_{\mathrm{L}}>0.05$, the 1986 Gungor and Winterton vertical flow correlation is used directly, otherwise multipliers were used to modify terms in the correlation.

The Gungor and Winterton [1986] correlation for the convection heat transfer coefficient depends on the coolant gas phase viscosity through the Martinelli parameter. Unfortunately, data for the gas phase viscosity of the selected coolant, DuPont Vertrel$\mathrm{XF}^{\circledR}$, was unavailable. Therefore, in place of the Gungor and Winterton [1986] correlation, the Gungor and Winterton [1987] correlation was used because it was not dependent on the gas phase viscosity. The Gungor and Winterton [1987] correlation

was $_{2 \phi}=\left[1+3000 B^{0.86}+1.12\left(\frac{\mathrm{x}}{1-\mathrm{x}}\right)^{0.75}\left(\frac{\rho_{\mathrm{L}}}{\rho_{\mathrm{V}}}\right)^{0.41}\right] \mathrm{h}_{\mathrm{DBL}}$

where: $\mathrm{h}_{2 \phi}=$ Two phase convection heat transfer coefficient $\left[\mathrm{W} / \mathrm{m}^{2} \mathrm{~K}\right]$

$$
\rho_{\mathrm{V}}=\text { Density of saturated vapor }\left[\mathrm{kg} / \mathrm{m}^{3}\right]
$$


WSRC-TR-2007-00439

Revision 0

$\mathrm{h}_{\mathrm{DBL}}=$ Dittus-Boelter convection heat transfer coefficient based on the local properties of the liquid coolant $\left[\mathrm{W} / \mathrm{m}^{2} \mathrm{~K}\right]$

$=0.023 \operatorname{Re}_{\mathrm{L}}^{0.8} \operatorname{Pr}_{\mathrm{L}}^{0.4}\left(\frac{\mathrm{k}_{\mathrm{L}}}{\mathrm{D}}\right)$

$\mathrm{k}_{\mathrm{L}}=$ Thermal conductivity for the saturated liquid coolant $[\mathrm{W} / \mathrm{m}-\mathrm{K}]$

$\operatorname{Re}_{\mathrm{L}}=$ Reynolds number for the liquid coolant $=\frac{G(1-\mathrm{x}) \mathrm{D}}{\mu_{\mathrm{L}}}$

$\operatorname{Pr}_{\mathrm{L}}=$ Prandtl number for the liquid coolant $=\frac{C \mathrm{p}_{\mathrm{L}} \mu_{\mathrm{L}}}{\mathrm{k}_{\mathrm{L}}}$

$\mu_{\mathrm{L}}=$ Viscosity of the saturated liquid coolant $[\mathrm{Pa}-\mathrm{s}]$

$\mathrm{Cp}_{\mathrm{L}}=$ Specific heat of the saturated liquid coolant $[\mathrm{J} / \mathrm{kg} \mathrm{K}]$

$$
\mathrm{B}=\frac{\mathrm{q}^{\prime \prime}}{\mathrm{Gh}_{\mathrm{lg}}}
$$

$\mathrm{q} "=$ Heat flux at tube wall $\left[\mathrm{W} / \mathrm{m}^{2}\right]$

$\mathrm{h}_{\mathrm{lg}}=$ Enthalpy of phase change for the coolant $[\mathrm{J} / \mathrm{kg}]$.

The heat flux at the inner wall of the coolant tube is given by $\mathrm{q}^{\prime \prime}=\mathrm{h}_{2 \phi}\left(\mathrm{T}_{\mathrm{w}}-\mathrm{T}_{\text {sat }}\right)$

where: $q "=$ Heat flux at inner wall of coolant tube $\left[\mathrm{W} / \mathrm{m}^{2}\right]$

$\mathrm{T}_{\mathrm{w}}=$ Temperature of the inner wall of the coolant tube $[\mathrm{K}]$

$\mathrm{T}_{\mathrm{sat}}=$ Saturation temperature of the coolant $[\mathrm{K}]$

For fixed values of q" and $\left(\mathrm{T}_{\mathrm{w}}-\mathrm{T}_{\text {sat }}\right)$, Equations 4.2.2-2 through 4.2.2-6 can be used to obtain the coolant mass flux, $\mathrm{G}$ via the iterative solver in Microsoft Excel ${ }^{\circledR}$.

\subsubsection{Input for Heat Transfer}

The input required to calculate heat transfer requirements for the system are listed in Table 4.2.3-1 
WSRC-TR-2007-00439

Revision 0

Table 4.2.3-1 Input for Calculation of Heat Transfer Parameters

\begin{tabular}{|c|c|c|}
\hline Parameter & Value & \begin{tabular}{|c|} 
Reference \\
\end{tabular} \\
\hline$\Delta \mathrm{H}_{\mathrm{Rxn} 1}$ & $37.00 \mathrm{~kJ} / \mathrm{mol} \mathrm{H} 2$ & $\begin{array}{l}\text { Heat of reaction from species } 2 \text { to } \\
\text { species 1, see Eq. 3.1-1, Gross [2003] }\end{array}$ \\
\hline$\Delta \mathrm{H}_{\mathrm{Rxn} 2}$ & $47.00 \mathrm{~kJ} / \mathrm{mol} \mathrm{H} 2$ & $\begin{array}{l}\text { Heat of reaction from species } 3 \text { to } \\
\text { species 2, see Eq.3.1-1, Gross [2003] }\end{array}$ \\
\hline Charging Time & $180.00 \mathrm{sec}$ & \\
\hline Wall Temp & $90.00^{\circ} \mathrm{C}$ & \\
\hline $\begin{array}{l}2 \phi \text { Coolant Liquid } \\
\text { Density }\end{array}$ & $1580 \mathrm{~kg} / \mathrm{m}^{3}$ & DuPont Vertrel-XF ${ }^{\circledR}$, see Attachment 2 \\
\hline $\begin{array}{l}2 \phi \text { Coolant Vapor } \\
\text { Density }\end{array}$ & $1.01 \mathrm{~kg} / \mathrm{m}^{3}$ & DuPont Vertrel-XF ${ }^{\circledR}$, see Attachment 2 \\
\hline $\begin{array}{l}2 \phi \text { Coolant Liquid } \\
\text { Themal Cond }\end{array}$ & $10.4 \mathrm{~W} /(\mathrm{m} \mathrm{K})$ & DuPont Vertrel-XF ${ }^{\circledR}$, see Attachment 2 \\
\hline $\begin{array}{l}2 \phi \text { Coolant Liquid } \\
\text { Viscosity }\end{array}$ & $0.001 \mathrm{~kg} /(\mathrm{m} \mathrm{s})$ & DuPont Vertrel-XF ${ }^{\circledR}$, see Attachment 2 \\
\hline $\begin{array}{l}2 \phi \text { Coolant Liquid } \\
\text { Specific Heat }\end{array}$ & $1130 \mathrm{~J} /(\mathrm{kg} \mathrm{K})$ & DuPont Vertrel-XF ${ }^{\circledR}$, see Attachment 2 \\
\hline $\begin{array}{l}2 \phi \text { Coolant Phase } \\
\text { Change Enthalpy }\end{array}$ & $129800 \mathrm{~J} / \mathrm{kg}$ & DuPont Vertrel-XF ${ }^{\circledR}$, see Attachment 2 \\
\hline $\begin{array}{l}2 \phi \text { Coolant Liquid } \\
\text { Prandtl No. }\end{array}$ & 7.29 & DuPont Vertrel-XF ${ }^{\circledR}$, see Attachment 2 \\
\hline \multicolumn{3}{|l|}{ Void Fraction $(\varepsilon)$} \\
\hline \multicolumn{3}{|l|}{ Quality (x) } \\
\hline $\begin{array}{l}1 \phi \text { Coolant Liquid } \\
\text { Density }\end{array}$ & $820 \mathrm{~kg} / \mathrm{m}^{3}$ & Dowtherm $\mathrm{T}^{\circledR}$, see Attachment 1 \\
\hline $\begin{array}{l}1 \phi \text { Coolant Liquid } \\
\text { Themal Cond }\end{array}$ & $0.104 \mathrm{~W} /(\mathrm{m} \mathrm{K})$ & Dowtherm $\mathrm{T}^{\circledR}$, see Attachment 1 \\
\hline $1 \phi$ Coolant Viscosity & $0.003 \mathrm{~kg} /(\mathrm{m} \mathrm{s})$ & Dowtherm $\mathrm{T}^{\circledR}$, see Attachment 1 \\
\hline $1 \phi$ Coolant Specific Heat & $2300 \mathrm{~J} /(\mathrm{kg} \mathrm{K})$ & Dowtherm $\mathrm{T}^{\circledR}$, see Attachment 1 \\
\hline $1 \phi$ Coolant Prandtl No. & 66.52 & Dowtherm $\mathrm{T}^{\circledR}$, see Attachment 1 \\
\hline
\end{tabular}

\subsection{RESULTS}

Results from the kinetics, geometry and heat transfer scoping models are discussed in the following sections. A full scoping analysis of the sodium alanate bed was performed, while only the kinetics of the alpha-aluminum hydride bed were evaluated.

\subsection{Kinetics Model}

In this report, the Mathcad ${ }^{\circledR}$ based kinetics model was applied to $\mathrm{TiCl}_{3}$ catalyzed $\mathrm{NaAlH}_{4}$ and to $\alpha-\mathrm{AlH}_{3}$. Charging and discharging rates calculated by the kinetics model were idealized because the temperature and pressure remained fixed throughout the process; quite different from what would occur in an actual storage bed. In an actual storage bed, there will be a transient change in the pressure when the bed is charged or discharged. Further, thermal inertia coupled with heat generated by chemical reactions will result in spatial variation in the temperature of the bed. The pressure and temperature variations from fixed values will result in variations from the reaction rates predicted by the Mathcad ${ }^{\circledR}$ model. These effects are the primary reason that a 3-dimensional model that 
couples thermal, mass and momentum transport is required to provide a more accurate assessment of bed peformance. However, because the temperature and pressure are fixed in the Mathcad ${ }^{\circledR}$ kinetics model, it can be used to predict the upper limit for loading and discharge for a particular storage media. In addition to reaction rates, the kinetics model can be used to predict both the long-time capacity of a storage media, as well as the best case loading for the allotted refueling time period.

\subsection{1 $\quad \mathrm{TiCl}_{3}$ Catalyzed $\mathrm{NaAlH}_{4}$}

At 68 bar, the UTRCTM kinetics model for $\mathrm{TiCl}_{3}$ catalyzed $\mathrm{NaAlH}_{4}$ from Attachments 3 and 4, gave the hydrogen uptake rates shown in Figure 5.1.1-1. Loading rates in this figure are expressed in terms of the weight fraction of hydrogen stored in the hydride, see Equation 3.1-7. This result identical to the rates obtained from UTRCTM, see the reports in Attachments 3 and 4 and Figure 5.1.1-2.

Loading a bed initially composed of pure $\mathrm{NaH}$, with an excess of $\mathrm{Al}$, at 50 bar and $100^{\circ} \mathrm{C}$. gives the loading curve shown in Figure 5.3.1-3. The bed gravimetric capacity, which is the maximum weight fraction, approaches 0.029 at the long time limit, rather than 0.056 , which is the theoretical limit based on the chemical balance in Equation 3.1-1.

Cycling a bed having an initial concentration of $13,333.33 \mathrm{~mole} / \mathrm{m}^{3}$ of $\mathrm{NaH}$, and 0 mole $/ \mathrm{m}^{3}$ of the other hydrides, with a stoichiometric quantity of $\mathrm{Al}$, between loading and discharging conditions, of $100^{\circ} \mathrm{C}$ at 50 bar and $120^{\circ} \mathrm{C}$ at $1 \mathrm{bar}$, respectively, gives the concentration curves shown in Figure 5.1.1-4. 
WSRC-TR-2007-00439

Revision 0

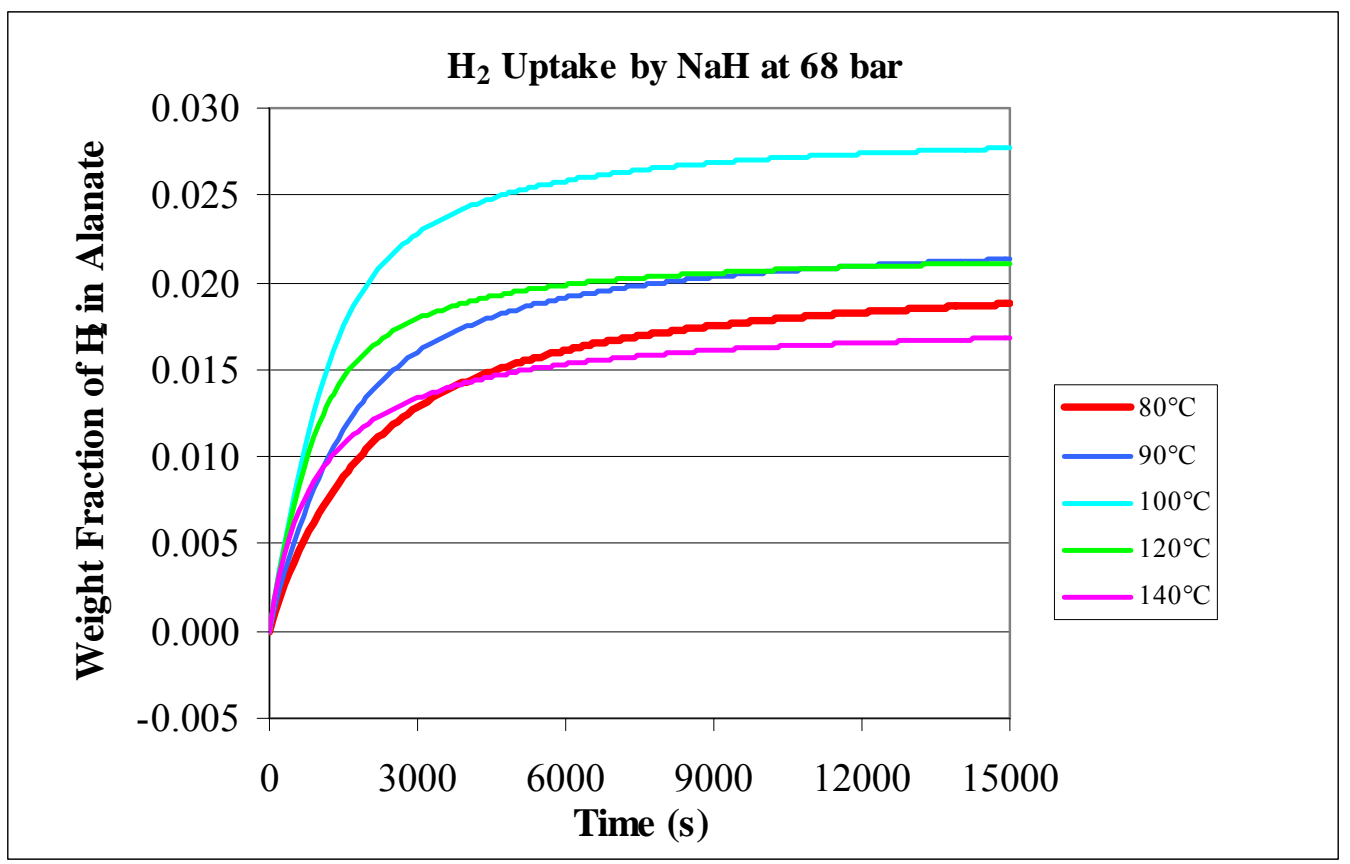

Figure 5.1.1-1 Hydrogen loading rates at 68 bar from the Mathcad ${ }^{\circledR}$ reaction kinetics model.

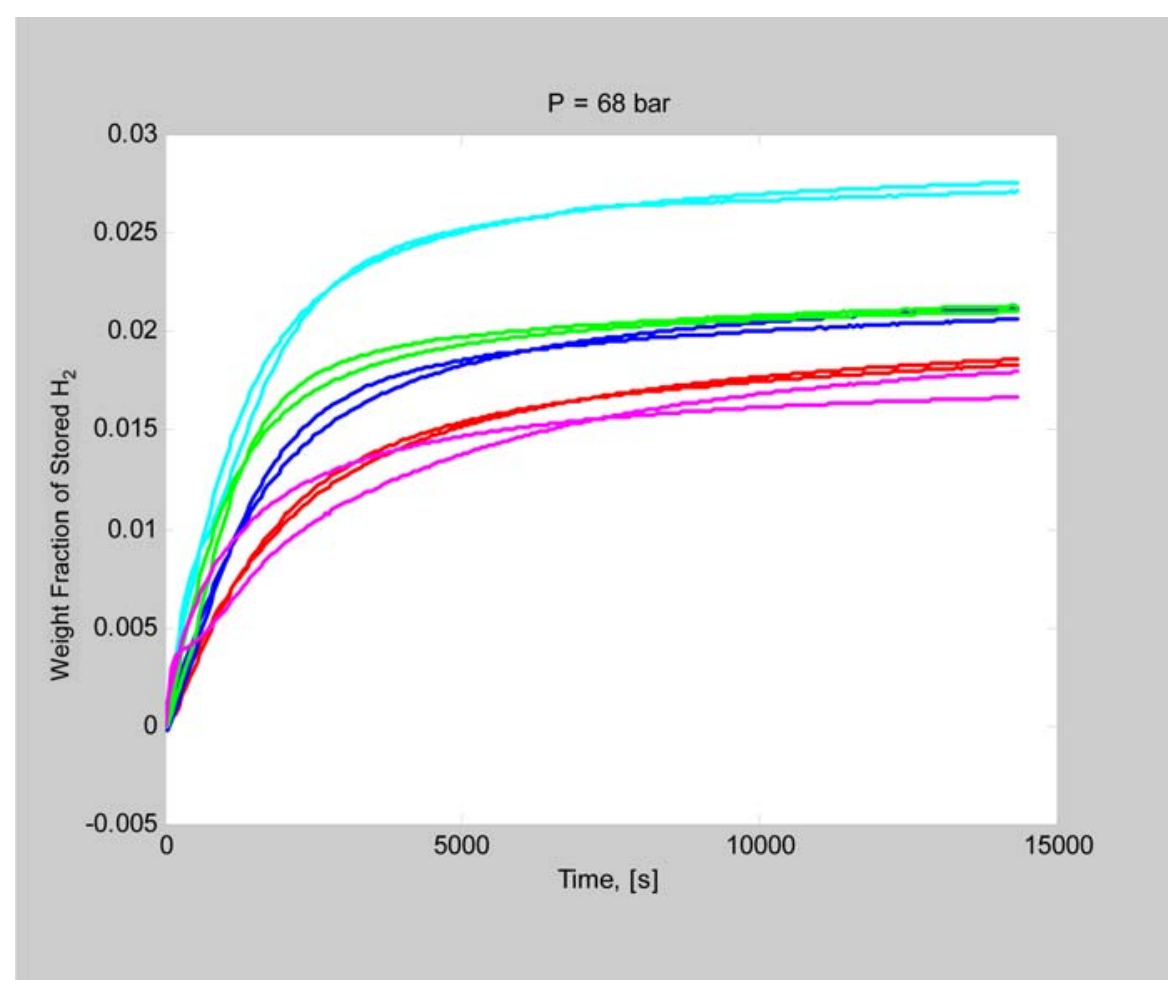

Figure 5.1.1-2 Hydrogen loading rates at 68 bar from the UTRC ${ }^{\text {TM }}$ reaction kinetics model in Attachments 3 and 4. Solid lines represent data and dashed lines 
WSRC-TR-2007-00439

Revision 0

represent the model. The legend of Figure 5.3.1-1 gives the loading temperatures

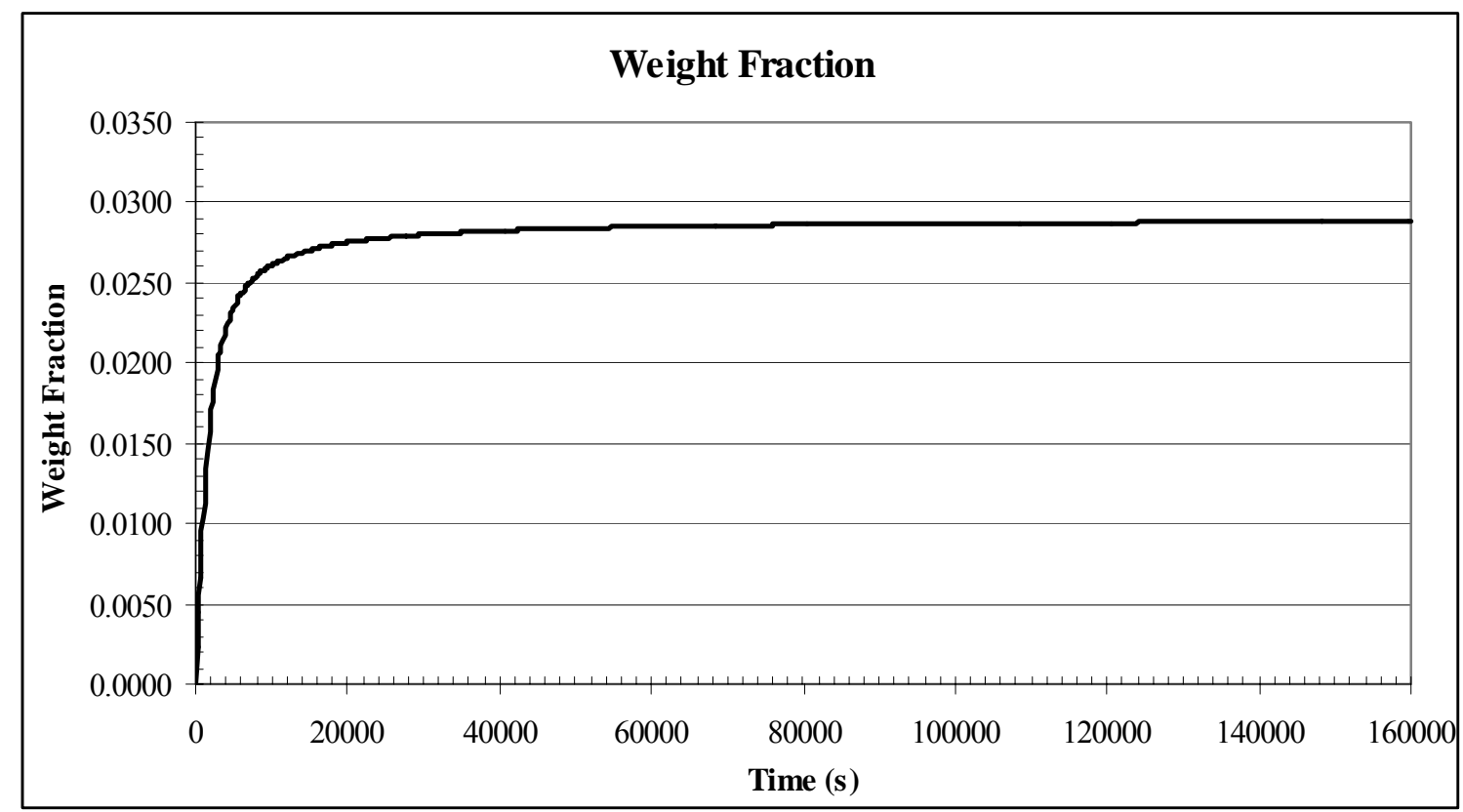

Figure 5.1.1-3 Loading of hydrogen in the hydride at 50 bar and $100^{\circ} \mathrm{C}$. Storage in both $\mathrm{NaAlH}_{4}$ and $\mathrm{Na}_{3} \mathrm{AlH}_{6}$ are included.

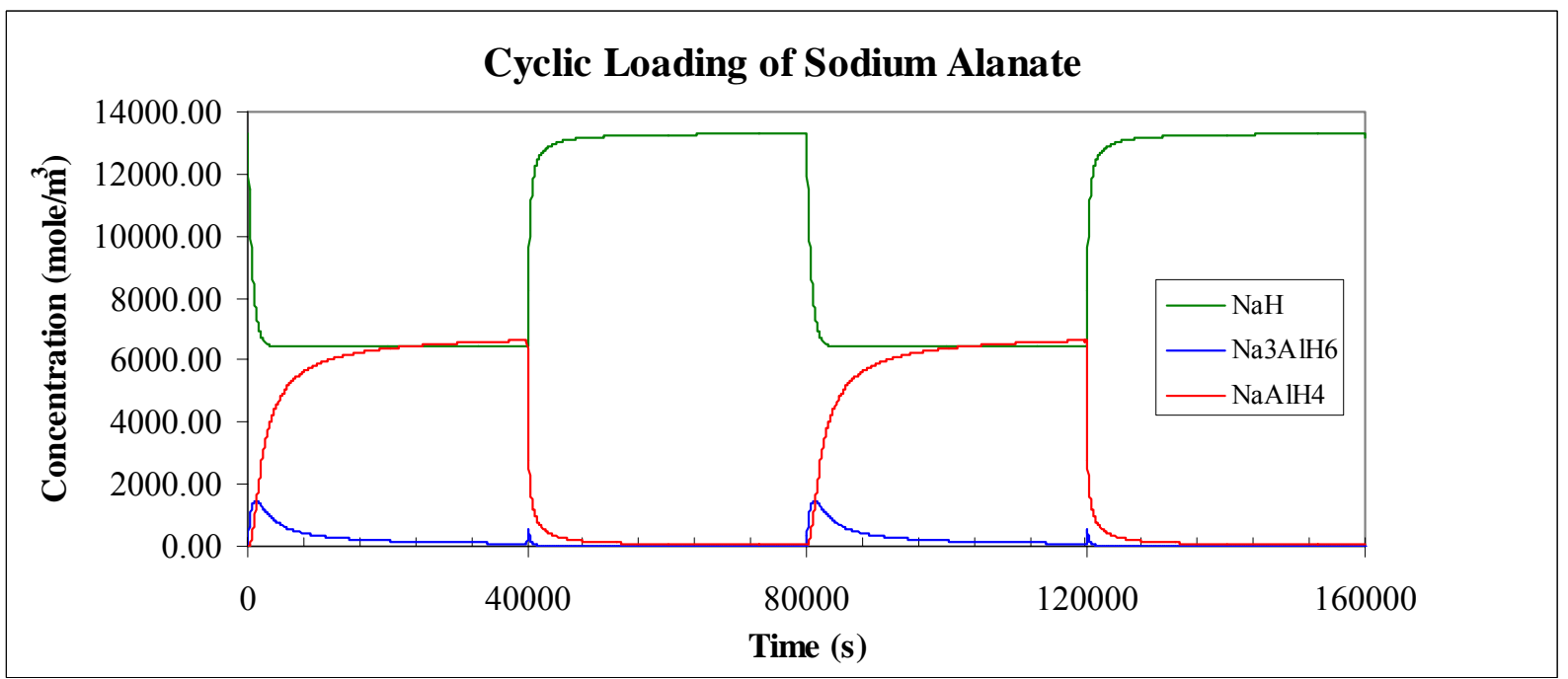

Figure 5.1.1-4 Concentration of all species in the sodium alanate reaction. The initial concentration of $\mathrm{NaH}$ was $13,333.33 \mathrm{~mole} / \mathrm{m}^{3}$ and $0 \mathrm{~mole} / \mathrm{m}^{3}$ for the other hydrides. 
WSRC-TR-2007-00439

Revision 0

\subsection{2 $\alpha-\mathrm{AlH}_{3}$ Discharge Kinetics}

Due to the unavailability of loading kinetics for $\alpha-\mathrm{AlH}_{3}$, only the discharge rates were modeled, using the kinetics proposed by Graetz and Reilly [2005]. The kinetics for this process were independent of pressure, hence, only the effect of temperature was considered.

The rate of decomposition of $\alpha-\mathrm{AlH}_{3}$, relative to the initial concentration, at constant temperature is given by the family of curves in Figure 5.3.2-1. The corresponding rate of $\mathrm{H}_{2}$ release, in units of $\left(\right.$ mole $\left.\alpha-\mathrm{AlH}_{30}\right) * \operatorname{second}$ , is shown in Figure 5.1.2-2.

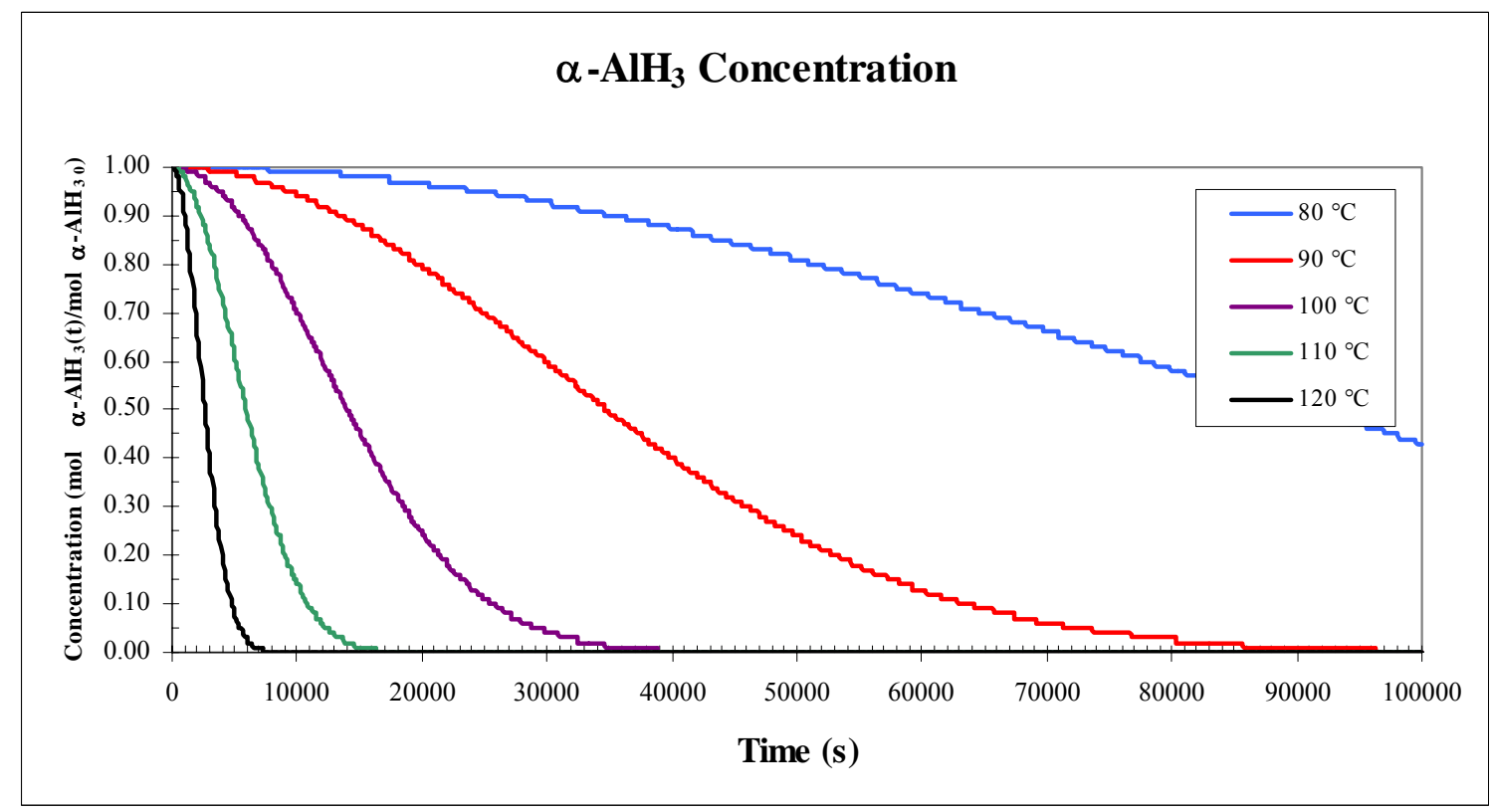

Figure 5.1.2-1 Decomposition of $\alpha-\mathrm{AlH}_{3}$ in terms of relative concentration, with respect to the initial concentration of $\alpha-\mathrm{AlH}_{3}$. 
WSRC-TR-2007-00439

Revision 0

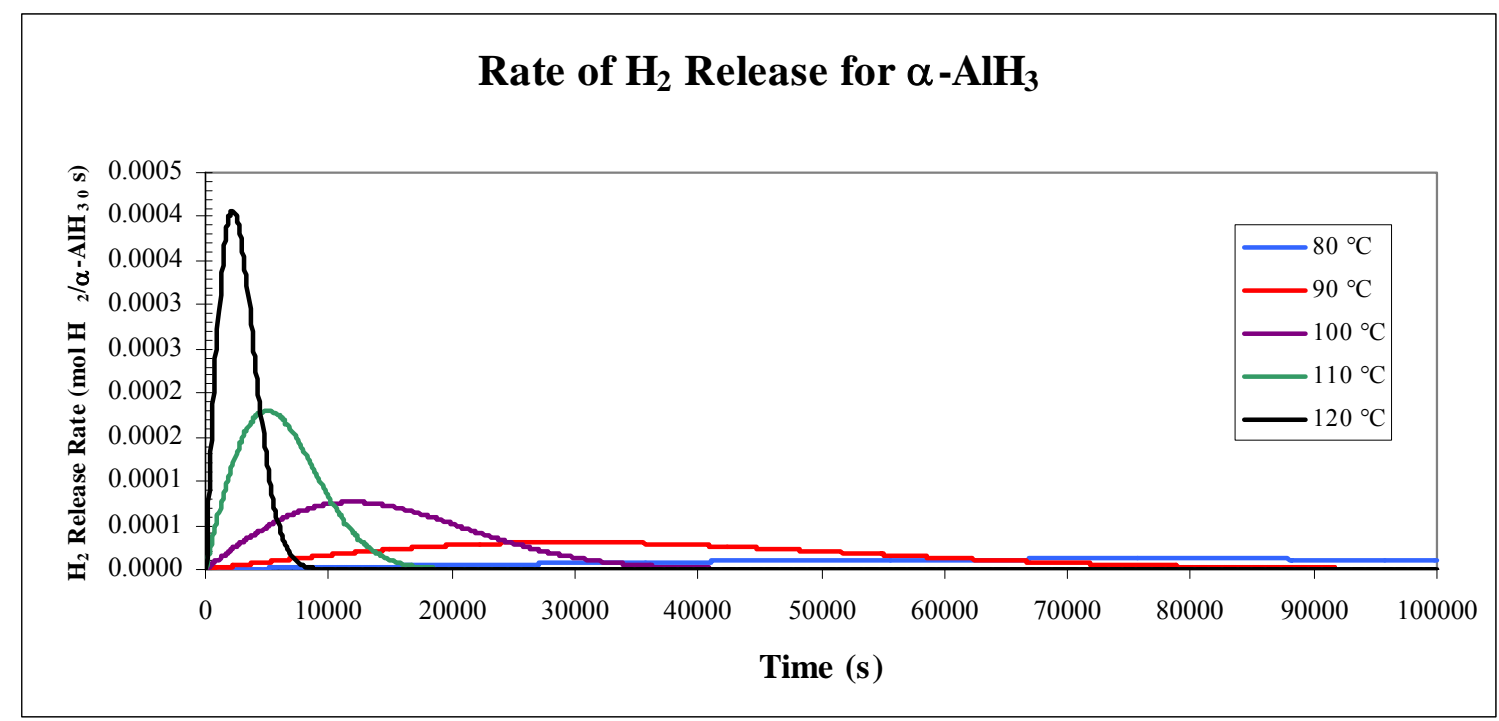

Figure 5.1.2-2 Rate of $\mathrm{H}_{2}$ generation due to decomposition of $\alpha-\mathrm{AlH}_{3}$. The rate is expressed in terms of the rate of $\mathrm{H}_{2}$ produced relative to the initial concentration of $\alpha-\mathrm{AlH}_{3}$.

\subsection{Bed Geometry}

Appendix A.1 contains a copy of the input and output used in the Microsoft Excel ${ }^{\circledR}$ spreadsheet used for scoping calculations related to the sodium alanate bed geometry. Due to the low loading rate predicted by the kinetics model, the time allowed for charging the bed was 12 minutes, rather than the DOE 2007 technical target of 10 minutes. In this sample calculation, however, the ratio of moles of recoverable $\mathrm{H}_{2}$ to moles of $\mathrm{NaAlH}_{4}$ in the fully converted bed was input as 1.5 rather than 0.213 , which is the value calculated by the kinetics scoping model for a 12 minute charging time, see Table 4.1.3-1. Based on the model input, the parameters in Table 5.2-1 were obtained.

\section{Table 5.2-1 Calculated Bed and Vessel Parameters}

\begin{tabular}{|l||c|}
\hline $\begin{array}{l}\text { Required length of hydride alone (no structural } \\
\text { members, fins or vessel) }\end{array}$ & $0.6562 \mathrm{~m}$ \\
\hline Total number of fin plates, including ends & 105 \\
\hline Total length of bed (with fins but no vessel) & $0.6890 \mathrm{~m}$ \\
\hline Actual spacing of plates & $0.0063 \mathrm{~m}$ \\
\hline Mass of bed; including fins, tubes \& NaAlH 4 & $24.643 \mathrm{~kg}$ \\
\hline Volume of bed with vessel \& liner & $0.0362 \mathrm{~m} 3$ \\
\hline $\begin{array}{l}\text { Overall length of vessel (assumed semi- } \\
\text { spherical ends) }\end{array}$ & $0.9264 \mathrm{~m}$ \\
\hline $\begin{array}{l}\text { Radial distance from axis of storage vessel to } \\
\text { center of cooling tube circle. The distance } \mathrm{r} \text { in } \\
\text { Figure 4.1.1-1 }\end{array}$ & \\
\hline & $0.0855 \mathrm{~m}$ \\
\hline $\begin{array}{l}\text { Gravimetric capacity of storage system } \\
\text { Volumetric capacity of storage system }\end{array}$ & $\begin{array}{c}0.041(\mathrm{~kg} \\
\left.\mathrm{H}_{2}\right) /(\mathrm{kg} \mathrm{Total})\end{array}$ \\
\hline
\end{tabular}


WSRC-TR-2007-00439

Revision 0

\subsection{Bed Heat Transfer}

The spreadsheet used to compute input and output for the loading phase bed heat transfer requirements is listed in Appendix A.2. For sodium alanate, loading heat transfer requirements were chosen because they present the greatest challenge to the heat removal system. The spreadsheet contains the input required for the sodium alanate system evaluated in this report and references the bed geometry model listed in Appendix A.1. Predicted system heat transfer parameters are also contained in the spreadsheet listed in Appendix A.2.

Based on the chemical reaction equation and heats of reaction for $\mathrm{NaAlH}_{4}$, the time required for loading (12 minutes) and the surface area of the coolant tubes, the surface heat flux at the interior wall of a coolant tube was calculated to be $3.45 \times 10^{5} \mathrm{~W} / \mathrm{m}^{2}$.

\subsubsection{Single Phase Flow}

For single phase flow the heat transfer fluid considered was Dowtherm $\mathrm{T}^{\circledR}$, having properties listed in Table 4.2.3-1. For this heat transfer fluid, the operating parameters required to remove the heat of reaction during loading are listed in Table 5.3.1-1. The required mass flux of coolant was computed using the Dittus-Boelter correlation, see Holman [1976].

\section{Table 5.3.1-1 Bed Heat Removal Parameters for a Single Coolant Tube}

\begin{tabular}{|l|c|}
\hline \multicolumn{1}{|c|}{ Parameter } & Value \\
\hline \hline Mass Flux & $10,300.4 \mathrm{~kg} /\left(\mathrm{m}^{2} \mathrm{~s}\right)$ \\
\hline Mean Flow Velocity & $12.61 \mathrm{~m} / \mathrm{s}$ \\
\hline Tube Reynolds Number & $58,861.02$ \\
\hline $\begin{array}{l}\text { Pressure Drop Over Length of } \\
\text { Tube }\end{array}$ & $8.134 \times 10^{4} \mathrm{~Pa}$ \\
\hline $\begin{array}{l}\text { Increase in Temperature Over } \\
\text { Length of Tube }\end{array}$ & $2.42{ }^{\circ} \mathrm{C}$ \\
\hline
\end{tabular}

\subsubsection{Two-Phase Flow}

In an attempt to enhance heat transfer from the bed during loading, cooling by two phase flow was investigated. The heat transfer fluid considered in the model was DuPont Vertrel-XF ${ }^{\circledR}$ and the required two phase mass flux was calculated from the GungorWinterton correlation [1986], assuming a low inlet quality for the coolant (on the order of $10^{-5}$ ). The required mass flux for two phase flows was calculated to be $16703.9 \mathrm{~kg} /\left(\mathrm{m}^{2} \mathrm{~s}\right)$.

Enhanced heat removal by the coolant is only effective if it is consistent with the rate of heat transfer from the hydride bed. The ratio of the rate of heat removal by convection in the coolant to heat transfer by conduction by the bed is given by the Biot modulus, Bi.

The Biot modulus is defined as

$$
\mathrm{Bi}=\frac{\mathrm{h}_{\text {conv }} \mathrm{L}}{\mathrm{k}_{\text {bed }}} \text {, }
$$


WSRC-TR-2007-00439

Revision 0

where: $\mathrm{h}_{\text {conv }}=$ Convection heat transfer coefficient for the coolant $\left[\mathrm{W} /\left(\mathrm{m}^{2}-\mathrm{K}\right)\right]$

$\mathrm{k}_{\text {bed }}=$ Thermal conductivity of the metal hydride bed $[\mathrm{W} /(\mathrm{m}-\mathrm{K})]$.

$\mathrm{L}=$ Characteristic length $[\mathrm{m}]$.

For the two-phase cooled system analyzed in this report, see Appendix A.2

$\mathrm{h}_{2 \phi}=\mathrm{h}_{\text {conv cool }}=0.9929 \mathrm{~W} /\left(\mathrm{cm}^{2}-{ }^{\circ} \mathrm{C}\right)=9929 \mathrm{~W} /\left(\mathrm{m}^{2}-\mathrm{K}\right)$

and, from Mosher, et. el. [2007]

$\mathrm{k}_{\text {bed }}=0.325 \mathrm{~W} / \mathrm{m}-\mathrm{K}$

Take $\mathrm{L}$ to be the distance from the center coolant tube to a coolant tube in the ring, see Figure 4.1.1-1 and Appendix A.1. Then

$\mathrm{L} \approx \mathrm{r}-\mathrm{D} \approx 0.076 \mathrm{~m}$

and,

$\mathrm{Bi} \approx 2,322$.

For a large Biot modulus, the rate of heat removal by convection far exceeds that by conduction. This implies that heat removal from the bed is limited by conduction and that the use of two-phase cooling alone will not improve heat removal for the bed configuration evaluated in this report. For this system geometry and storage material, it is more important to reduce the conduction transport length in the bed, L, or increase the bed thermal conductivity than to enhance convection heat transfer.

\subsection{CONCLUSIONS}

The kinetics, geometry and heat transfer, scoping models developed in this task can be used to quickly assess whether or not a hydrogen storage system meets operational requirements and should be evaluated with a more detailed model. Further, the scoping models may also be used to identify design modifications that improve performance. While the models do not perform detailed, coupled physics calculations, as would the more complete numerical model discussed in Hardy [2007], they provide sufficient information to estimate the dimensions and heat transfer parameters required for the storage system.

For a particular hydride and bed configuration the kinetics, geometry and heat transfer scoping models are applied in the following sequence. First, the mass of hydride required to store a given amount of hydrogen in the allotted refueling time is calculated with the kinetics model. Optimal temperatures and pressures during the loading and discharge phases are also determined from the model. Next, the required mass of hydride is input to the geometry scoping model via the ratio of moles of stored $\mathrm{H}_{2}$ to moles of final moles of hydride. The remaining input from Table 4.1.3-1 is then entered. Finally, for a particular heat transfer fluid, the heat transfer requirements for the system are determined from the bed heat transfer scoping model. 
WSRC-TR-2007-00439

Revision 0

When applied to the UTRCTM kinetics correlation for $\mathrm{NaAlH}_{4}$, the kinetics model replicated the UTRC ${ }^{\mathrm{TM}}$ predictions, see Figures 5.3.1-1 and 5.3.1-2. Even under the most favorable loading conditions, however, the model showed that the approach to the theoretical weight fraction of stored hydrogen was very slow. Hence, to store sufficient hydrogen in the DOE target refueling time the mass of hydride will need to be increased to the point that the gravimetric capacity of the bed will be far below the DOE 2007 technical target gravimetric capacity of 0.045 for the system. For $\alpha-\mathrm{AlH}_{4}$, the kinetics model showed that the release rate of hydrogen is very strongly dependent on temperature.

\subsection{REFERENCES}

COMSOL Multiphysics $^{\circledR}$, version 3.3.0.405. Copyright 1994-2006, COMSOL AB

Graetz, J. and J. J. Reilly. "Decomposition Kinetics of the $\mathrm{AlH}_{3}$ Polymorphs." J. Phys. Chem., B, 109, 22181-22185, 2005.

Gross, K. J. "The Reversible Hydrides Solution for Hydrogen Storage.” Slide Presentation for G-CEP Hydrogen Workshop, April 14 \& 15, 2003.

Gungor, K. E., and R. H. S. Winterton. "A General Correlation for Flow Boiling in Tubes and Annuli." Int. J. Heat Mass Transfer, Vol. 29, 351-358, 1986.

Gungor, K. E., and R. H. S. Winterton. "Simplified General Correlation for Saturated Flow Boiling and Comparisons of Correlations With Data" Chem. Eng. Des. Rev., Vol. 65, 148-156, 1987.

Hardy, B. J. "Integrated Hydrogen Storage System Model." Washington Savannah River Company Document, WSRC-TR-20007-00440, Rev.1, 2007.

Holman, J. R. "Heat Transfer." $4^{\text {th }}$ Edition, McGraw-Hill, New York 1976.

Mathcad $^{\circledR}$, version 14.0.0.163. Copyright (C) 2007 Parametric Technology Corporation.

Microsoft $^{\circledR}$ Excel 2002 (10.6834.6830) SP3. Microsoft Corporation.

Mosher, D, X. Tang, S. Arsenault, B. Laube, M. Cao, R. Brown and S. Saitta. "High Density Hydrogen Storage System Demonstration Using NaAlH4 Complex Compound Hydrides." DOE Hydrogen Program Annual Peer Review, Arlington, VA, 2007. 
WSRC-TR-2007-00439

Revision 0

\section{APPENDIX}

\section{A.1 GEOMETRY AND HEAT REMOVAL SCOPING MODEL REQUIREMENTS}

\section{A.1.1 Geometry Scoping Model}

The size, number of fins, gravimetric and volumetric capacities of the system evaluated in this report were based on parameters input to the Microsoft Excel ${ }^{\circledR}$ geometry scoping model shown in Figure A.1.1.

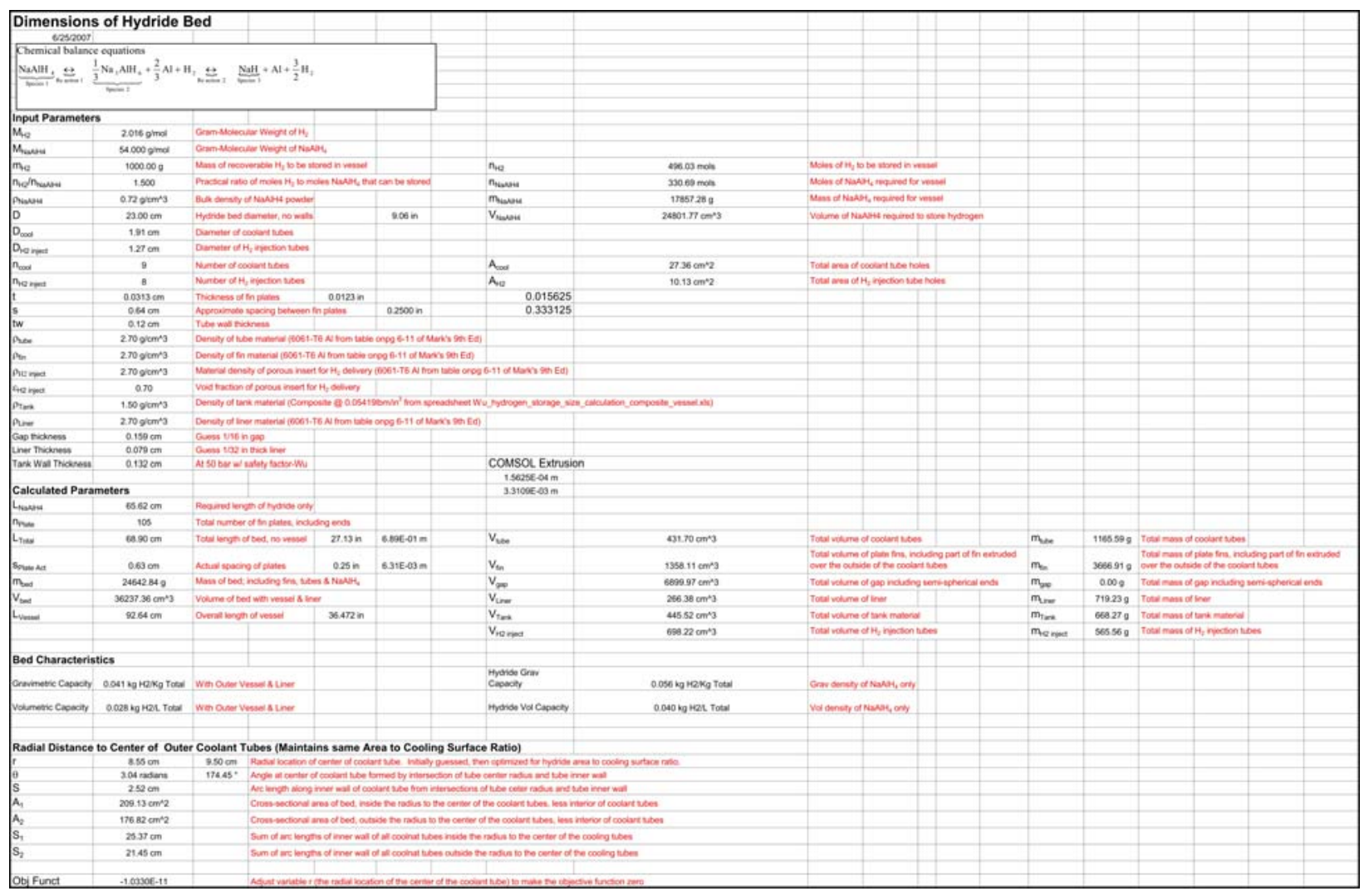

Figure A.1.1 System dimensions calculated with the geometry scoping model.

\section{A.1.2 Heat Removal Scoping Model}

Operating parameters for the heat removal system were based on calculations with the Microsoft Excel ${ }^{\circledR}$ heat removal scoping model shown in Figure A.1.2. The system in this report used Dowtherm $\mathrm{T}^{\circledR}$ heat transfer fluid for single phase cooling and DuPont Vertrel$\mathrm{XF}^{\circledR}$ heat transfer fluid for two phase cooling. Data sheets, from the respective vendors are listed in Attachments 1 and 2. 
WSRC-TR-2007-00439

Revision 0

\begin{tabular}{|c|c|c|c|c|c|c|c|c|}
\hline \multicolumn{9}{|c|}{ Heat Generation on Uptake } \\
\hline \multicolumn{9}{|c|}{ 6/26/2007 } \\
\hline \multirow{2}{*}{\multicolumn{9}{|c|}{$\begin{array}{l}\text { This worksheet calculates the heat generation occurring during hydration of } \mathrm{NaAlH}_{4} \text {. } \\
\text { The total moles of hydrogen taken up by the reaction are from the worksheet "Bed }\end{array}$}} \\
\hline & & & & & & & & \\
\hline \\
\hline \multicolumn{9}{|c|}{ Chemical balance equations } \\
\hline \multirow{2}{*}{\multicolumn{9}{|c|}{ 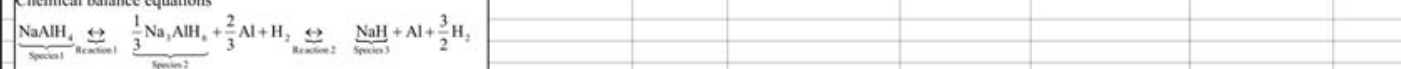 }} \\
\hline & & & & & & & & \\
\hline & & & & & & & & \\
\hline \multicolumn{9}{|l|}{ Input Parameters } \\
\hline$\Delta \mathrm{H}_{\text {Pent }}$ & $37.00 \mathrm{~kJ} / \mathrm{mol} \mathrm{H} 2$ & \multicolumn{7}{|c|}{ Heat of reaction from species 2 to species 1 (from Karl Gross, Sandia Sides) } \\
\hline$\Delta H_{\text {Rer2 }}$ & $47.00 \mathrm{~kJ} / \mathrm{mol} \mathrm{H} 2$ & \multirow{2}{*}{\multicolumn{7}{|c|}{ Heat of reacton from species 3 to species 2 (from Kart Gross, Sandia Slides) }} \\
\hline Charging Time & $180.00 \mathrm{sec}$ & & & & & & & \\
\hline Wall Temp & $90.00^{\circ} \mathrm{C}$ & & & & & & & \\
\hline 26 Coolant Liquid Density & $1.58 \mathrm{~g}_{\mathrm{cm} \wedge} 3$ & $1.58 \mathrm{~g} / \mathrm{cm}^{*} 3$ & DuPont Vetrol-.XF & $\begin{array}{l}2 \phi \text { Coolant Sat } \\
\text { Temp }\end{array}$ & $55.00^{\circ} \mathrm{C}$ & & & \\
\hline $2 \phi$ Coolant Vapor Density & $0.0101 \mathrm{~g} / \mathrm{am} / 3$ & $0.0101 \mathrm{~g} / \mathrm{cm} / 3$ & DuPant Vetrel $X F$ & \multicolumn{2}{|c|}{ Approxinste, from DiMarco Paper } & & & \\
\hline $\begin{array}{l}2 \phi \text { Coolant Liquid Themal } \\
\text { Cond }\end{array}$ & 0.060 Btu(hrif F) & $1.04 E-03$ Wi(cm $\left.{ }^{\circ} \mathrm{C}\right) \mathrm{D}$ & DuPont Vetrel-XF & \multicolumn{2}{|c|}{ Guessed from Dowtherm $T$} & & & \\
\hline \multirow{2}{*}{$\begin{array}{l}26 \text { Coolant Liquid Viscosity } \\
26 \text { Coolant Lquid Spocific } \\
\text { Heat }\end{array}$} & $0.67 \mathrm{cps}$ & $0.01 \mathrm{~g}(\mathrm{am} \mathrm{s})$ & Dupont Vertrel-XF & & & & & \\
\hline & 0.27 Btu(lbm 'F) & $1.13 \mathrm{~N}\left(\mathrm{~g}^{\circ} \mathrm{C}\right)$ & Dupont Vertrel-XF & & & & & \\
\hline $\begin{array}{l}26 \text { Coolant Phase Change } \\
\text { Enthalpy }\end{array}$ & 31.00 callg & $129.80 / \mathrm{J}_{9}$ & DuPont Vertsel-XF & & & & & \\
\hline $\begin{array}{l}26 \text { Coolant Liquid Prandt } \\
\text { No. }\end{array}$ & & 7.29 & DuPant Vertrol-XF & & & & & \\
\hline Void Fraction $(x)$ & 0.01 & & & & & & & \\
\hline Quality $(x)$ & $6.45656 \mathrm{E}-05$ & & & & & & & \\
\hline \multirow{2}{*}{$\begin{array}{l}16 \text { Coolant Liquid Density } \\
16 \text { Coolant Liquid Themal } \\
\text { Cond }\end{array}$} & $51.00 \mathrm{lbm} / \mathrm{tt}^{3} 3$ & $0.82 \mathrm{~g} / \mathrm{cm}^{\star 3}$ & Dowtherm $\mathrm{T}$ & $\begin{array}{l}16 \text { Coolant } \\
\text { Inilet Temp }\end{array}$ & $20.00^{\circ} \mathrm{C}$ & & & \\
\hline & 0.060 Btu(hrt iff) & $1.04 E-03 \mathrm{~W} /\left(\mathrm{cm}{ }^{\circ} \mathrm{C}\right) \mathrm{D}$ & Dowtherm $T$ & & & & & \\
\hline 16 Coolant Visoosity & $3.00 \mathrm{cps}$ & $3.00 E-02 \mathrm{~g} /(\mathrm{cm} s)$ & Dowtherm T & & & & & \\
\hline 16 Coolant Specific Heat & $0.55 \mathrm{Btu}\left(\mathrm{lbm} \mathrm{F}^{\circ} \mathrm{F}\right)$ & $2.30 \mathrm{~N}\left(\mathrm{~g}^{\circ} \mathrm{C}\right)$ & Dowtherm $T$ & & & & & \\
\hline 16 Coolant Prande Na. & & 66.52 & Dowtherm T & & & & & \\
\hline & & & & & & & & \\
\hline Calculated Paramet & & & & & & & & \\
\hline$\Delta \mathrm{H}_{\text {overeal }}$ & $40.33 \mathrm{~kJ} / \mathrm{mol} \mathrm{H} 2$ & Overall heat of reaction t & to form $\mathrm{NaNH}_{4}$ per mo & de of $\mathrm{H}_{2}$ & & & & \\
\hline & & & & & & & & \\
\hline Total Heat Released & & & & & & & & \\
\hline $8 \mathrm{Q}$ & $20006.61 \mathrm{~kJ}$ & Total heat removal tequit & uirement & & & & & \\
\hline $3 \mathrm{Q} / \bar{t} \mathrm{t}$ & $111147.85 \mathrm{~W}$ & Required rate of hoat rer & omoval & $\delta Q /(\delta t \sigma 6)$ & $4.4814 \mathrm{E}+06 \mathrm{~W} / \mathrm{m}^{\wedge} 3$ & Volumetric Rate & oat Generation & \\
\hline$q^{*}$ & $3.51 \mathrm{E}+01 \mathrm{~W} / \mathrm{cm} \times 2$ & Hoat flux to coolant insid & ide tubes & & & & & \\
\hline & & & & & & & & \\
\hline Coolant Mass Flux & & & & & & & & \\
\hline Single Ph & Coolant & & & Two t & hase Coolant & & & \\
\hline & Dowther & & & & DuPon & it Vertrel-XF & & \\
\hline$G_{1 \phi}$ & $1054.94 \mathrm{~g}(\mathrm{~cm} \times 2$ s) & From Ditus-Boetter com & rrelation & $\mathrm{G}_{2 \phi}$ & $1670.39 \mathrm{~g} /\left(\mathrm{cm}^{\wedge} 2 \mathrm{~s}\right.$ & From Gungor-W & on (1987) conreation & \\
\hline $\mathrm{v}$ & $1291.20 \mathrm{~cm} / \mathrm{s}$ & $h_{D B}$ & $0.5017 \mathrm{~W} /\left(\mathrm{cm}^{\wedge} 2^{\prime} \mathrm{C}\right)$ & $v_{\text {mix }}$ & $1067.82 \mathrm{~cm} / \mathrm{s}$ & $h_{\mathrm{GW}}$ & $0.9929 \mathrm{~W} /\left(\mathrm{cm}^{\wedge} \mathrm{z}^{\circ} \mathrm{C}\right)$ & \\
\hline $\operatorname{Re}_{\mathrm{D}}$ & 58235.51 & & & $\mathrm{Re}_{L}$ & 412853.11 & $q^{*} \sigma w-q^{*}$ & $-3.04 \mathrm{E}-10 \mathrm{~W} / \mathrm{cm} / 2$ & Correlation is OK \\
\hline$\Delta P$ & $1.23 \mathrm{E}+01 \mathrm{psi}$ & & & $\Delta \mathrm{P}$ & & $\mathrm{Fr}_{\mathrm{L}}$ & 687.8815 & \\
\hline$\Delta \mathrm{T}$ & $2.41 \mathrm{E}+00^{\circ} \mathrm{C}$ & & & $\Delta x$ & 0.02695 & & & \\
\hline By Dittus Boelter, & Holman, $4^{\text {th }} \mathrm{Ed}$ & 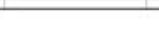 & & $\Delta E$ & 0.80288 & & & \\
\hline $\mathrm{Nu}_{0}=0.023 \mathrm{Re}^{\mathrm{es}} \mathrm{Pr}^{\mathrm{0}}$ & $\mathrm{Nu}_{\mathrm{o}}=\mathrm{hD}, \mathrm{Re}$ & $=\underline{\mathrm{GD}}, \mathrm{Pr}=\underline{\mathrm{v}}=\underline{\mu \mathrm{C}}$ & & & & & & \\
\hline $\mathrm{Nu}_{\mathrm{D}}=0.023 \mathrm{Re}_{\mathrm{D}} \mathrm{Pr}^{\mathrm{P}}$ & $\mathrm{Nu}_{\mathrm{o}}=\frac{\bar{k}}{\mathrm{k}} \cdot \mathrm{Re}_{\mathrm{s}}$ & $=\frac{\bar{\mu}}{\mu}, \operatorname{Pr}=\frac{\bar{\alpha}}{\alpha}=\frac{\mathrm{k}}{\mathrm{k}}$ & & & & & & \\
\hline $\mathrm{g}^{\prime \prime}=\mathrm{h}\left(\mathrm{T}_{\mathrm{L}}-\mathrm{T}_{\mathrm{\omega}}\right)=0.0$ & $k(\underline{G D})^{e s} \operatorname{Pr}^{0.4}\left(T_{0}\right.$ & $\left.-T_{1}\right)$ & & & & & & \\
\hline$q^{q}=h\left(T_{w}-T_{\text {liqu }}\right)=0.0$ & $\overline{\mathrm{D}}(\bar{\mu}) \mathrm{Pr}^{-1}\left(\mathrm{~T}_{\mathrm{w}}\right.$ & $\left.-\mathrm{T}_{\text {hiq }}\right)$ & & & & & & \\
\hline[ & ]$^{1 / 0 s}$ & & & & & & & \\
\hline & & & & & & & & \\
\hline $\mathrm{G}=\frac{\mathrm{q}^{\prime \prime}}{(\mathrm{n})^{0.5}}$ & & & & & & & & \\
\hline $0.023 k\left(\frac{D}{D}\right)^{0.5}$ & ${ }^{+}\left(T_{2}-T_{\text {ibe }}\right)$ & & & & & & & \\
\hline$\left[{ }^{0.020} \mathrm{D}(\bar{\mu})\right.$ & $\left(I_{\infty}-1_{\text {liq }}\right)$ & & & & & & & \\
\hline & & & & & & & & \\
\hline
\end{tabular}

Figure A.2.2 System heat transfer parameters estimated with the heat removal scoping model. 
WSRC-TR-2007-00439

Revision 0

\section{A.2 KINETICS SCOPING MODEL}

\section{A.2.1 $\mathrm{TiCl}_{3}$ Catalyzed $\mathrm{NaAlH}_{4}$ Kinetics}

The Mathcad ${ }^{\circledR}$ based UTRC ${ }^{\text {TM }}$ kinetics scoping model for $\mathrm{TiCl}_{3}$ catalyzed $\mathrm{NaAlH}_{4}$ is listed in this section of the Appendix. The model can run the reaction of Equation A.2.11 in either direction and for any initial composition of $\mathrm{NaAlH}_{4}, \mathrm{Na}_{3} \mathrm{AlH}_{6}$ or $\mathrm{NaH}$. As given by the kinetics, the direction of the reaction depends on the temperature and $\mathrm{H}_{2}$ pressure. The input parameters for the model below were chosen to cycle the bed.

$$
\underbrace{\mathrm{NaAlH}_{4}}_{\text {Species1 }} \underbrace{\leftrightarrow}_{\text {Reaction 1 }} \underbrace{\frac{1}{3} \mathrm{Na}_{3} \mathrm{AlH}_{6}}_{\text {Species 2 }}+\frac{2}{3} \mathrm{Al}+\mathrm{H}_{2} \underbrace{\leftrightarrow}_{\text {Reaction } 2} \underbrace{\mathrm{NaH}}_{\text {Species3 }}+\mathrm{Al}+\frac{3}{2} \mathrm{H}_{2}
$$

\section{Evaluation of Kinetics Model for $\mathrm{NaH}$}
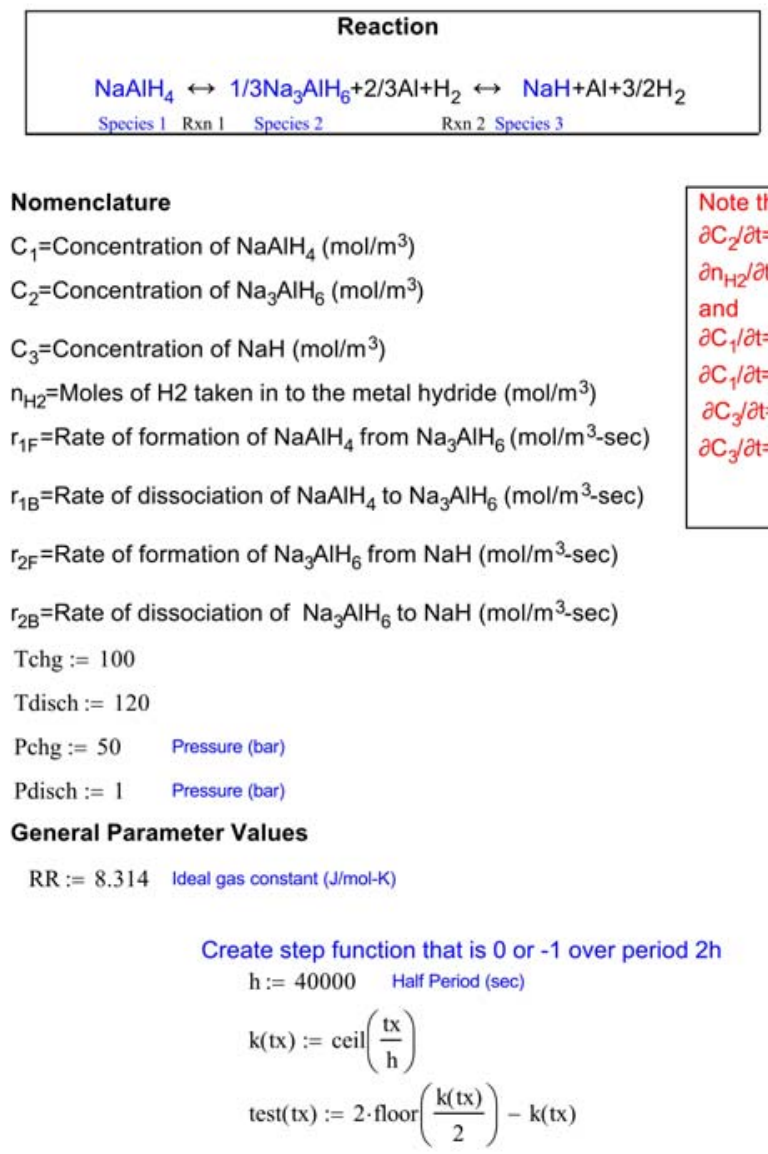

and

Note that

$\partial \mathrm{C}_{2} / \partial \mathrm{t}=-1 / 3\left(\partial \mathrm{C}_{1} / \partial \mathrm{t}+\partial \mathrm{C}_{3} / \partial \mathrm{t}\right)$

$\partial \mathrm{n}_{\mathrm{H} 2} / \partial \mathrm{t}=\partial \mathrm{C}_{1} / \partial \mathrm{t}-1 / 2 \partial \mathrm{C}_{3} / \partial \mathrm{t}$

$\partial \mathrm{C}_{1} / \partial \mathrm{t}=\mathrm{r}_{1 \mathrm{~F}}$ If $\mathrm{P}>\mathrm{Peq} 1(\mathrm{~T})$

$\partial \mathrm{C}_{1} / \partial t=-\mathrm{r}_{1 \mathrm{~B}}$ If $\mathrm{P}<\mathrm{Peq} 1(\mathrm{~T})$

$\partial \mathrm{C}_{3} / \partial t=\mathrm{r}_{2 \mathrm{~B}}$ If $\mathrm{P}<\mathrm{Peq} 1(\mathrm{~T})$

$\partial \mathrm{C}_{3} / \partial t=-\mathrm{r}_{2 \mathrm{~F}}$ If $\mathrm{P}>\mathrm{Peq} 1(\mathrm{~T})$ 
WSRC-TR-2007-00439

Revision 0

$\mathrm{P}(\mathrm{tx}):=$ if $($ test $(\mathrm{tx})<0$, Pchg, Pdisch) Pressure (bar)

Parameter Values (From Fit to Data)

\section{Reaction 1}

A1F $:=10^{8} \quad$ A1B $:=4 \cdot 10^{12} \quad \chi_{1 \mathrm{~F}}:=2.0 \quad \chi_{1 \mathrm{~B}}:=2.0$

E1F $:=8000$ activation Energy $(\mathrm{KJ} / \mathrm{mol}) \quad$ E1B $:=11000$ Activation Energy $(\mathrm{KJ} / \mathrm{mol})$

$\Delta H_{-} R 1:=-4475 \quad \Delta$ S_R $1:=-14.83$

\section{Reaction 2}

$\mathrm{A} 2 \mathrm{~F}:=1.5 \cdot 10^{5} \quad$ A2B $:=6 \times 10^{12} \quad \chi_{2} \mathrm{~F}:=1.0 \quad \chi_{2 \mathrm{~B}}:=1.0$

E2F $:=70000$ Activation Energy $(\mathrm{KJ} / \mathrm{mol}) \quad$ E2B $:=110000$ Activation Energy $(\mathrm{KJ} / \mathrm{mol})$

$\Delta H \_R 2:=-6150 \quad \Delta S \_R 2:=-16.22$

Equilibrium Pressure (in bar?)

Reaction 1

P_eq1(TT) $:=\exp \left(\frac{\Delta H_{-} R 1}{T T+273}-\Delta S_{-} R 1\right) \quad T$ is Temperature in (C)

Reaction 2

P_eq2(TT) $:=\exp \left(\frac{\Delta H_{-} R 2}{T T+273}-\Delta S_{-} R 2\right) \quad T$ is Temperature in (C)
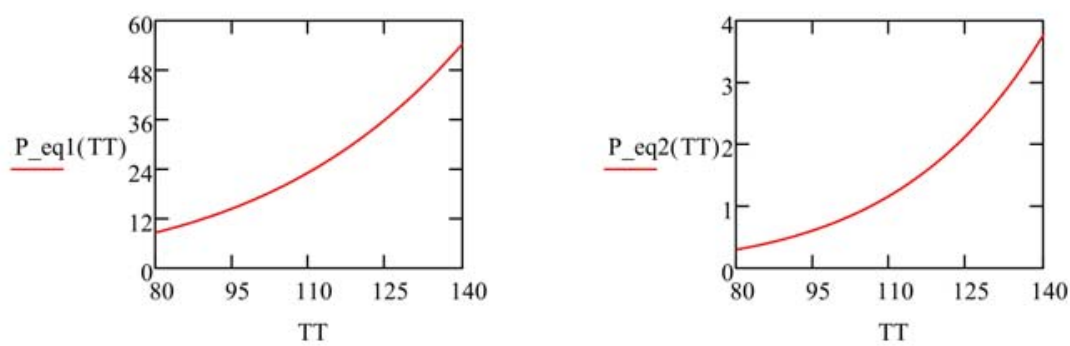

Initial Conditions

$\mathrm{C} 10:=0 \quad \mathrm{C} 20:=0 \quad \mathrm{C} 30:=330.69 \mathrm{nH} 20:=0$

Temp $(\mathrm{tx}):=\mathrm{if}(\mathrm{test}(\mathrm{tx})<0$, Tchg, Tdisch) $\quad$ Temperature (C)

Saturation Concentrations

Ceqv : $=\mathrm{C} 10+3 \cdot \mathrm{C} 20+\mathrm{C} 30 \begin{aligned} & \text { Equivalent Concentration, Needed to relate species concentrations }\left(\mathrm{mol} / \mathrm{m}^{3}\right) \text { to the } \\ & \text { non-dimensional concenrations used in calculations }\end{aligned}$

Fit the saturation weight fraction to temperature

$\pi$ is in $C$ 
WSRC-TR-2007-00439

Revision 0

wfdata :=

\begin{tabular}{|r|r|r|}
\hline & \multicolumn{1}{|c|}{0} & \multicolumn{1}{l|}{1} \\
\hline 0 & 300 & 0.021 \\
\hline 1 & 353 & 0.021 \\
\hline 2 & 353.15 & 0.021 \\
\hline 3 & 359 & 0.022 \\
\hline 4 & 363.15 & 0.023 \\
\hline 5 & 373.15 & 0.029 \\
\hline 6 & 393.15 & 0.022 \\
\hline 7 & 405 & 0.019 \\
\hline 8 & 413.15 & 0.018 \\
\hline 9 & 413.5 & 0.018 \\
\hline 10 & 600 & 0.018 \\
\hline
\end{tabular}

$\underset{\text { wfdata }}{\text { wa }}:=\operatorname{csort}($ wfdata, 0$)$

vTT $:=$ wfdata $^{\langle 0\rangle}-273.15$

$\mathrm{TT}$ is in $\mathrm{C}$

vy $:=$ wfdata $\left\langle{ }_{1}\right\rangle$

vs $:=1$ spline(vTT, vy)

wf_sat(TT) $:=$ interp(vs, vTT, vy, TT)

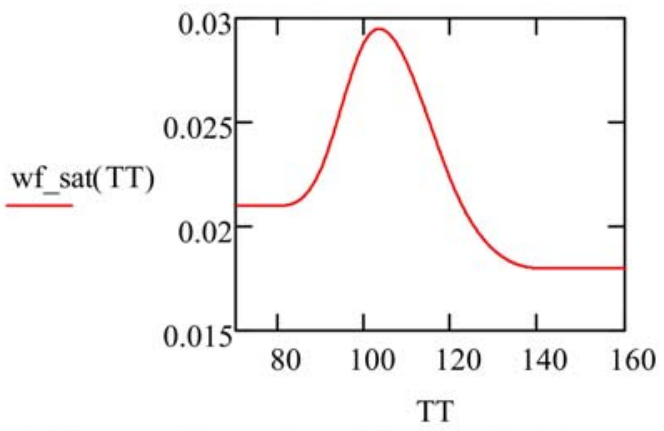

Compute the non-dimensional "saturation" concentrations from fit

$$
\begin{array}{ll}
\operatorname{rsat}(\mathrm{TT}):=\max \left(1,1-\frac{0.056-0.0187}{0.056-\mathrm{wf} \_\operatorname{sat}(\mathrm{TT})}\right) & \text { TT is in C } \\
\text { C3sat(TT) }:=\left(1-\frac{\mathrm{wf} \text { sat(TT) }}{0.056}\right) \cdot \operatorname{rsat}(\mathrm{TT}) & \text { TT is in C } \\
\text { C2sat(TT) }:=\frac{(1-\operatorname{rsat}(\mathrm{TT})) \cdot(0.056-\text { wf_sat(TT)) }}{(0.056-0.0187)} & \text { TT is in C }
\end{array}
$$


WSRC-TR-2007-00439

Revision 0

Forward and Backward Reaction Rates

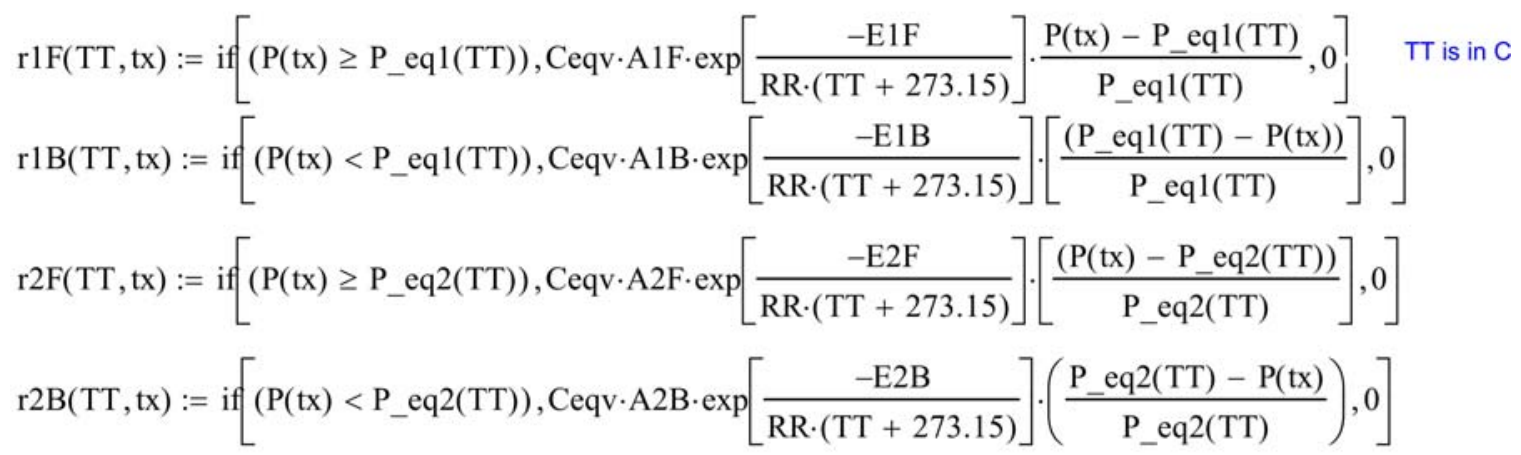

Hydrogen Concentration From Kinetics Equations

Given

$$
\begin{aligned}
& \frac{\mathrm{d}}{\mathrm{dt}} \mathrm{C} 1(\mathrm{t})=\operatorname{r1F}(\operatorname{Temp}(\mathrm{t}), \mathrm{t}) \cdot\left(\left(\frac{3 \mathrm{C} 2(\mathrm{t})}{\operatorname{Ceqv}}-\mathrm{C} 2 \operatorname{sat}(\operatorname{Temp}(\mathrm{t}))\right)\right)^{\chi_{1 F}}-\operatorname{rlB}(\operatorname{Temp}(\mathrm{t}), \mathrm{t}) \cdot\left(\frac{\mathrm{C} 1(\mathrm{t})}{\mathrm{Ceqv}}\right)^{\chi_{1 B}} \\
& \frac{\mathrm{d}}{\mathrm{dt}} \mathrm{C} 2(\mathrm{t})=-\left[\frac{1}{3} \cdot\left(\frac{\mathrm{d}}{\mathrm{dt}} \mathrm{C} 1(\mathrm{t})+\frac{\mathrm{d}}{\mathrm{dt}} \mathrm{C} 3(\mathrm{t})\right)\right] \\
& \frac{\mathrm{d}}{\mathrm{dt}} \mathrm{C} 3(\mathrm{t})=-\mathrm{r} 2 \mathrm{~F}(\operatorname{Temp}(\mathrm{t}), \mathrm{t}) \cdot\left(\frac{\mathrm{C} 3(\mathrm{t})}{\mathrm{Ceqv}}-\mathrm{C} 3 \operatorname{sat}(\operatorname{Temp}(\mathrm{t}))\right)^{\chi_{2 \mathrm{~F}}}+\mathrm{r} 2 \mathrm{~B}(\operatorname{Temp}(\mathrm{t}), \mathrm{t}) \cdot\left(\frac{3 \mathrm{C} 2(\mathrm{t})}{\mathrm{Ceqv}}\right)^{\chi_{2} \mathrm{~B}} \\
& \frac{\mathrm{d}}{\mathrm{dt}} \mathrm{nH} 2(\mathrm{t})=\frac{\mathrm{d}}{\mathrm{dt}} \mathrm{C} 1(\mathrm{t})-\frac{1}{2} \cdot\left(\frac{\mathrm{d}}{\mathrm{dt}} \mathrm{C} 3(\mathrm{t})\right) \quad \begin{array}{l}
\mathrm{nH} 2 \text { is the number of moles of } \mathrm{H} 2 \text { per volume of hydride that } \\
\text { are contained for release in the metal hydride }
\end{array} \\
& \mathrm{C} 1(0)=\mathrm{C} 10 \quad \mathrm{C} 2(0)=\mathrm{C} 20 \quad \mathrm{C} 3(0)=\mathrm{C} 30 \quad \mathrm{nH} 2(0)=\mathrm{nH} 20 \\
& \left(\begin{array}{c}
\mathrm{C} 1 \\
\mathrm{C} 2 \\
\mathrm{C} 3 \\
\mathrm{nH} 2
\end{array}\right):=\text { Odesolve }\left[\left(\begin{array}{c}
\mathrm{C} 1 \\
\mathrm{C} 2 \\
\mathrm{C} 3 \\
\mathrm{nH} 2
\end{array}\right), \mathrm{t}, 240000,20000\right]
\end{aligned}
$$


WSRC-TR-2007-00439

Revision 0

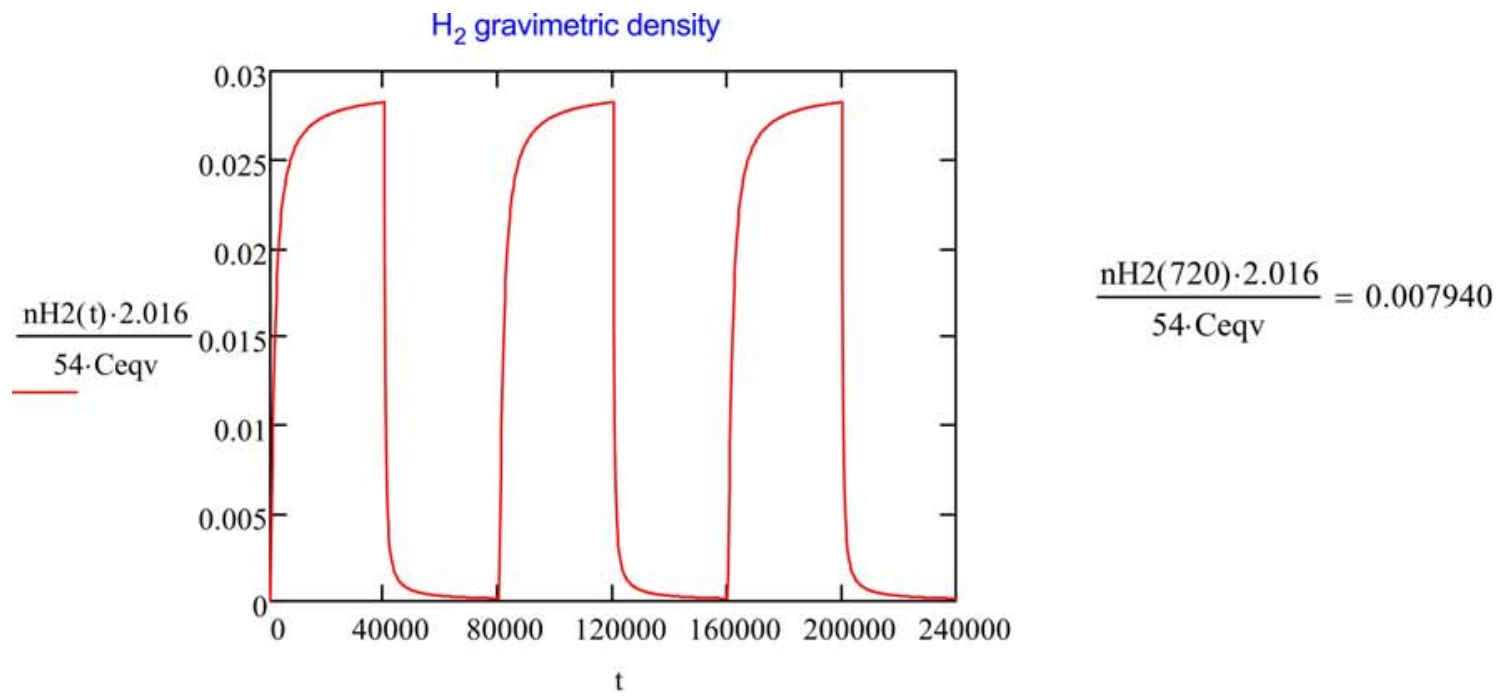

Time (s)

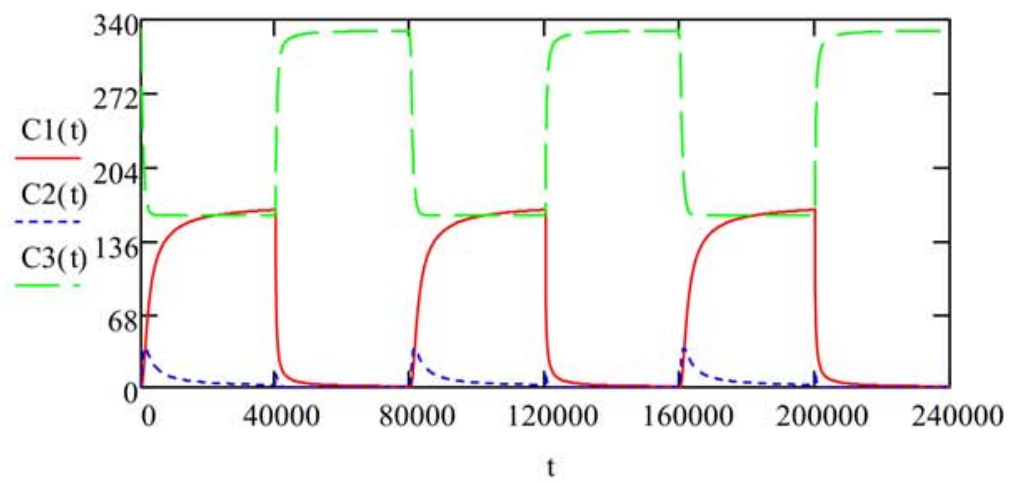

Time (s)

Fractional Utilization of Bed

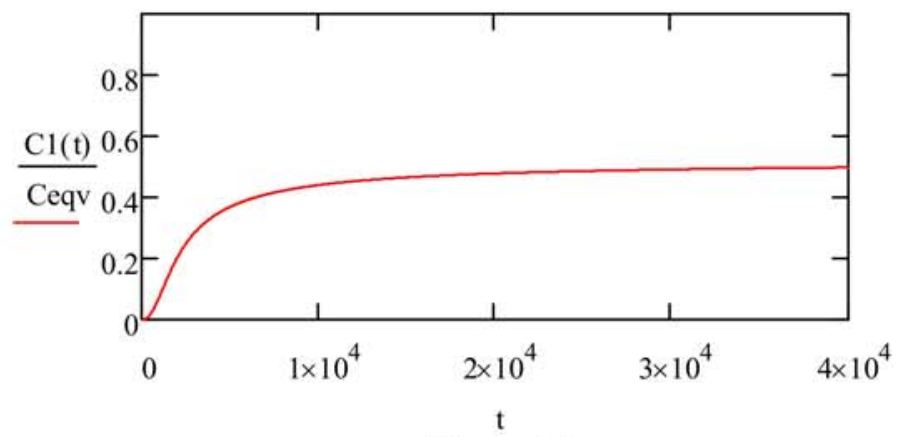

Time (s) 
WSRC-TR-2007-00439

Revision 0

\section{A.2.2 $\alpha-\mathrm{ALH}_{4}$ Kinetics}

The kinetics for $\alpha-\mathrm{AlH}_{4}$ is based on the correlation of Graetz and Reilly [2005]. The correlation was input to Mathcad $^{\circledR}$ and used to calculate the transient concentration of $\alpha-\mathrm{AlH}_{4}$ and the release rate of $\mathrm{H}_{2}$, under discharge conditions for temperatures ranging from $80^{\circ} \mathrm{C}$ to $120^{\circ} \mathrm{C}$. An example of the Mathcad ${ }^{\circledR}$ model, at $110^{\circ} \mathrm{C}$, used for these calculations is listed below.

\section{Evaluation of $\alpha-\mathrm{AlH}_{3}$ Decomposition Kinetics}

\section{Nomenclature}

$\mathrm{C}_{\mathrm{a} \_\mathrm{AlH} 3}=$ Concentration of $\alpha$-phase $\mathrm{AlH}_{3}\left(\mathrm{~mol} / \mathrm{m}^{3}\right)$

\section{General Parameter Values}

$$
\begin{array}{ll}
\mathrm{RR}:=8.314 & \text { Ideal gas constant }(\mathrm{J} / \mathrm{mol}-\mathrm{K}) \\
\mathrm{P}:=68 & \text { Pressure (bar) }
\end{array}
$$

Fit Parameter Values (From Graetz, J. and J. J.

Reilly. "Decomposition Kinetics of the $\mathrm{AlH}_{3}$ Polymorphs." J. Phys Chem, B 2005, 109, 22181-22185)
A_AlH3 $:=1.2 \cdot 10^{10}$
E_AlH3 $:=102.2$ Activation Energy $(\mathrm{KJ} / \mathrm{mol})$

\section{Reaction Rate}

$\mathrm{k}(\mathrm{TT}):=$ A_AlH3 $\cdot \exp \left(\frac{-\mathrm{E} \_ \text {AlH3 } \cdot 1000}{\mathrm{RR} \cdot \mathrm{TT}}\right)$

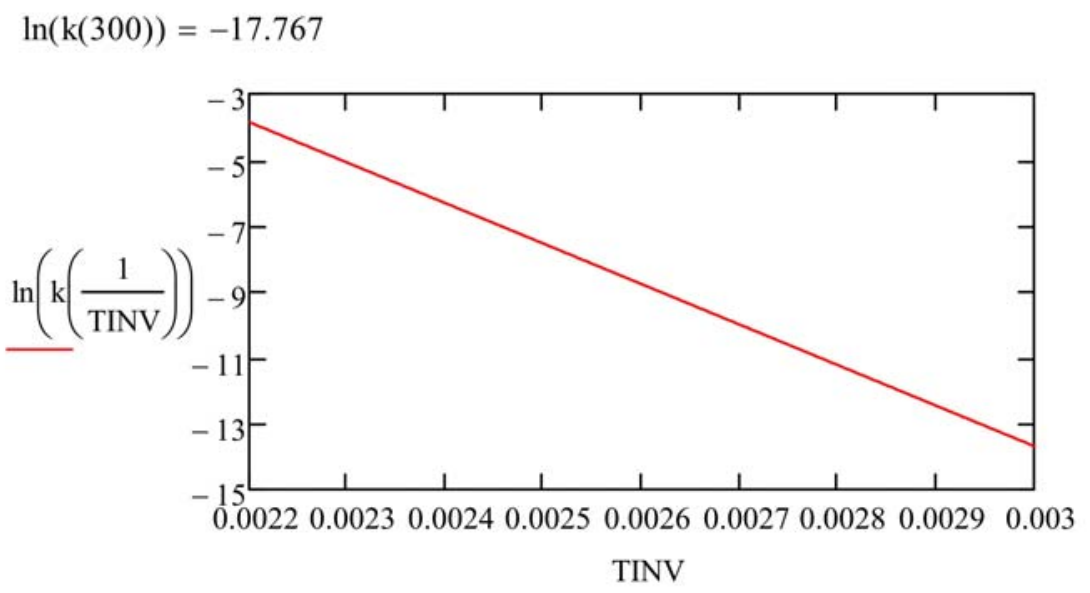


WSRC-TR-2007-00439

Revision 0

TempAlane $:=110 \quad$ AlaneTemperature $(C)$

Ca_AlH30 $:=30 \quad$ AlaneConcentration $\left(\mathrm{mol} / \mathrm{m}^{3}\right)$

alpha $(\mathrm{t}, \mathrm{TT}):=1-\exp \left[-(\mathrm{k}(\mathrm{TT}+273.15) \cdot \mathrm{t})^{2}\right]$

$\operatorname{deriv}(\mathrm{t}$, TempAlane $):=2 \mathrm{Ca} \_$AlH30 $\cdot \mathrm{k}(\text { TempAlane }+273.15)^{2} \cdot \mathrm{t} \cdot \exp \left[-(\mathrm{k}(\text { TempAlane }+273.15) \mathrm{t})^{2}\right]$

\section{Alane Concentration From Rate Equations}

Given

$\frac{\mathrm{d}}{\mathrm{dt}} \mathrm{Ca} \_\mathrm{AlH} 3(\mathrm{t})=$ if $\left[\left(\mathrm{Ca} \_\mathrm{AlH} 3(\mathrm{t}) \geq 0\right),-\mathrm{Ca} \_\mathrm{AlH} 30 \cdot \frac{\mathrm{d}}{\mathrm{dt}} \mathrm{alpha}(\mathrm{t}\right.$, TempAlane $\left.), 0\right]$

Ca_AlH3 $(0)=$ Ca_AlH30

Ca_AlH3 $:=$ Odesolve $(\mathrm{t}, 110000,1000)$

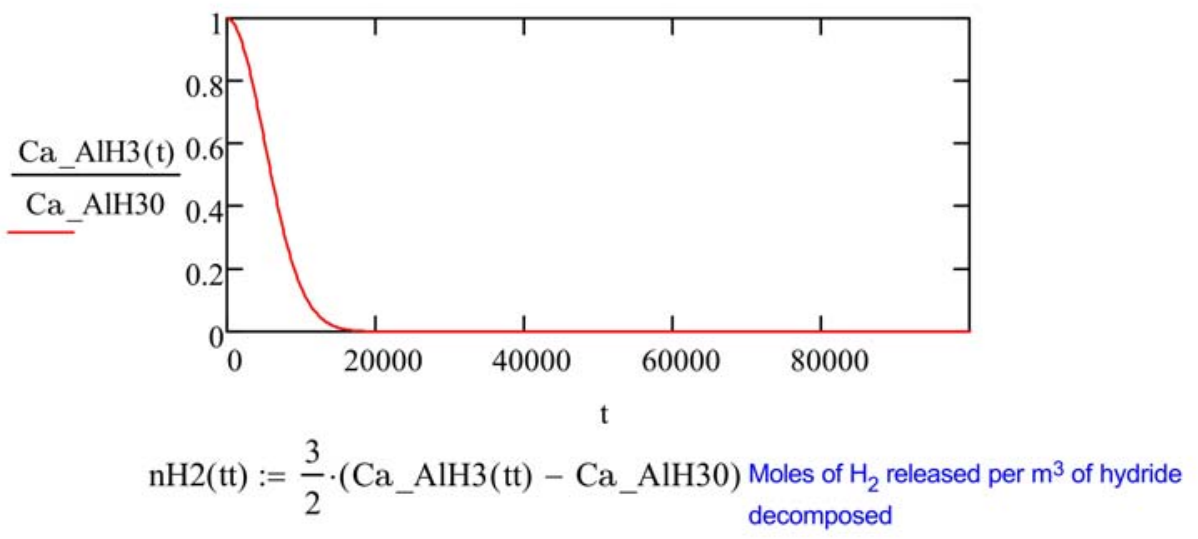

rate_nH2 $(\mathrm{t}):=-\frac{3}{2 \cdot \mathrm{Ca} \_\mathrm{AlH} 30} \frac{\mathrm{d}}{\mathrm{dt}} \mathrm{Ca} \_\mathrm{AlH} 3(\mathrm{t}) \quad \begin{aligned} & \text { Rate of moles of } \mathrm{H}_{2} \text { released per mole } \\ & \text { of } \alpha-\mathrm{AlH}_{3} \text { decomposed }\end{aligned}$

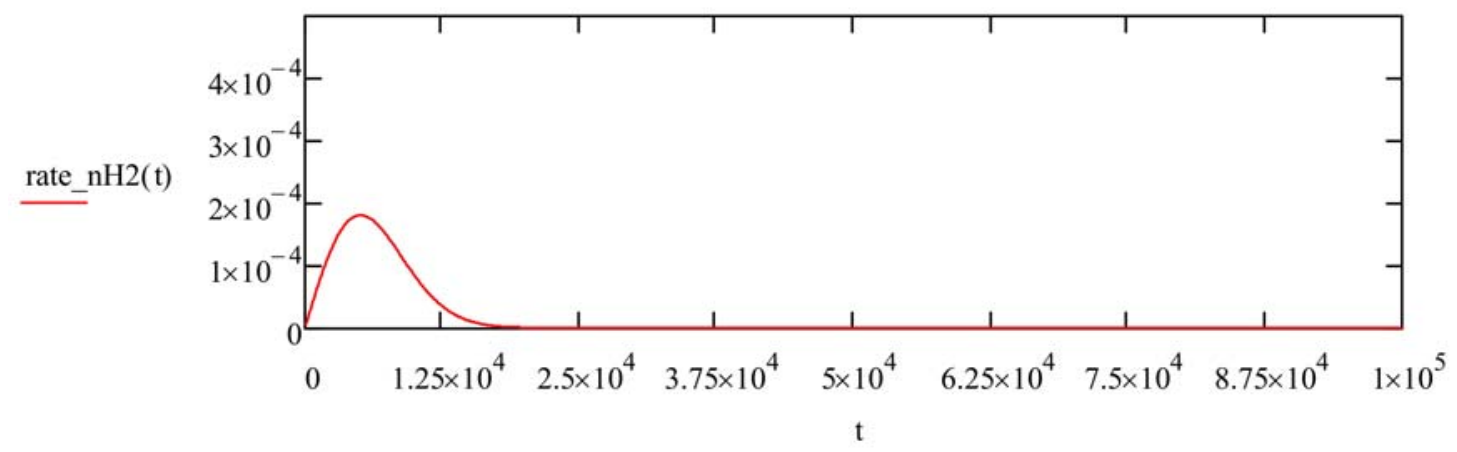


WSRC-TR-2007-00439

Revision 0

\section{ATTACHMENTS}

\section{Att.1 Properties of Dowtherm $T^{\circledR}$}

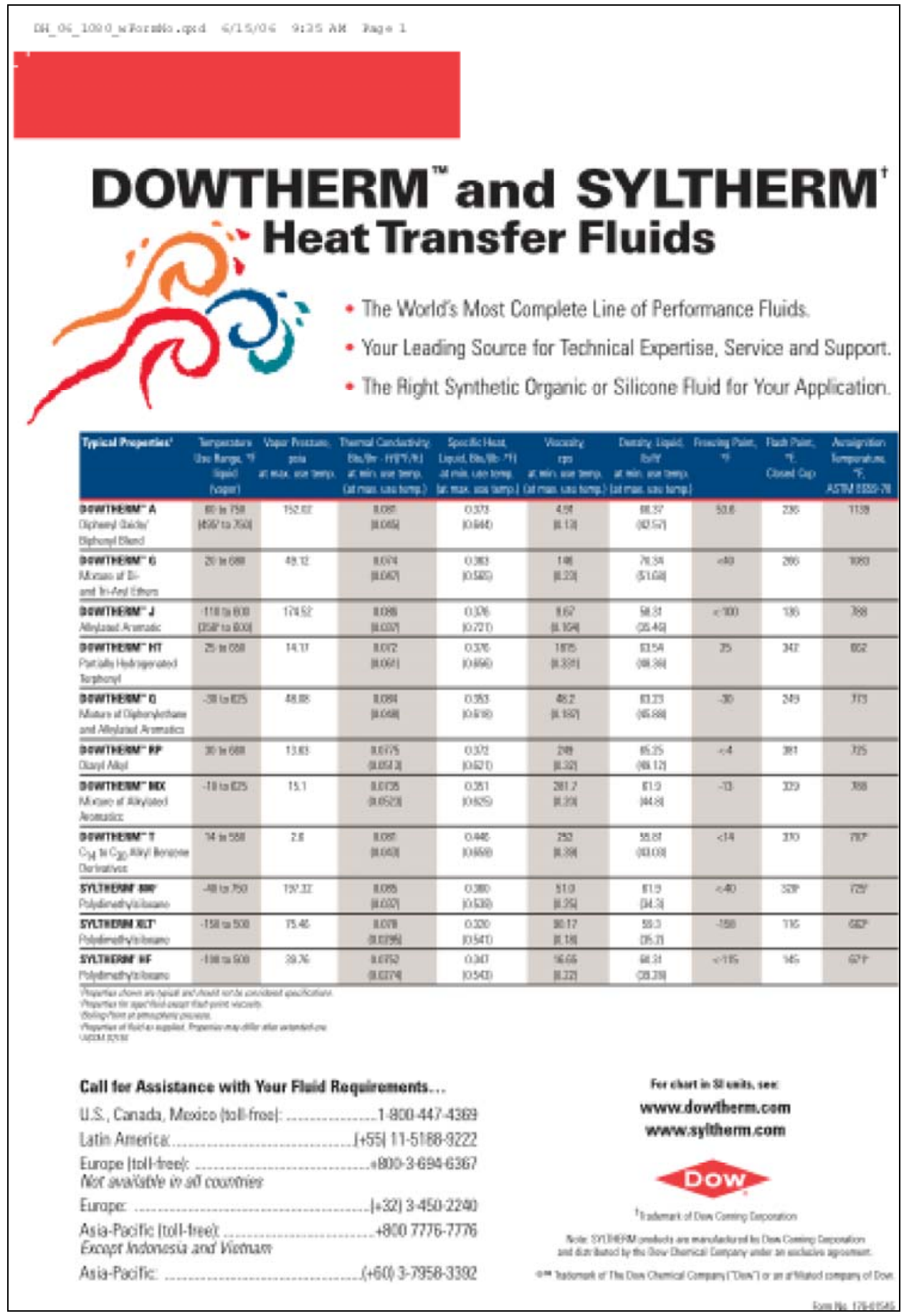


WSRC-TR-2007-00439

Revision 0

\section{Att.2 Properties of DuPont Vertrel-XF ${ }^{\circledR}$}

\section{Technic thformatin}

\section{DuPont $^{\mathrm{TM}}$ Vertrel $^{\circledR} \mathrm{XF}$}

\section{Specialty Fluid}

\section{Introduction}

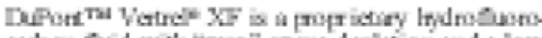

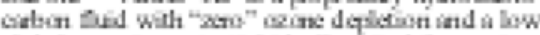

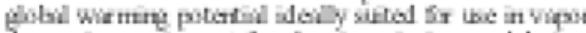
degroioing equpment Sir cloining, rinsing ind dryene

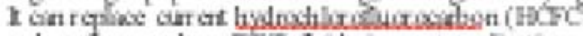

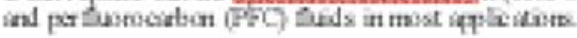

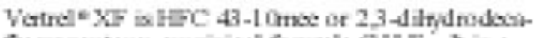

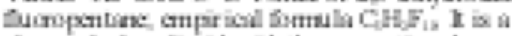

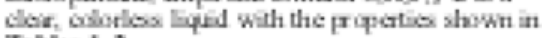
Tathos 1-2

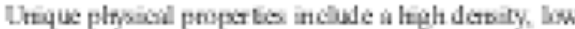
visecsery, ind low surfice tersion. Thiscombind with nerfummis ry, cherricil ind themil stablity, Lw

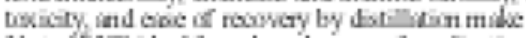

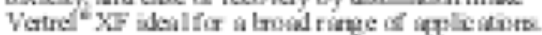

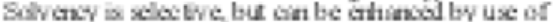

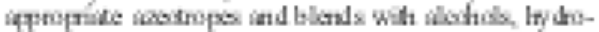
cirbons, sters, ete (see Talle 3)

Table 1

Physical Properties

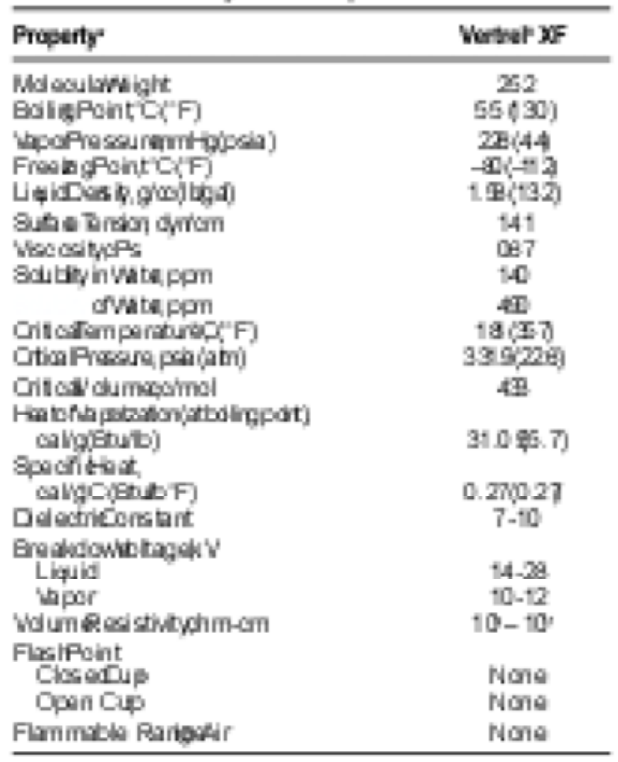

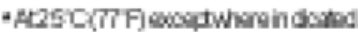

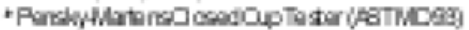

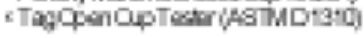

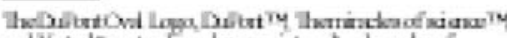

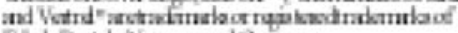

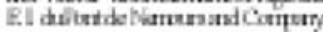

\section{Typical Applications}

- Cleirne ind rinsing ingert.

- Dryine Suid

- Pirticillue remiser

- Rusnciabsin Dericint cirr ic

- Seviver ind dispersain mela

- Heic triasíar molia

- Dedoctric rifad

- Requaconer Sor miaty HCFC. PSC, ind

CH. 113 ippotitions

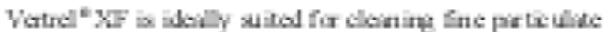

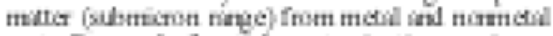

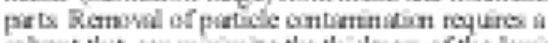

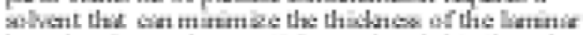
boundary liver whe pirticles ine bindal to the siubstrite I the boundary lower thicknss is less thin the pir tic timeter, mincribu fnom the fowing suvert.

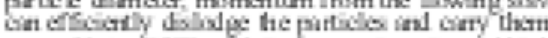
way. Vetrele XF, with its lower viscosity ind highe denxty, roults in à timer boundiry lincr, which en-

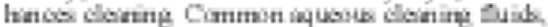
mextures of witer ind deferiot, hine hipher visenetio

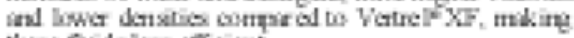

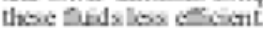

The electrons utriction bewosn pirticle and surfice cin be overiome fir ther by incroioing the polinty of the

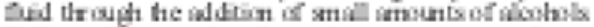

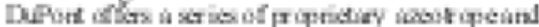

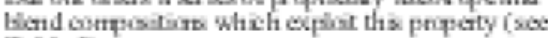
Talke 3).

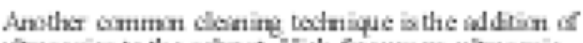

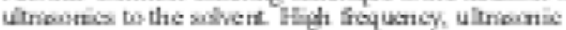

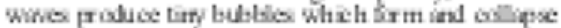
fow tide io the wowe pose Cinterien energy in-

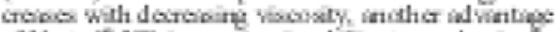

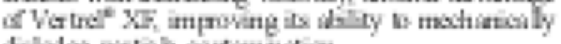
Aslide pirtice contimnition.

\section{Vapor Degreasing Process}

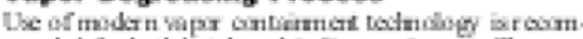

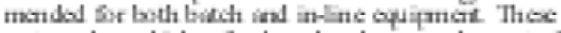

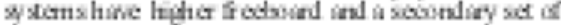
liw-temper ibure $(-29 \mathrm{C}[-20 \mathrm{~F}])$ onderiser ools.

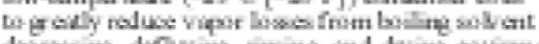
degroibing. derlusing, niming ind dying equpmert.

Now Vertrele XF cin be usod ser riming. dryng ind

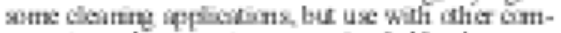

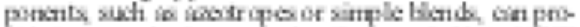

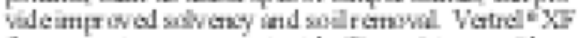

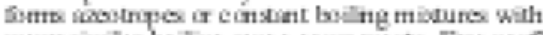

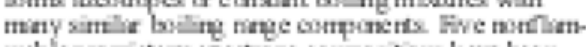

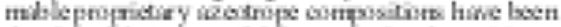

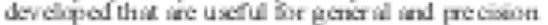

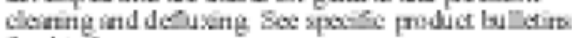
Sit detirls.

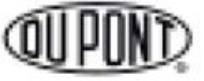

The miracles of science 
WSRC-TR-2007-00439

Revision 0

Table 2

Densty and Vapor Piessure Change with Temperature

\begin{tabular}{|c|c|c|}
\hline $\begin{array}{c}\text { Temperiaure, } \\
\text { " } C\left({ }^{2} F\right)\end{array}$ & $\begin{array}{c}\text { Density } \\
\text { gres 0ishy }\end{array}$ & $\begin{array}{c}\text { Waper } \\
\text { Presisure, } \\
\text { mmitg (boia) }\end{array}$ \\
\hline 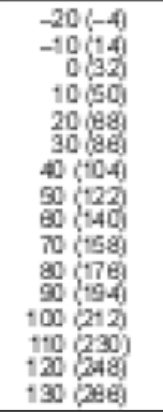 & 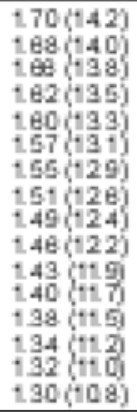 & 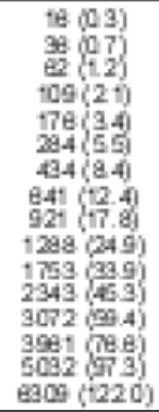 \\
\hline
\end{tabular}

Table 3

Azeotropes of Vettel" XF

\begin{tabular}{|c|c|c|}
\hline Product & Verturt XFWh & $\begin{array}{c}\text { Bsiling } \\
\text { Potrt, "Ci'F }\end{array}$ \\
\hline vetuet Xu & Moterd & $46(115)$ \\
\hline WaturexE & Etwern & sacines \\
\hline Vatoer $x^{2}$ & iscproporal & $52 y+24$ \\
\hline Vetof MOA & Trars-1,20ubloochines & 3 sion \\
\hline SMT & 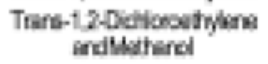 & $37000)$ \\
\hline
\end{tabular}

\section{Co-solvent Process}

The co-solvent pocoss is a cloining pocoss thit

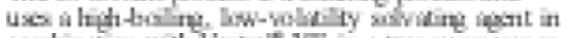
combinien with Vor tre" $\mathrm{XF}$, in a two-sinmp vipa dogrober. Rir ts ire immersed ints the bod sumpein.

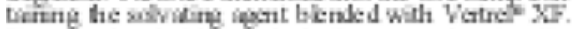
Rats ire then held ove the boll sumpind optinn squiged to remive base contiminits and the sivitng igeri. The rine sump contuns inly Vortre" XF. Rirts

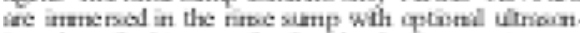

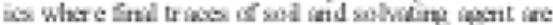
removel The ports ire thin held in the vipse sne to complese the dryng cycle.

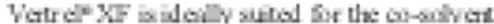
proses, besiuse the typicil solvating igerts ire pir-

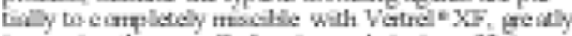
mproving the ovenill cloning ind rinsing ef fesency.

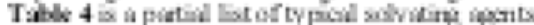

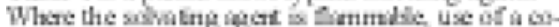

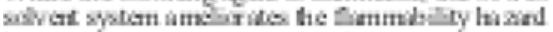
by poviding in inst vipur blinket

\section{Solvency}

Lhilke the PFCx Vetrel" XI is completely misc ble

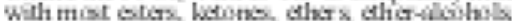

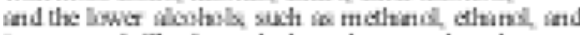

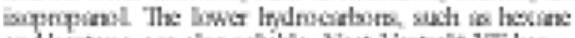

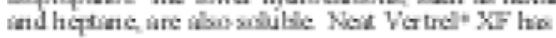

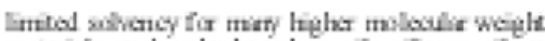

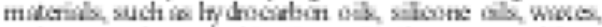

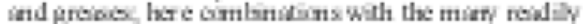

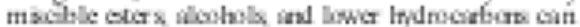

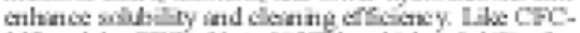

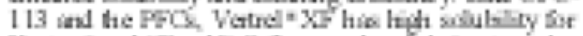

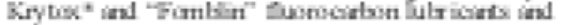

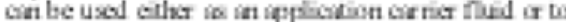
rumove them.

Table 4

Vertrelv XF solvating Agents.

Dhad: Edems rone

Aphsis: An atols

Alphwio $H$ yernoartions

Propyene Gyed Hithers!

Metrid Doo ang

NHetry-2+Peroldone ôM FI

Descotaty DeE

Dipopiene Cyod Butyleh

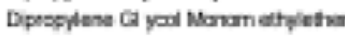

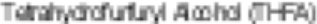

\section{Plastic and Elastomer Compatibility}

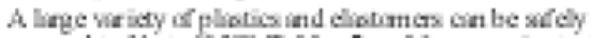

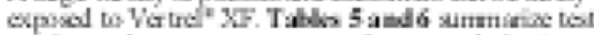

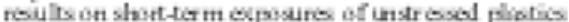

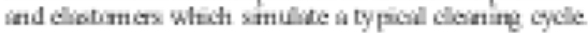

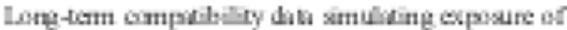

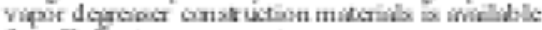
fim buRint upan request.

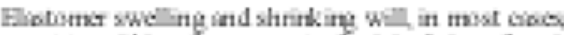

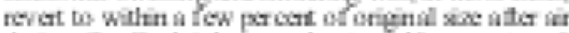

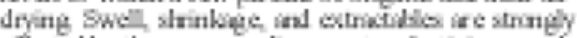

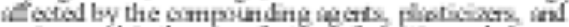

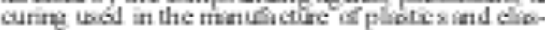
tomar. Theresoe, prix in-lac toling is pieticulialy impertint

Table 5

\section{Plsstic Compst b ty}

immersion: 15 M nutes at Room Temperatuse

\begin{tabular}{|c|c|}
\hline \multicolumn{2}{|c|}{ Cempatele } \\
\hline Polpettriane & ABS \\
\hline Polvercoplene & Aostal \\
\hline Polyctyrene & Epoxy \\
\hline Polvester, PET, PGT & lonomer \\
\hline Rolyphanyene Owdia PPO & Liquid Gratal Fodyma \\
\hline 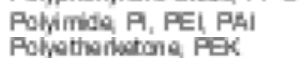 & $\begin{array}{l}\text { Phendis } \\
\text { PWC QPVC }\end{array}$ \\
\hline Polyarylotherictone, $P \boxplus x$ & PTIFE ETFE \\
\hline $\begin{array}{l}\text { Polvaúfone } \\
\text { Polyoulone }\end{array}$ & \\
\hline Polyphenvene sunde, PP8 & \\
\hline \multicolumn{2}{|c|}{ incemparible } \\
\hline Acryic & Coluosis \\
\hline
\end{tabular}


WSRC-TR-2007-00439

Revision 0

Table 6

Elastomer Compst b th Immersion: 15 Minutes at floom Temperature

\begin{tabular}{|c|c|}
\hline \multicolumn{2}{|c|}{ Compatio is } \\
\hline Buna N, NER, Nutrik & Bua B 8gR ORB \\
\hline Baty Pulter, IIR & Ghionesufonatod $P E$ \\
\hline EM ERCM rendel & Pov younde \\
\hline ratural Pulter, Isspren & Nooprene \\
\hline Unothane & Whon= 8 \\
\hline & gloone \\
\hline
\end{tabular}

incempateis.

riven Tested

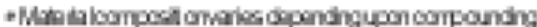

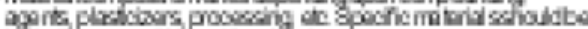

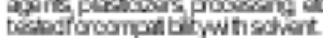

Metals and Other Compatibility

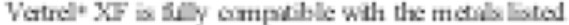

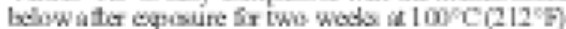

in seiliod tulses with and whisut wher contict

- Znime

- Aluminim

- Sturiliss Sted

- Copper

- Bnios"

Vertel $\mathrm{XF}$ is not compotis wh seong bios, there

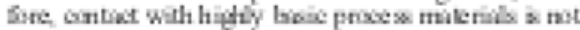
recommind ed.

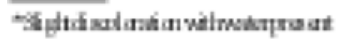

\section{Exposure Limits}

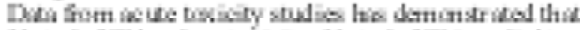
Vertel- XF hio low tosicty. Verted XF is a sleght

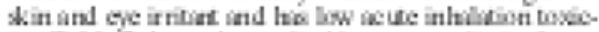

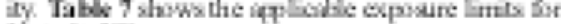
Vertrel- XE:

Tathle 7

Exposure Limits

\begin{tabular}{|c|c|c|}
\hline Component & Limit, pen & Type \\
\hline Wertrel yf & AE. $\begin{aligned} 200 \\
400\end{aligned}$ & $\begin{array}{c}\text { 8- and } 12 \text {-h TWA } \\
\text { Celing }\end{array}$ \\
\hline
\end{tabular}

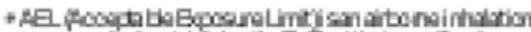

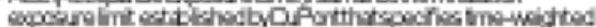

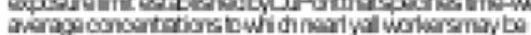

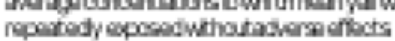

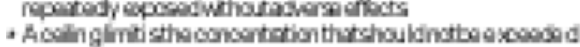

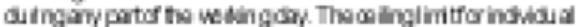
componerteaplesibablendprosucher we

\section{Safety/Flammability}

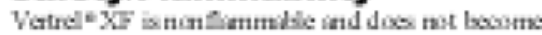

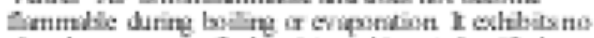

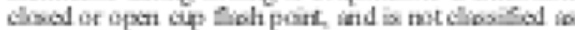

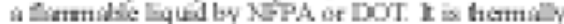

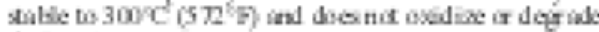
diring sturige

\section{Recovery}

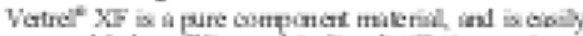

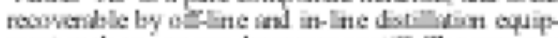

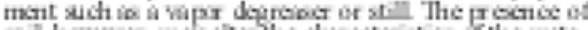
sell however, miny biter the chir icteristics if the moterid diring the recovery operition. Reverery should be clisely minitired to insire oper iting levels ire mintornd. Uber x should test the spant Vertede XF to ensure. mepr clioxifition fix waste disposit

\section{Storage/Handling}

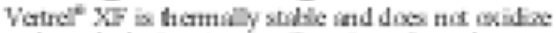

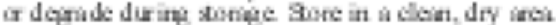

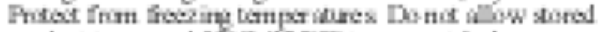
moduct to excoed 52 C (125\%) to prevert levilige is

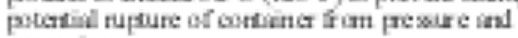
eqpiriseon

Corsidention thisuld be fiven to retrost of exsting of purchise of new, Viper degrobing equpment to provide vipar ontinanent toctrisigy the enibios sibe ind

Drum purnps ire recimmanded to disperse Ver tre X:

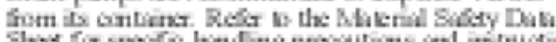

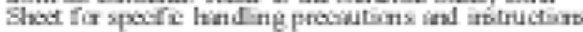

\section{Environmental Legislation}

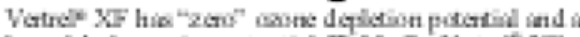

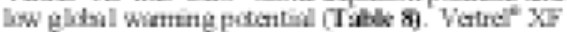

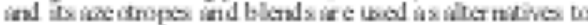

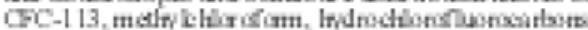

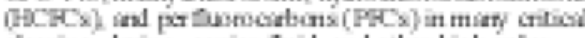

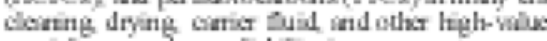

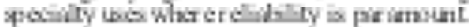

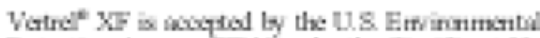

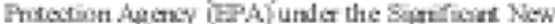

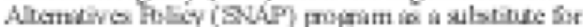

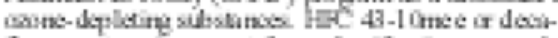

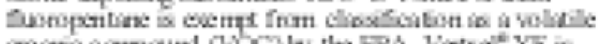

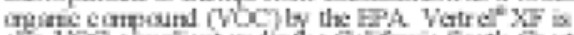

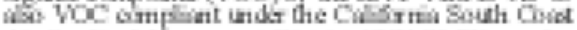

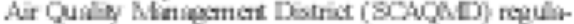
tins, which reque wocostent les thin $50 \mathrm{gL}$. a s:kent

Verter XF is listed in the TSCA incery. $\mathrm{I}$ is subect wo the Bert Sint Kew the Ruke (BNLR) ind shoul be

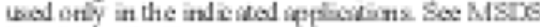
Bopilitisy Section.

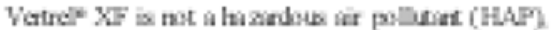

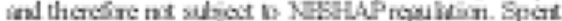

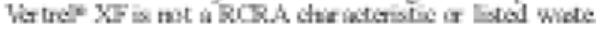
However, whision of conburmints cald chinge the stous. Verter XF is nit included in the SARK. Tile III

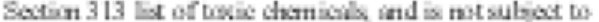
BARA T te III (FPCRA) ripatine requiremarts

\section{Packaging and Availability}

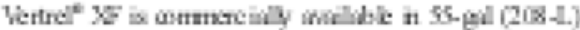
drums with a ne weight of $660 \mathrm{lb}$ (29) ka hind in 5 -ent

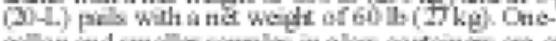
fillon ind smilier simples in plios cortinutrs ire iwe?

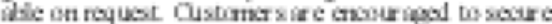
sumples now Sorompititity ind persimance teting 
WSRC-TR-2007-00439

Revision 0

\section{Specifications}

Campostion ind spocifotions ir shwn in Table9. Vertre XF is listed in the TSCA hrictiory.

Table 8

Emironmental Poperties

\begin{tabular}{|c|c|}
\hline Proserty & Wertogi" XF \\
\hline Formula & C.H. \\
\hline Cless & Hyanofucoertoon $\mathrm{HFC}$ \\
\hline Abmospherie Lfotme yr & เ \\
\hline $\begin{array}{l}\text { Coose-Depotion } \\
\text { Potenta (OCP) }\end{array}$ & 0 \\
\hline \multicolumn{2}{|l|}{ Chbal Waming } \\
\hline Potental (ow Prtoo vitr-) & 1300 \\
\hline \multicolumn{2}{|l|}{ Wolatis Organis } \\
\hline Compound (WOG gL) & Exemp \\
\hline
\end{tabular}

Table 9

Vestrel" XF Apscilications

\begin{tabular}{|c|c|}
\hline Flucropentanes, ws & $999 \mathrm{~min}$ \\
\hline Nonvalis Peaidie fem wt & $2.0 \max$ \\
\hline Noichura pen wt & $50 \max$ \\
\hline foddty, mg kOHig & $0.0 * \max$ \\
\hline Appearance & Clear, Cobriss \\
\hline
\end{tabular}

Morth Ameriea, Canada, Mexieo

Micro Care Markdim Savicss

Qus bahn Bowney Drwe

New Eritin Croviost

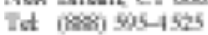

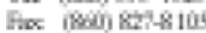

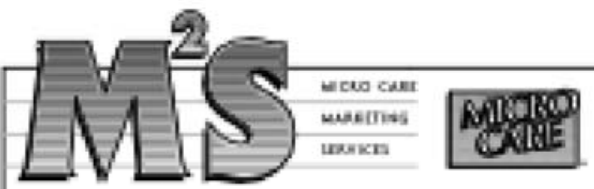

\section{YOUR DIRECT SOURCE FOR DUPOKT VERTREL}

\section{Europe, Alrica,} Middlle East

Dulitut de binuma

Intsmationd $3 A$.

2 Churin de llwilbn

Po. Box 50

CH-1218 LeQnad-Sanmox

Gueva, Initantand

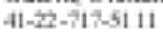

\section{South Amerioa}

Cuilot do Arail 8 .

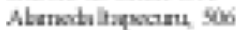

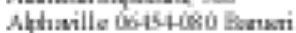

Sov Prado, Rnuil

55-11-7rio-sicto

\section{Pacilie}

Bullot Ausindia

Pro Rox ivio

Wath Bydry, WBw

Autraka toio

61-2-9ch-ólós

\section{Japan}

Culibukitai

Husaduaricat

Co. It d

Chiyou Hasala Bdp 5-18 Sang ba-do 1 -Chare

Chiyota-k.. Takyo lúi.

Jasen

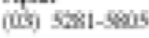

\section{Asia}

Duliot triman

Po. $\operatorname{Rox} 81-7 \%$

Taqsi, Tawan

$60-2-51+400$

Dulbt haialacialc, LH

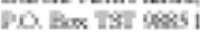

Tim Sta Tai

Bowloon Harg Ras

$852-734-545$

Dubtot Traland

G.o Biox zisos

Bangave losen, thiland

6i-2-26owion
Dulivet fir Rut, Inc.

BF Solid Fank Hid

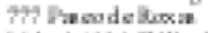

Madadi 1tab Btilipines

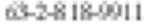

Dulint fir Eut lne

No. Bhos The

dinoe Strd Alan Matryia

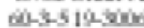

Dilint har a lit

CaO Bux Mrit

Anod, Massa

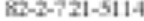

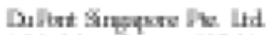

1 Maritime Square a

World Trudecise

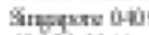

65-273-204

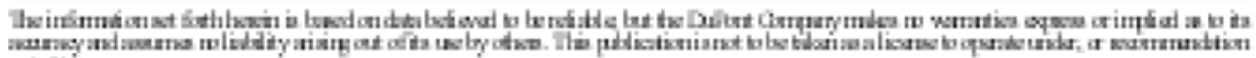
toinciag, arypotat 
WSRC-TR-2007-00439

Revision 0

\title{
Att.3 UTRC ${ }^{\text {TM }}$ Sodium Alanate Kinetics 1
}

\author{
Practical Sorption Kinetics of $\mathrm{TiCl}_{3}$ Catalyzed $\mathrm{NaAlH}_{4}$ \\ Xia Tang, Daniel A Mosher and Donald L Anton \\ United Technologies Research Center
}

411 Silver Lane

East Hartford, CT 06108

\begin{abstract}
Sodium alanate has been studied as a promising candidate material for reversible hydrogen storage due to its intermediate temperature range and relatively high storage capacity. Its rates of desorption and absorption of hydrogen have been shown to be enhanced by the addition of Ti in various compounds. To date, the sorption kinetics, especially absorption kinetics, is not well understood. In this study, a practical sorption kinetics model for $\mathrm{TiCl}_{3}$ catalyzed $\mathrm{NaAlH}_{4}$ has been developed to assist in the engineering design and evaluation of a prototype hydrogen storage system.
\end{abstract}

\section{Introduction}

The design of a hydrogen storage system using any exothermic hydriding compound, such as $\mathrm{NaAlH}_{4}$, requires detailed consideration of local heat management. This is especially important in the critical hydrogen absorption stage, where high kinetics are required and heat flow is at its maximum. Thermal transport architectures such as cooling tubes and metal foam structures need to be designed to meet the optimum operational characteristics of the hydrogen storage media. In order to design and model these architectures and obtain a gravimetrically and volumetrically optimized storage system, absorption and desorption kinetic models need to be identified and validated. Many current models, such as the wellknown Arrhenius model, are insufficient to characterize materials behavior under transient or partially discharged conditions. Previous kinetics studies of $\mathrm{NaAlH}_{4}$ mainly focused on the desorption reaction [14]. Aborption and desorption kinetics models were developed by Luo and Cross [5] to simulate $\mathrm{NaH}+\mathrm{Al}$ $\leftrightarrow \mathrm{NaAlH}_{4}$ reactions using $\mathrm{NaH}$ and $\mathrm{Al}$ as starting materials. No kinetics model was reported to simulate transient hydriding rate and hydrogen absorption capacity of $\mathrm{NaH}+\mathrm{Al}$ derived from $\mathrm{NaAlH}_{4}$. In this study, a solid/gas chemical kinetics model originally developed by El-Osery [6-9] to design conventional metal hydride systems was utilized. This model was adapted for use in the multi-step hydrogen absorption mechanisms of $\mathrm{NaH}+\mathrm{Al} \rightarrow \mathrm{NaAlH}_{4}$.

\section{Basic Kinetics Model}

The dehydrogenation and hydrogenation of sodium alanate involve the following well-known reactions: $\mathrm{NaAlH}_{4} \leftrightarrow 1 / 3 \mathrm{Na}_{3} \mathrm{AlH}_{6}+2 / 3 \mathrm{Al}+\mathrm{H}_{2} \leftrightarrow \mathrm{NaH}+\mathrm{Al}+3 / 2 \mathrm{H}_{2}$

For compactness, the compositional state can be tracked by a single variable for each product/reactant, $\mathrm{C}_{1}, \mathrm{C}_{2}$ and $\mathrm{C}_{3}$ as:

$\mathrm{C}_{1}: \mathrm{NaH}+\mathrm{Al}+3 / 2 \mathrm{H}_{2}$

$\mathrm{C}_{2}: 1 / 3 \mathrm{Na}_{3} \mathrm{AlH}_{6}+2 / 3 \mathrm{Al}+\mathrm{H}_{2}$

$\mathrm{C}_{3}: \mathrm{NaAlH}_{4}$

The nomenclatures for all reactions are listed in Table 1. 
WSRC-TR-2007-00439

Revision 0

Table 1 Nomenclature for All Reactions

\begin{tabular}{|c|c|c|c|}
\hline Label & Action & Reactant & Product \\
\hline$r_{1}$ & Dehydriding of $\mathrm{Na}_{3} \mathrm{AlH}_{6}$ & $\mathrm{C}_{2}$ & $\mathrm{C}_{1}$ \\
\hline $\mathrm{r}_{2}$ & Hydriding of $\mathrm{NaH}$ & $\mathrm{C}_{1}$ & $\mathrm{C}_{2}$ \\
\hline $\mathrm{r}_{3}$ & Dehydriding of $\mathrm{NaAlH}_{4}$ & $\mathrm{C}_{3}$ & $\mathrm{C}_{2}$ \\
\hline $\mathrm{r}_{4}$ & Hydriding of $\mathrm{Na}_{3} \mathrm{AlH}_{6}$ & $\mathrm{C}_{2}$ & $\mathrm{C}_{3}$ \\
\hline
\end{tabular}

Reaction rates can be represented by equation (1) based on the metal hydride model developed by ElOsery [6-7]:

$\left(\frac{d C_{j}}{d t}\right)_{r_{i}}=f_{T}(T) * f_{P}(P) * f_{C}\left(C_{k}\right)$

$i$ for reaction $r_{i}$

$j$ for composition product $C_{j}$

$k$ for composition reactant $C_{k}$

The temperature dependant term is that of the typical Arrhenius equation given as:

$f_{T}=A_{i} \exp \left(-\frac{E_{i}}{R T}\right)$

The pressure dependant term can be expressed simply as a first order expression:

$f_{P}=(-1)^{i} *\left(\frac{P-P_{e, i}}{P_{e, i}}\right)$

where $\mathrm{P}_{\mathrm{e}, \mathrm{i}}$ is the equilibrium pressure for the reaction and is valid for both hydriding and dehydriding.

Equilibrium pressure $P_{e, i}$ is temperature dependant and obeys the van't Hoff equation:

$\ln \left(P_{e, i}\right)=\frac{\Delta H}{R T}-\frac{\Delta S}{R}$

In El-Osery's description, a first order function of hydrogen/metal atomic ratio was used in a concentration factor for hydriding. In hydriding reactions of the $\mathrm{NaH}+\mathrm{Al}$ system, however, two solid reactants are involved in each reaction respectively. They may have higher reaction orders. The concentration factor is thus represented as being proportional to the reactant concentration to some power, $\chi_{\mathrm{i}}$ as:

$f_{C}=\left(C_{k}\right)^{\chi_{i}}$

Combining these factors results in the rate equation:

$\frac{d C_{j}}{d t}=A_{i} \exp \left(-\frac{E_{i}}{R T}\right) *(-1)^{i} *\left(\frac{P-P_{e, i}}{P_{e, i}}\right) *\left(C_{k}\right)^{\chi_{i}}$

Applying equation (2) to $r_{2}$ and $r_{4}$, one obtains the following equations for high pressure hydriding $\left(r_{2}\right.$ and $\mathrm{r}_{4}$ are active).

$$
\begin{aligned}
& \left(\frac{d C_{2}}{d t}\right)_{r 2}=A_{2} \exp \left(-\frac{E_{2}}{R T}\right) *\left(\frac{P-P_{e, 2}}{P_{e, 2}}\right) *\left(C_{1}\right)^{\chi_{2}} \text { and }\left(\frac{d C_{1}}{d t}\right)_{r 2}=-\left(\frac{d C_{2}}{d t}\right)_{r 2} \\
& \left(\frac{d C_{3}}{d t}\right)_{r 4}=A_{4} \exp \left(-\frac{E_{4}}{R T}\right) *\left(\frac{P-P_{e, 4}}{P_{e, 4}}\right) *\left(C_{2}\right)^{\chi_{4}} \text { and }\left(\frac{d C_{2}}{d t}\right)_{r 4}=-\left(\frac{d C_{3}}{d t}\right)_{r 4}
\end{aligned}
$$


The reaction rate of each composition can be represented as:

$$
\begin{aligned}
& \frac{d C_{1}}{d t}=-A_{2} \exp \left(-\frac{E_{2}}{R T}\right) *\left(\frac{P-P_{e, 2}}{P_{e, 2}}\right) *\left(C_{1}\right)^{\chi_{2}} \\
& \frac{d C_{2}}{d t}=A_{2} \exp \left(-\frac{E_{2}}{R T}\right) *\left(\frac{P-P_{e, 2}}{P_{e, 2}}\right) *\left(C_{1}\right)^{\chi_{2}}-A_{4} \exp \left(-\frac{E_{4}}{R T}\right) *\left(\frac{P-P_{e, 4}}{P_{e, 4}}\right) *\left(C_{2}\right)^{\chi_{4}} \\
& \frac{d C_{3}}{d t}=A_{4} \exp \left(-\frac{E_{4}}{R T}\right) *\left(\frac{P-P_{e, 4}}{P_{e, 4}}\right) *\left(C_{2}\right)^{\chi_{4}} \\
& 0 \leq C_{i} \leq 1
\end{aligned}
$$

with the initial reaction conditions: $C_{1}^{t=0}=1, C_{2}^{t=0}=0, C_{3}^{t=0}=0$,

\section{Experimental Procedure}

To validate the applicability of this kinetic model, a well-known alanate composition was chosen for empirical assessment. Commercial grade $\mathrm{NaAlH}_{4}$ was purchased from Albemarle Co. (Baton Rouge, LA) with a chemical certification analysis of $86.3 \% \mathrm{NaAlH}_{4}, 4.7 \% \mathrm{Na}_{3} \mathrm{AlH}_{6}, 7.5 \%$ free $\mathrm{Al}$ and $10.1 \%$ insoluble $\mathrm{Al}$ (with all analyses given in $\mathrm{wt} \%$ ). The catalyst, $\mathrm{TiCl}_{3}(99.99 \%$ ), was obtained from Aldrich Corp. All materials were used in the as-received condition.

The $\mathrm{NaAlH}_{4}$ was catalyzed with $4 \mathrm{~mol} \% \mathrm{TiCl}_{3}$ by high energy SPEX ball milling for three hours under nitrogen. Immediately after ball milling, approximately $1 \mathrm{~g}$ of the sample was transferred into the sample holder of a modified Sievert's apparatus. All the storage and transferring of $\mathrm{NaAlH}_{4}$ and $\mathrm{TiCl}_{3} \mathrm{were}$ performed under a high purity nitrogen environment inside a glove box with an oxygen concentration $<10^{-}$ ${ }^{5}$ ppm.

$\mathrm{TiCl}_{3}$ catalyzed $\mathrm{NaAlH}_{4}$ was first desorbed at $150^{\circ} \mathrm{C}$ in vacuum for more than 7 hours to ensure maximum desorption. Absorption was conducted with the hydrogen pressure ranging from 6.8-6.0 MPa. Extent of reaction versus time was measured by monitoring hydrogen pressure change using a gas reaction controller made by Advanced Materials Co. (Pittsburg, PA).

\section{Results and Discussion}

Rate equations (5) to (7) represent an ideal kinetics model, where the total charging capacity over long periods approaches the ideal capacity of $5.6 \mathrm{wt} \%$. However, in reality, the total capacity is usually less than the theoretical value. Saturation compositions, $C_{k}^{\text {Sat }}(T)$, are introduced into the rate equations to reflect this non-ideal capacity. They represent the residual reactant compositions at the hydriding saturation point fordifferent temperature values.

The concentration factors in equation (1d) are thus changed to:

$$
\begin{aligned}
& f_{C}=\left(C_{k}-C_{k}^{s a t}(t)\right)^{\chi_{i}} \text { if } C_{k}-C_{k}^{s a t}(T) \geq 0 \\
& f_{C}=0 \text { if } C_{k}-C_{k}^{s a t}(T)<0
\end{aligned}
$$

The rate equations are represented accordingly by:

$$
\frac{d C_{1}}{d t}=-A_{2} \exp \left(-\frac{E_{2}}{R T}\right) *\left(\frac{P-P_{e, 2}}{P_{e, 2}}\right) *\left[C_{1}-C_{1}^{s a t}(T)\right]^{\chi_{2}}
$$




$$
\begin{aligned}
& \frac{d C_{2}}{d t}=A_{2} \exp \left(-\frac{E_{2}}{R T}\right) *\left(\frac{P-P_{e, 2}}{P_{e, 2}}\right) *\left[C_{1}-C_{1}^{s a t}(T)\right]^{\chi_{2}}-A_{4} \exp \left(-\frac{E_{4}}{R T}\right) *\left(\frac{P-P_{e, 4}}{P_{e, 4}}\right) *\left[C_{2}-C_{2}^{s a t}(T)\right]^{\chi_{4}}(9) \\
& \frac{d C_{3}}{d t}=A_{4} \exp \left(-\frac{E_{4}}{R T}\right) *\left(\frac{P-P_{e, 4}}{P_{e, 4}}\right) *\left[C_{2}-C_{2}^{s a t}(T)\right]^{\chi_{4}}
\end{aligned}
$$

The modified compositions and total hydriding capacity at saturation are:

$C_{1}=C_{1}^{s a t}(T), \quad C_{2}=C_{2}^{s a t}(T), \quad C_{3}=1-C_{1}^{s a t}(T)-C_{2}^{s a t}(T)$

The total $\mathrm{H}_{2}$ absorption capacity $w_{\text {iso }}^{\text {sat }}(T)$ :

$w_{\text {iso }}^{\text {sat }}(T)=0.0187 * C_{2}^{\text {sat }}(T)+0.056 *\left(1-C_{1}^{\text {sat }}(T)-C_{2}^{\text {sat }}(T)\right)$

Curve fitting with experimental data using equations (8) to (13) is shown in Figure 1. The parameters used for fitting are listed in Table 2. The slope and intercept in the van't Hoff plot were derived from data published by Cross et al. [10].

\begin{tabular}{|c|c|c|}
\hline$(\Delta \mathrm{H} / \mathrm{R}) \mathrm{r}_{2}$ & -6150 & Slope in van't Hoff plot \\
\hline$-(\Delta \mathrm{S} / \mathrm{R}) \mathrm{r}_{2}$ & 16.22 & Intercept in van't Hoff plot \\
\hline $\mathrm{A}_{2}$ & $1.50 \mathrm{E}+05$ & Pre-exponent coefficient for $r_{2}$ \\
\hline $\mathrm{E}_{2}$ & 70 & Activation energy for $\mathrm{r}_{2}, \mathrm{KJ} / \mathrm{mol}$ of $\mathrm{H}_{2}$ for $\mathrm{r}_{2}$ \\
\hline$\chi_{2}$ & 1 & Reaction order for $\mathrm{r}_{2}$ \\
\hline$(\Delta \mathrm{H} / \mathrm{R}) \mathrm{r}_{4}$ & -4475 & Slope in van't Hoff plot, $r_{4}$ \\
\hline$-(\Delta \mathrm{S} / \mathrm{R}) \mathrm{r}_{4}$ & 14.83 & Intercept in van't Hoff plot, $\mathrm{r}_{4}$ \\
\hline $\mathrm{A}_{4}$ & $1.00 \mathrm{E}+08$ & Pre-exponent coefficient for $r_{4}$ \\
\hline$\overline{\mathrm{E}_{4}}$ & 80 & Activation energy for $r_{2}, k J / m o l$ of $\mathrm{H}_{2}$ for $r_{4}$ \\
\hline$\chi_{4}$ & 2 & Reaction order for $r_{4}$ \\
\hline
\end{tabular}

Table 2 Fitting Parameters in Figure 1

The activation energies, $E_{i}$, for $r_{2}$ and $r_{4}$ are 70 and $80 \mathrm{KJ} / \mathrm{mol}$ of $\mathrm{H}_{2}$ and the pre-exponent coefficients, $\mathrm{A}_{\mathrm{i}}, 1.50 \mathrm{E}+05$ and $1.00 \mathrm{E}+08$ respectively. The hydriding reaction, $\mathrm{r}_{4}\left(\mathrm{Na}_{3} \mathrm{AlH}_{6}\right.$ to $\left.\mathrm{NaAlH}_{4}\right)$ has a higher activation energy than the reaction, $\mathrm{r}_{2}, \mathrm{NaH}$ to $\mathrm{Na}_{3} \mathrm{AlH}_{6}$. However, the pre-exponential coefficient of $\mathrm{r}_{4}$ is much higher than $r_{2}$. This could be due to catalyst placement preferentially at positions favorable to $r_{4}$ reaction. The reaction orders of the two hydriding steps appear to be different, with $r_{2}$ being nominally a first order reaction, and $\mathrm{r}_{4}$ a second order reaction. The reaction orders are consistent with those reported by Luo and Gross [5]. During the formation of $\mathrm{Na}_{3} \mathrm{AlH}_{6}, \mathrm{NaH}$ is the limiting reactant and $\mathrm{Al}$ is in access. Al concentration can be considered as constant and the reaction becomes a pseudo first order. In $\mathrm{r}_{4}$, the reactants, $\mathrm{Na}_{3} \mathrm{AlH}_{6}$ and $\mathrm{Al}$, are in stichometric ratio. Both concentrations can affect reaction rate. The formation of $\mathrm{NaAlH}_{4}$, therefore, is a second order reaction. 


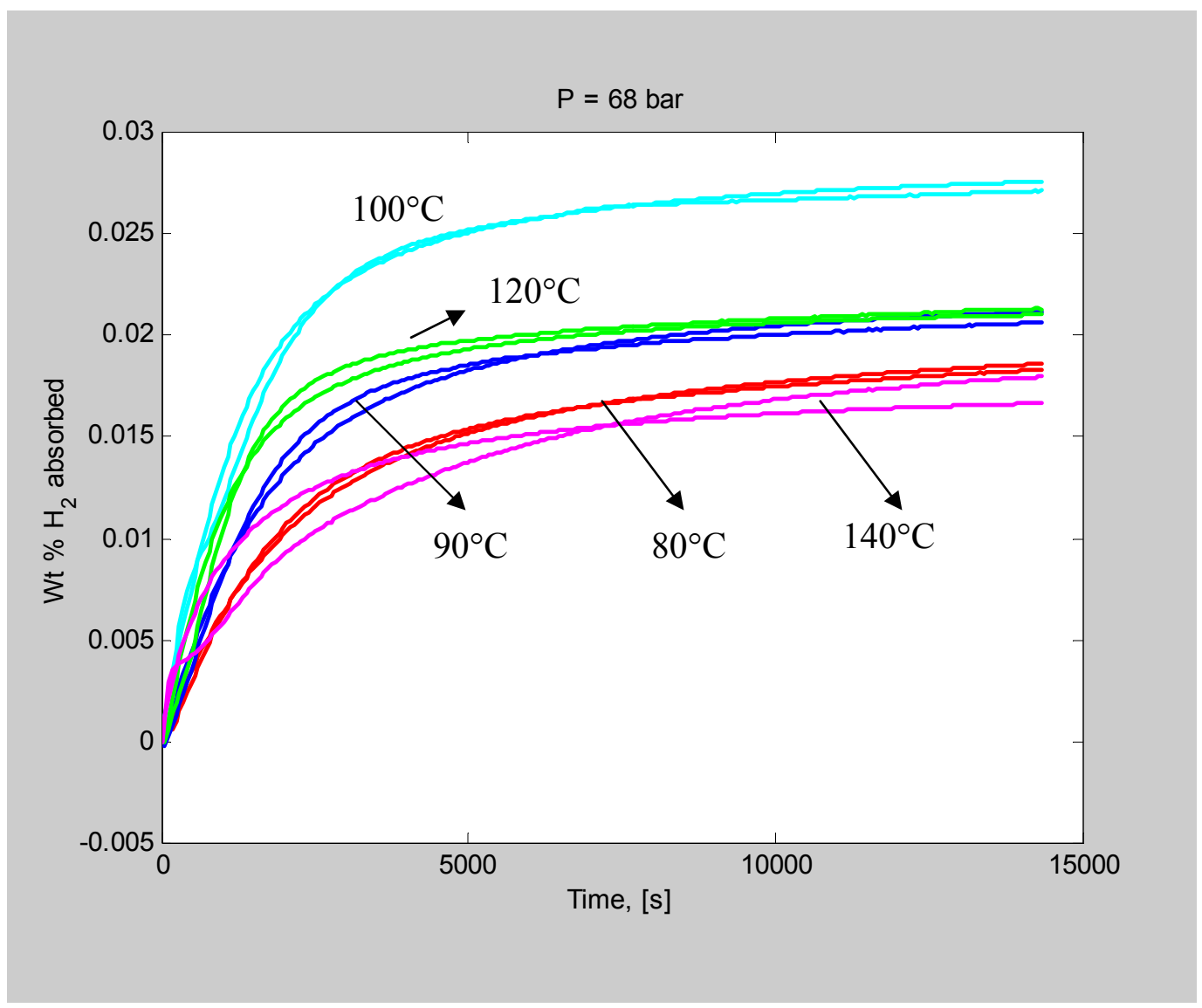

Figure $1 \quad \mathrm{H}_{2}$ absorption curves at $80-140^{\circ} \mathrm{C}$ with $\mathrm{H}_{2}$ pressure ranging from $6.0-6.8 \mathrm{MPa}$. The dashed lines are model results, with red $=80^{\circ} \mathrm{C}$; blue $=90^{\circ} \mathrm{C}$; cyan $=100^{\circ} \mathrm{C}$; green $=120^{\circ} \mathrm{C}$; and magenta $=140^{\circ} \mathrm{C}$.

As shown in Figure 1, the model fits experimental data well in absorption temperature range of $80^{\circ} \mathrm{C}$ $120^{\circ} \mathrm{C}$. However, the fit is not as accurate for absorption at $140^{\circ} \mathrm{C}$. As the temperature increases, the hydriding reaction of $\mathrm{Na}_{3} \mathrm{AlH}_{6}$ to $\mathrm{NaAlH}_{4}$ approaches its thermodynamic equilibrium at 6.0-6.8 $\mathrm{MPa}$ hydrogen pressure. The $P_{e}$ for $2 \mathrm{~mol} \% \mathrm{Ti}\left(\mathrm{OBu}^{\mathrm{n}}\right)_{4}$ catalyzed materials is $5.4 \mathrm{MPa}$ [9]. Although the reaction rate increases with temperature, the capacity decreases as a result of decreasing thermodynamic driving force. Absorption at this temperature is not recommended at this hydriding pressure.

By close inspection. it can be seen in Figure 1 that inflection regions are present during the initial rapid hydriding. Similar inflections were also observed in previous absorption data published by Sandrock et al. [11]. There are two possibilities for this observation; (i) a temperature rise in the sample upon exothermic hydriding of $\mathrm{NaH}$ to form $\mathrm{Na}_{3} \mathrm{AlH}_{6}$ or (ii) the combination of slowing down of the first hydriding reaction, $r_{2}$, and starting of the second reaction, $r_{4}$. To resolve this question, accurate sample temperature measurement is required. This non-isothermal factor can be included in future models when accurate in-situ measurement of the sample temperature becomes available. In addition, the current model is fit to isothermal hydriding data, with the assumption that the hydriding rate is not affected by thermal histories except that captured by the variables $C_{k}$. Reactions involving solid reactants and products usually involve product nucleation and growth periods, and reaction rates are closely related to the characteristics of these periods. Previous thermal histories could affect particle sizes, packing and reactant/catalyst distribution. These changes will have an effect on the characteristics of nucleation and growth, therefore altering reaction rates. Future kinetics models should take these factors into consideration. 


\section{Conclusion}

A practical kinetics model has been developed to simulate hydrogen absorption of $\mathrm{NaH}+\mathrm{Al}$ obtained from $\mathrm{TiCl}_{3}$ catalyzed $\mathrm{NaAlH}_{4}$. Physical meaning of the basic model is discussed. Modification of the model has been made with additional parameters for non-stoichiometric saturation compositions. The modified model fits well with experimental data at temperatures ranging from $80^{\circ} \mathrm{C}$ to $120^{\circ} \mathrm{C}$ in the pressures range 6.0-6.8MPa. This model has provided kinetic information needed in the design of $1 \mathrm{~kg}$ hydrogen storage system using $\mathrm{NaAlH}_{4}$ as storage media. Although this model needs further refinement to include nonisothermal factors and solid state reaction mechanisms, it has given valuable insights in optimizing thermal management and operational conditions for the $1 \mathrm{~kg}$ prototype system.

\section{Acknowledgements}

The funding for this study is provided by U.S. Department of Energy, under the contract DE-FC3602AL67610 and the input of Dr. C. Read. The authors also acknowledge Mr. R. Brown for his valuable contribution in performing experimental work.

\section{References}

1. T. Kiyobayashi, S.S. Srinivasan, D. Sun and C.M. Jensen, J. Phys. Chem.A 107, 7671-7674 (2003).

2. G. Sandrock, K. Gross and G. Thomas, J. Alloys Comp. 339 299-308 (2002).

3. K.J. Gross, E.H. Majzoub and S.W. Spangler, J. Alloys Comp. 356-357, 423-428 (2003).

4. D.L. Anton, J. Alloys Comp. 356-357, 400-404 (2003).

5. W. Luo and K.J. Gross, J. Alloys Comp. 385 224-231 (2002).

6. I.A. El-Osery, Int. J. Hydrogen Energy, 8, 191-198 (1983).

7. M.A. El-Osairy, I.A. El-Osery, A.M. Metwally and M.A. Hassan, J. Alloys Comp. 202, $125-$ 128(1993)

8. M.A. El-Gammal, I.A. El-Osery, A.M. Metwally and M.A. Hassan, Modeling, Measurement and Control, 46, 35-44 (1994).

9. M.A. El-Osairy, I.A. El-Osery, A.M. Metwally and M.A. Hassan, Int. J. Hydrogen Energy, 18, 517-524 (1993)

10. K.J. Gross, G.J. Thomas and C.M. Jensen, J. Alloys Comp. 330-332 683-690 (2002).

11. G. Sandrock, K. Gross and G. Thomas, J. Alloys Comp. 339 299-308 (2002). 
WSRC-TR-2007-00439

Revision 0

\section{Att.4 UTRC ${ }^{\text {TM }}$ Sodium Alanate Kinetics 2}

\section{DLA}

\section{Kinetics Model Refinements \\ Dan Mosher \\ $6 / 26 / 03$

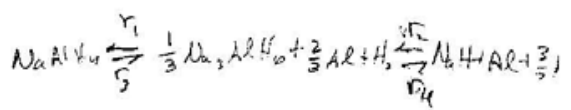

A number of refinements have been added to the kinetics model framework:

1. Check to make sure the composition variables are not outside the bounds of

$$
0 \leq C_{i} \leq \mathrm{I}
$$

2. Modify the reaction rate forms to allow different saturation hydrogen weight percentages at different temperatures.

1 Maintaining consistent values of the compositions, $C_{i} \longleftarrow$ Mole fiestisu ${ }^{2}$ ?

1.1 Comment on Model Aspect which Keeps Consistent values of $C_{i}$

What is it in the modeling framework that maintains consistent values for the compositions? The consistency requirements are

and

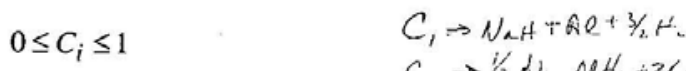

Equation 1 $\quad \sum_{i=1}^{3} C_{i}=1$

$$
\begin{aligned}
& C_{2} \rightarrow 1 / 3 \alpha_{a_{3}} \mathrm{AlH}_{6}+2 / 3 \mathrm{Al}+H^{\prime} \\
& C_{3} \rightarrow \mathrm{N}_{4} \mathrm{AlN} \mathrm{H}_{4}
\end{aligned}
$$

$$
\begin{aligned}
& d c_{1}=d C_{N_{n}} \\
& d c_{0}=3 d C_{N_{4}} A Q H_{0} \\
& d c_{3}=d c_{N_{1}} A C_{H} H_{4}
\end{aligned}
$$

For reaction 2 involving the hydriding of $\mathrm{NaH}$ (in the original model form with no saturation levels), we have

Equation 2

$$
\left(\frac{d C_{2}}{d t}\right)_{r 2} \propto\left(C_{1}\right)^{\chi_{2}}
$$

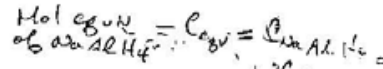

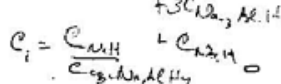

This produces a $C_{2}$ that will reach a limit as $C_{1} \rightarrow 0$, but it does not ensure that $0 \leq C_{2} \leq 1$. $C_{2}-C_{1, j u b}$

However, the relationship which balances the product formation rate with the reactant consumption rate,

\section{Equation 3}

$$
\left(\frac{d C_{1}}{d t}\right)_{r 2}=-\left(\frac{d C_{2}}{d t}\right)_{r 2}
$$

when integrated over a small time step, will produce

In this case,

$$
\left(\Delta C_{1}\right)_{r 2}=-\left(\Delta C_{2}\right)_{r 2}^{\prime}
$$

$$
\left(\Delta C_{1}+\Delta \dot{C}_{2}\right)_{r 2}=\left(-\Delta C_{2}+\Delta C_{2}\right)_{r 2}=0
$$

If we consider pressure regime three where both reactions 2 and 4 are active, we will also have

If we add these two equations,

$$
\left(\Delta C_{2}+\Delta C_{3}\right)_{r 4}=0
$$

Equation $4 \quad\left(\Delta C_{1}+\Delta C_{2}\right)_{r 2}+\left(\Delta C_{2}+\Delta C_{3}\right)_{r 4}=0$

Since the model framework specifies that for pressure regime 3 ,

$$
\begin{gathered}
\left(\Delta C_{1}\right)_{\text {total }}=\left(\Delta C_{1}\right)_{r 2} \\
\left(\Delta C_{2}\right)_{\text {total }}=\left(\Delta C_{2}\right)_{r 2}+\left(\dot{\Delta} C_{2}\right)_{r 4} \\
\left(\Delta C_{3}\right)_{\text {total }}=\left(\Delta C_{3}\right)_{r 4}
\end{gathered}
$$


WSRC-TR-2007-00439

Revision 0

Equation 4 becomes

$$
\left(\Delta C_{1}+\Delta C_{2}+\Delta C_{3}\right)_{\text {total }}=0
$$

or

$$
C_{1}+C_{2}+C_{3}=\text { constant }
$$

If we start with values which sum to 1, then Equation 1 will be satisfied for all time.

Figure 1 demonstrates that this indeed does occur during the simultations even with the potential errors associated with numerical integration. The sum of C's is $1.000000+1-8 \mathrm{e}-7$.

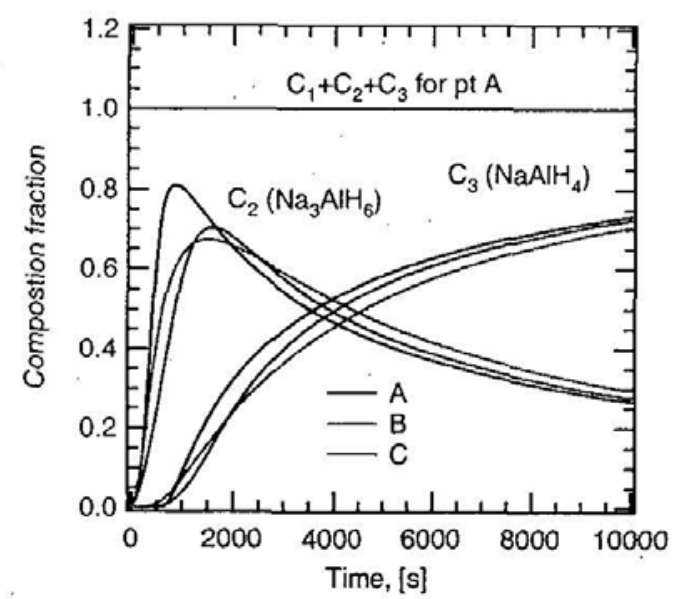

Figure 1: Composition results for four hole configuration.

\subsection{Potential Issue with Numerical Integration which Should Be Corrected}

With numerical integration, finite time steps are used. In this case, it is conceivable that the value of a reactant would not hit exactly 0 but could overshoot and become negative. An important influence of this is the value of the exponent $\chi$ on the composition variable. For the specific reaction of Equation 2 with $\chi_{2}=1$, if $C_{1}<0$ then $d C_{2} / d t<0$ and by Equation 3 , $d C_{1} / d t>0$ which will self correct the value of $C_{1}$ toward 0 . However, if $\chi_{2}=2$, the square of a negative number is a positive number, so that $C_{1}$ will become more negative in a run away numerical effect where $C_{1}$ becomes substantially less than 0 and $C_{2}$ becomes substantially greater thàn 1. As discussed above,

$$
\left(\Delta \dot{C_{1}}+\Delta C_{2}\right)_{r 2}=0
$$

would still apply but the individual values of $C_{1}$ and $C_{2}$ will diverge and be meaningless. Even though a value of $\chi=2$ has been used in ABAQUS simulations, this problem has not been observed probably because the reaction rates slow down adequately as $C_{1} \rightarrow 0$ so that the finite time steps do not produce an overshoot.

Nevertheless, modifications should be added to the coding to make sure that all of the compositions stay within the physical bounds of 0 and 1 . One approach is to simply check the values of the compositions and if they are starting to deviate, to set them equal to 0 or 1 as appropriate. For the particular reaction, it also might be necessary to adjust the conjugate variable in the reaction to avoid any drifting of the composition sum. Another approach is to modify the coding used to represent Equation 2 as 
WSRC-TR-2007-00439

Revision 0

$$
\left(\frac{d C_{2}}{d t}\right)_{r 2} \propto \operatorname{sign}\left(C_{1}\right) *\left[a b s\left(C_{1}\right)\right]^{\chi_{2}}
$$

This has two advantages. First, the self correcting nature is preserved even if $\chi=2$. Second, there will not be computation errors if $C_{1}$ is negative and the exponent is non-integer. Another, perhaps perferrable approach is to have

$$
\begin{gathered}
\left(\frac{d C_{2}}{d t}\right)_{r 2} \propto\left[C_{1}\right]^{\chi_{2}} \text { if } C_{1} \geq 0 \\
\left(\frac{d C_{2}}{d t}\right)_{r 2}=0 \text { if } C_{1}<0
\end{gathered}
$$

This essentially stops the hydriding reaction when the reactant concentration become slightly negative.

\section{Modeling of Saturation Weight Percentages Which Vary with Temperature}

\subsection{Introduction}

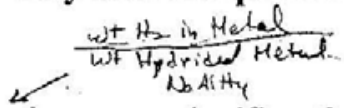

As shown in Figure 2, the saturation weight fraction absorbed can vary significantly with temperature. The value of $90 \mathrm{C}$ is 0.02 and that for $100 \mathrm{C}$ is 0.027 . In the present modeling structure, the hydrogen weight fraction stored in the material is calculated from the composition variables as

Equation 5

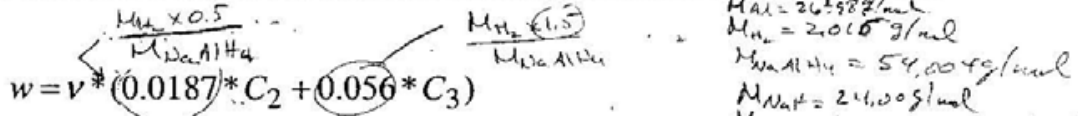

$$
\begin{aligned}
& M_{\omega_{a} A l H_{6}}=1.65 .029 \mathrm{~g} / \mathrm{mol}
\end{aligned}
$$

The variable $v$ represents the nonideal capacity. As a first attempt to fit the data in Figure 2, this variable was made temperature dependent,

$$
\text { Equation } 6 \quad w=v(T) *\left(0.0187 * C_{2}+0.056 * C_{3}\right)
$$

and the comparison with data in Figure 2 is reasonably good at longer times. The complexities of the incubation period where not modeled and therefore the short time comparison is not good.

This approach is adequate to match the constant temperature data, but it will have unrealistic behavior when temperature is changing. As an example, if at $10,000 \mathrm{~s}$, the temperature is changed from 90 to $100 \mathrm{C}$, the weight fraction will jump instantaneously from 0.02 to 0.027 which would not occur physically. Additional experiments in which the temperature is changed will be conducted to examine this effect. 
WSRC-TR-2007-00439

Revision 0

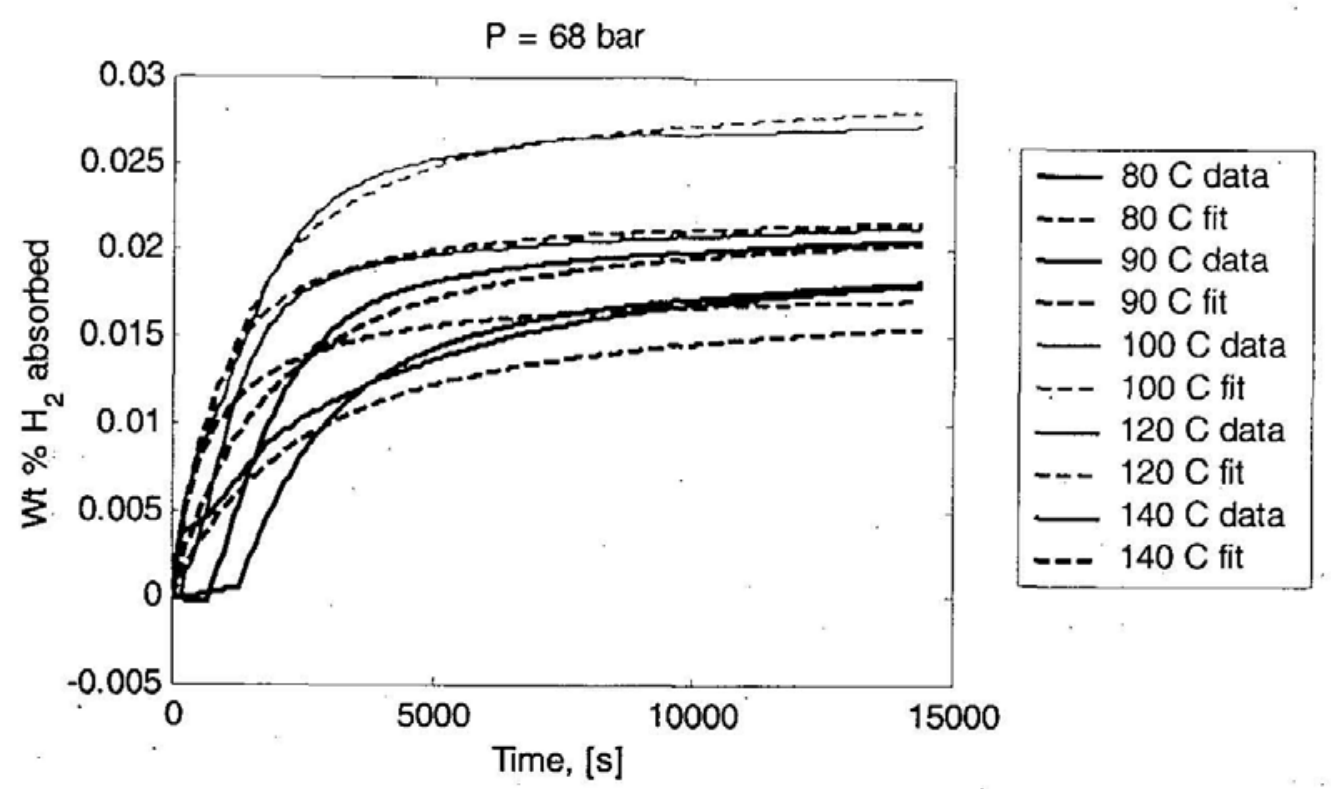

Figure 2: Absorption data for $6 \% \mathrm{TiCl} 3$ with fit to constant temperature model.

\subsection{Saturation Form for Single Composition, $C_{l}$}

The framework modifications to allow for saturation weight fraction differences for arbitrary temperature histories are discussed next. One modeling approach is to have

$$
\left(\frac{d C_{2}}{d t}\right)_{r 2} \propto\left(C_{1}-C_{1}^{s a t}(T)\right)^{z_{2}}
$$

which should be represented in the coding as

Equation $7 \quad\left(\frac{d C_{2}}{d t}\right)_{r 2} \propto\left[C_{1}-C_{1}^{s a t}(T)\right]^{x_{2}}$ if $C_{1}-C_{1}^{s a t}(T) \geq 0$

Equation 8

$$
\left(\frac{d C_{2}}{d t}\right)_{r 2}=0 \text { if } C_{1}-C_{1}^{s a t}(T)<0
$$

The value of this saturation $C_{1}$ is calcuated by considering the resulting long-time composition,

$$
C_{1}=C_{1}^{\text {sat }}, \quad C_{2}=0, \quad C_{3}=1-C_{1}^{\text {sat }} .
$$

and substituting these values into a modified version of Equation 5 where the obsolete factor of $v$ has been removed,

$$
\text { Equation } 9 \quad w=0.0187 * C_{2}+0.056 * C_{3}
$$

This results in a saturation value for the weight fraction under an isothermal temperature history of

or

$$
w_{i s o}^{\text {sat }}=0.056 *\left(1-C_{1}^{\text {sat }}\right)
$$


WSRC-TR-2007-00439

Equation 10

$$
C_{1}^{s a t}(T)=1-\frac{w_{i s o}^{s a t}(T)}{0: 056}
$$

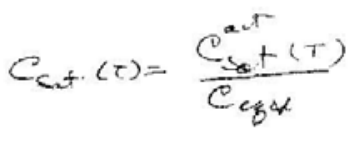

The parameter $w_{i s o}^{s a t}(T)$ represents the saturation level at long times for the absorbed weight fraction of hydrogen under an isothermal temperature history.

Because reaction 2 is a hydriding reaction, it can only proceed in the direction where $C_{2}$ is being produced and therefore we must have $C_{1}>C_{1}^{\text {sat }}$. If not, then Equation 8 applies.

The equation for the second hydriding reaction would not necessarily need to be altered with a saturation level for the reactant,

$$
\left(\frac{d C_{3}}{d t}\right)_{r 4} \propto\left(C_{2}\right)^{\chi_{4}}
$$

To illustrate this with an example, consider if $w_{i s o}^{\text {sat }}=0.020$ and so $C_{1}^{\text {sat }}=0.643$. If we start off with $C_{1}=1, C_{2}=0, C_{3}=0$, then after a long amount of hydriding, we would obtain $C_{1}=0.643, C_{2}=0, C_{3}=0.357$. then we will obtain the desired value of

$$
w=0.0187 * 0+0.056 * 0.357=0.020
$$

This approach appears to give reasonble physical behavior when changing temperatures for $C_{1}^{\text {sat }}$. increasing with time. If for example, we hydride at $90 \mathrm{C}$ for $10,000 \mathrm{~s}$ and then increase the temperature to $100 \mathrm{C}$, the value of $C_{1}^{\text {sat }}$ will decrease and reaction 2 will become active again. This will produce a gradual change in $w$ rather than the step change of Equation 6 . Whether this rate of change matches experiment is another question which needs to be addressed with additional experiments.

\subsection{Saturation Form for Two Compositions, $C_{1}$ and $C_{2}$}

If we are not able to match experiments (or if we just prefer the approach below with more adjustabie parameters), a possible modification is to have a saturation level of $C_{2}^{\text {sat }}$ for reaction 4

Equation $11 \quad\left(\frac{d C_{3}}{d t}\right)_{r 4} \propto\left[C_{2}-C_{2}^{s a t}(T)\right]^{\chi_{4}}$ if $C_{2}-C_{2}^{s a t}(T) \geq 0$

Equation 12

$$
\left(\frac{d C_{3}}{d t}\right)_{r 4}=0 \text { if } C_{2}-C_{2}^{s a t}(T)<0
$$

and to choose values of $C_{1}^{\text {sat }}$ and $C_{2}^{\text {sat }}$ from $w_{\text {iso }}^{\text {sat }}$ so that they are consistent with the final capacity. For this, after long times of hydriding in pressure regime 3 at a certain temperature $T$,

Applying Equation 9,

$$
C_{1} \doteq C_{1}^{\text {sat }}(T), \quad C_{2}=C_{2}^{\text {sat }}(T), \quad C_{3}=1-C_{1}^{\text {sat }}(T)-C_{2}^{\text {sat }}(T)
$$

Equation $13 \quad w_{i s o}^{\text {sat }}(T)=0.0187 * C_{2}^{\text {sat }}(T)+0.056 *\left(1-C_{1}^{\text {sat }}(T)-C_{2}^{\text {sat }}(T)\right)$ 
WSRC-TR-2007-00439

Revision 0

There are two unknowns and one equation, so we cannot uniquely determine $C_{1}^{\text {sat }}$ and $C_{2}^{\text {sat }}$.

An assumption on their relationship to each other or additional data is required to proceed. If we relate the two saturation values by (an alternate relation given in Equation 17 below was used ultimately in the coding implementation)

$$
R^{s a t}=\frac{C_{2}^{\text {sat }}(T)}{C_{1}^{\text {sat }}(T)},
$$

assuming that $R^{\text {sat }}$ does not depend on temperature, then

$$
\text { Equation } 14 \quad C_{2}^{\text {sat }}(T)=R^{s a t} * C_{1}^{\text {sat }}(T)
$$

and from Equation 13,

$$
w_{\text {iso }}^{\text {sat }}(T)=0.0187 * R^{\text {sat }} * C_{1}^{\text {sat }}(T)+0.056 *\left(1-C_{1}^{\text {sat }}(T)-R^{\text {sat }} * C_{1}^{\text {sat }}(T)\right)
$$

Solving for $C_{1}^{\text {sat }}$,

$$
\begin{gathered}
w_{\text {iso }}^{\text {sat }}=C_{1}^{\text {sat }} *\left(0.0187 * R^{\text {sat }}+0.056 *\left(-1-R^{\text {sat }}\right)\right)+0.056 \\
w_{\text {iso }}^{\text {sat }}-0.056=C_{1}^{\text {sat }} *\left(R^{\text {sat }} *(0.0187-0.056)-0.056\right) \\
C_{1}^{\text {sat }}=\frac{w_{\text {iso }}^{\text {sat }}-0.056}{R^{\text {sat }} *(0.0187-0.056)-0.056}
\end{gathered}
$$

and multiplying numerator and denominator by -1 ,

\section{Equation 15}

$$
C_{1}^{\text {sat }}=\frac{0.056-w_{\text {iso }}^{\text {sat }}}{0.056+R^{\text {sat }} *(0.056-0.0187)}
$$

And putting the temperature dependencies back in,

Equation 16

$$
C_{1}^{\text {sat }}(T)=\frac{0.056-w_{\text {iso }}^{\text {sat }}(T)}{0.056+R^{\text {sat }} *(0.056-0.0187)}
$$

As a check, if we only have $C_{1}^{\text {sat }}$, so that $R^{\text {sat }}=0$, then

which agrees with Equation 10.

$$
C_{1}^{\text {sat }}=\frac{0.056-w_{i s o}^{\text {sat }}}{0.056}=1-\frac{w_{\text {iso }}^{\text {sat }}}{0.056}
$$

The parameter $R^{\text {sat }}$ is an additional model parameter that can be adjusted to give the best match of all the data. In particular, it is expected that the data from temperature change tests will be the most useful in determining a representative value of $R^{\text {sat }}$. Also, it was noted in parameter fits that the value of $R^{\text {sat }}$ produced an inflection of the curve in some circumstances.

Returning to Equation 13 and solving for $C_{2}^{\text {sat }}(T)$,

$$
\begin{aligned}
& w_{\text {iso }}^{\text {sat }}(T)=(0.0187-0.056) * C_{2}^{\text {sat }}(T)+0.056 *\left(1-C_{1}^{\text {sat }}(T)\right) \\
& (0.0187-0.056) * C_{2}^{\text {sat }}(T)=w_{\text {iso }}^{\text {sat }}(T)-0.056 *\left(1-C_{1}^{\text {sat }}(T)\right)
\end{aligned}
$$


WSRC-TR-2007-00439

Revision 0

$$
\begin{aligned}
& \left.C_{2}^{\text {sat }}(T)=\frac{w_{\text {iso }}^{\text {sat }}(T)-0.056 *\left(1-C_{1}^{\text {sat }}(T)\right)}{(0.0187-0.056)}\right] \quad C_{2}(\tau)=\frac{3 C_{s}^{\text {sit }}(T)}{C_{c_{z i v}}}
\end{aligned}
$$

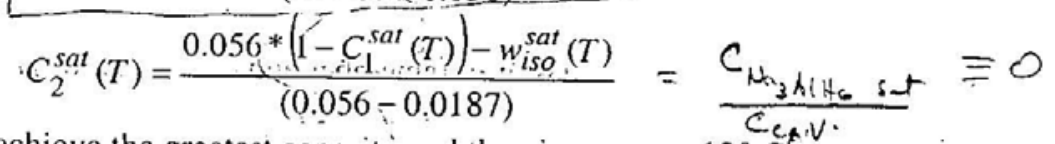

If we hydride at $100 \mathrm{C}$ to achieve the greatest capacity and then increase to $120 \mathrm{C}$, we would not expect the saturation weight fraction to drop to the lower level of a constant $120 \mathrm{C}$ history. Experiments need to examine this. If experiments do find that the saturation weight fraction does not change after the temperature change from 100 to $120 \mathrm{C}$, then this will be consistent with the model described above. To step through examination of the model, when the temperature is increased from 100 to $120 \mathrm{C}$, the value of $w_{i s o}^{\text {sat }}(T)$ will drop. The values of $C_{1}^{\text {sat }}(T)$ and $C_{2}^{\text {sat }}(T)$ determined from Equation 16 and Equation 14 will increase so that the arguments $\left(C_{1}-C_{1}^{\text {sat }}\right)$ and $\left(C_{2}-C_{2}^{\text {sat }}\right)$ will be less than zero and according to Equation 8 and Equation 12, the reaction rates will be zero as desired.

Physically, if $C_{1}^{\text {sat }}(T)=1$, then both reactions $\mathrm{r} 2$ and $\mathrm{r} 4$ will be eliminated and the saturated weight fraction can be set as low as 0 . However, setting $C_{2}^{\text {sat }}(T)=1$ by itself will only restrict reaction r4. If $C_{1}^{\text {sat }}(T) \approx 0$ associated with large values of $R^{\text {sat }}$, then the minimum weight fraction stored will be 0.0187 and this will all occur during reaction $\mathrm{r} 2$ giving little opportunity for an inflected curve. Because of this, restrictions on valid values of $R^{\text {sat }}$ and $w_{i s o}^{\text {sat }}(T)$ would be needed.

Rather than attempt such restrictions, akd alternate form relating $C_{1}^{\text {sat }}(T)$ and $C_{2}^{s a t}(T)$. was developed. In order for $C_{1}^{\text {sat }}(T) \geq 0$,

$$
\begin{gathered}
0.056 *\left(1-C_{1}^{\text {sat }}(T)\right) \geq w_{\text {iso }}^{\text {sat }}(T) \\
C_{1}^{\text {sat }}(T) \leq 1-\frac{w_{i s o}^{\text {sat }}(T)}{0.056}
\end{gathered}
$$

A convenient way to impose this restriction is to define

Then define a new independent parameter, $r^{\text {sat }}$,

$$
C_{1}^{\text {sat }, \max }(T)=1-\frac{w_{\text {iso }}^{\text {sat }}(T)}{0.056}
$$

Equation 17

$$
r^{s a t}=\frac{C_{1}^{s a t}(T)}{C_{1}^{s a t, \max }(T)}
$$

such that

or

$$
C_{1}^{\text {sat }}(T)=r^{\text {sat }} * C_{1}^{\text {sat }, \max }(T)
$$


WSRC-TR-2007-00439

Revision 0

\section{Equation 18}

$$
C_{1}^{s a t}(T)=r^{s a t} *\left(1-\frac{w_{i s o}^{s a t}(T)}{0.056}\right)
$$

In this way, the restriction is easier to remember and enforce as $0 \leq r^{\text {sat }} \leq 1$. Note that the right hand factor in Equation 18 will also be between 0 and 1 for reasonable values of $w_{i s o}^{\text {sat }}(T)$ so that after multiplying these two factors, we will have $0 \leq C_{1}^{\text {sat }}(T) \leq 1$. Once $r^{\text {sat }}$ is chosen, compute $C_{1}^{\text {sat }}(T)$ from Equation 18 and computc $C_{2}^{\text {sat }}(T)$ from

$$
\begin{aligned}
C_{2}^{\text {sat }}(T) & =\frac{0.056 *\left(1-r^{\text {sat }} *\left(1-\frac{w_{\text {iso }}^{\text {sat }}(T)}{0.056}\right)\right)-w_{\text {iso }}^{\text {sat }}(T)}{(0.056-0.0187)} \\
& =\frac{\left(0.056-r^{\text {sat }} *\left(0.056-w_{\text {iso }}^{\text {sat }}(T)\right)\right)-w_{\text {iso }}^{\text {sat }}(T)}{(0.056-0.0187)} \\
& =\frac{\left(1-r^{\text {sat }}\right) *\left(0.056-w_{\text {iso }}^{\text {sat }}(T)\right)}{(0.056-0.0187)}
\end{aligned}
$$

or

Equation 19

$$
C_{2^{\prime \prime}}^{s a t}(T)=\frac{\left(1-r^{s a t}\right) *\left(0.056-w_{i s o}^{s a t}(T)\right)}{\left(0.056^{\prime}-0.0187\right)}
$$

The form of Equation 19 shows that $C_{2}^{\text {sat }}(T)$ must go to zero as $r^{\text {sat }}$ approaches 1 or $w_{\text {iso }}^{\text {sat }}(T)$ approaches 0.056 . This is intuitive since the first condition is if all of the nonideal capacity is accounted for in $C_{1}^{\text {sat }}(T)$ and the latter is that the actual capacity equals the ideal level, i.e. no need for saturation compositions. An additional restriction is needed however, because it is possible for $C_{2}^{\text {sat }}(T)$ to become greater than 1 if $w_{i s o}^{\text {sat }}(T)$ is less than 0.0187 and $r^{\text {sat }}$ is 0 or nearly 0 . To examine this second restriction,

$$
\begin{gathered}
C_{2}^{\text {sat }}(T) \leq 1 \\
\frac{\left(1-r^{\text {sat }}\right) *\left(0.056-w_{i s o}^{\text {sat }}(T)\right)}{(0.056-0.0187)} \leq 1 \\
\left(1-r^{\text {sat }}\right) *\left(0.056-w_{i s o}^{\text {sat }}(T)\right) \leq(0.056-0.0187) \\
1-r^{\text {sat }} \leq \frac{(0.056-0.0187)}{\left(0.056-w_{\text {iso }}^{\text {sat }}(T)\right)} \\
r^{\text {sat }} \geq 1 \frac{0.056-0.0187}{0.056-w_{\text {iso }}^{\text {sat }}(T)}
\end{gathered}
$$

One characteristic of the model with both $C_{\mathrm{l}}^{\text {sat }}(T)$ and $C_{2}^{\text {sat }}(T)$ is if we start out with an initial composition of $C_{2}=0$, the first hydriding reaction will need to proceed to the point were $C_{2}>C_{2}^{\text {sat }}$ before reaction 4 will begin. Thus there will be a time lag between when some $C_{2}$ reactant is available and when reaction 4 becomes active. This may produce an inflection in the curve. 
WSRC-TR-2007-00439

Revision 0

\subsection{Modified Form for All Pressure Regimes}

The previous examination has focused just on pressure regime 3 for which both reactions are proceeding in the hydriding direction. For reversible reactions, we would anticipate that the amount stored would need to equal the amount released, at lcast after steady state has been reached. Because the amount stored was limited by introducing saturation levels for $C_{1}$ and $C_{2}$, the amount released will already be limited and we do not need to change the form for the dehydriding reactions (although the parameters will need to be modified from previous estimates). Another way to consider whether to have saturation levels on the dehydriding reactions is to think that in the dehydriding direction, we want all of the reactants to be consumed so the compositions can return to the initial state of $C_{1}=1, C_{2}=0, C_{3}=0$. If we have saturation levels for $C_{2}$ or $C_{3}$, then the dehydriding rate will go to zero before the compositions drop to zero. Therefore, we do not want saturation values on the reactants for the dehydriding reactions.

In the current model framework, the composition at the start of hydriding test after complete dehydriding would be

$$
C_{1}=1, \quad C_{2}=0, \quad C_{3}=0
$$

and the composition at the start of dehydriding after complete hydriding at temperature $T$ would be

$$
C_{1}=C_{1}^{s a t}(T), \quad C_{2}=C_{2}^{s a t}(T), \quad C_{3}=1-C_{1}^{s a t}(T)-C_{2}^{s a t}(T)
$$

A sketch of the three pressure regimes is shown in Figure 3.

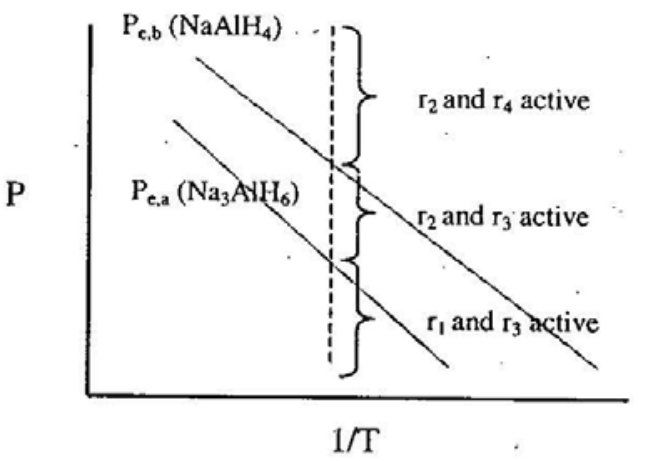

Figure 3: Reaction pressure regimes. 
WSRC-TR-2007-00439

Revision 0

The complete model for all three pressure regimes will be,

Table 1: Complete listing of reaction rate equations.

\begin{tabular}{|c|c|}
\hline $\mathrm{r} 1$ and $\mathrm{r} 3$ active & $\begin{array}{l}\text { If } C_{2} \geq 0, \quad\left(\frac{d C_{1}}{d t}\right)_{r 1}=A_{1} \exp \left(-\frac{E_{1}}{R T}\right) *\left(\frac{P_{e, 1}-P}{P_{e, 1}}\right) *\left(C_{2}\right)^{\chi_{1}} \\
\left(\frac{d C_{2}}{d t}\right)_{r 1}=-\left(\frac{d C_{1}}{d t}\right)_{r 1} \\
\text { If } C_{3} \geq 0, \quad\left(\frac{d C_{2}}{d t}\right)_{r 3}=A_{3} \exp \left(-\frac{E_{3}}{R T}\right) *\left(\frac{P_{e, 3}-P}{P_{e, 3}}\right) *\left(C_{3}\right)^{\chi_{3}} \\
\left(\frac{d C_{3}}{d t}\right)_{r 3}=-\left(\frac{d C_{2}}{d t}\right)_{r 3}\end{array}$ \\
\hline $\begin{array}{l}\text { Pressure regime } 2 \\
\mathrm{r} 2 \text { and } \mathrm{r} 3 \text { active }\end{array}$ & $\begin{array}{l}\text { If } C_{1}-C_{1}^{s a t}(T) \geq 0,\left(\frac{d C_{2}}{d t}\right)_{r 2}=A_{2} \exp \left(-\frac{E_{2}}{R T}\right) *\left(\frac{P-P_{e, 2}}{P_{e, 2}}\right) *\left(C_{1}-C_{1}^{s a t}(T)\right)^{\chi_{2}} \\
\left(\frac{d C_{1}}{d t}\right)_{r 2}=-\left(\frac{d C_{2}}{d t}\right)_{r 2} \\
\text { If } C_{3} \geq 0, \quad\left(\frac{d C_{2}}{d t}\right)_{r 3}=A_{3} \exp \left(-\frac{E_{3}}{R T}\right) *\left(\frac{P_{e, 3}-P}{P_{e, 3}}\right) *\left(C_{3}\right)^{\chi_{3}} \\
\left(\frac{d C_{3}}{d t}\right)_{r 3}=-\left(\frac{d C_{2}}{d t}\right)_{r 3}\end{array}$ \\
\hline $\begin{array}{l}\text { Pressure regime } 3 \\
\mathrm{r} 2 \text { and } \mathrm{r} 4 \text { active }\end{array}$ & $\begin{array}{l}\text { If } C_{1}-C_{1}^{s a t}(T) \geq 0,\left(\frac{d C_{2}}{d t}\right)_{r 2}=A_{2} \exp \left(-\frac{E_{2}}{R T}\right) *\left(\frac{P-P_{e, 2}}{P_{e, 2}}\right) *\left(C_{1}-C_{1}^{s a t}(T)\right)^{x_{2}} \\
\left(\frac{d C_{1}}{d t}\right)_{r 2}=-\left(\frac{d C_{2}}{d t}\right)_{r 2} \\
\text { If } C_{2}-C_{2}^{s a t}(T) \geq 0,\left(\frac{d C_{3}}{d t}\right)_{r 4}=A_{4} \exp \left(-\frac{E_{4}}{R T}\right) *\left(\frac{P-P_{e, 4}}{P_{e, 4}}\right) *\left(C_{2}-C_{2}^{s a t}(T)\right)^{\chi_{4}} \\
\left(\frac{d C_{2}}{d t}\right)_{r 4}=-\left(\frac{d C_{3}}{d t}\right)_{r 4}\end{array}$ \\
\hline
\end{tabular}

If the quantities stated in Table 1 which need to be $\geq 0$ are actually $<0$, then the associated reaction rate is set to 0 .

For all three pressure regimes, the total rate of change for $C_{2}$ will be the sum for each of the two active reactions,

$$
\left(\frac{d C_{2}}{d t}\right)_{\text {total }}=\left(\frac{d C_{2}}{d t}\right)_{\mathrm{r} 1 \text { or } \mathrm{r} 2}+\left(\frac{d C_{2}}{d t}\right)_{\mathrm{r} 3 \text { or } \mathrm{r} 4}
$$


WSRC-TR-2007-00439

Revision 0

As present previously, the equilibrium pressure is

$$
\ln \left(P_{e}\right)=\frac{\Delta H}{R T}-\frac{\Delta S}{R}
$$

or

Equation 20

$$
P_{e}(T)=\exp \left(\frac{\Delta H}{R T}-\frac{\Delta S}{R}\right)
$$

\section{Effect of Parameters on Curve Characteristics}

Some parameter fitting and sensitivity studies were conducted with the initial relation of

Equation 14 using $R^{\text {sat }}$ for the saturation compositions. The value of $R^{\text {sat }}$ influences the weight fraction level at which the inflection point occurs for the transition between the reactions. This is shown in Figure 4 through Figure 7 for the $100 \mathrm{C}$ data. A slightly different set of parameters was used to fit the $120 \mathrm{C}$ data shown in Figure 8 through Figure 11.

Using Equation 17 to choose different values of the saturation compositions, it seemed more difficult to produce the inflection point in the curves during parameter estimatation trials using MATLAB. There is no restriction in the new form that should make this happen, and it is likely that this was caused by having different values of the other model parameters that affect the relative rates etc. of the two hydriding reactions. A small amount of thought was invested into what conditions would lead to a more prominent inflection region, but this was shelved in the interest of completing the model and its application. For an inflection region to occur, one needs reaction 2 to slow down, to have reaction 4 become active, to have reaction 2 still proceed to produce more reactant for reaction 4 but to have reaction 4 accelerate in hydrogen production. It is still unclear what values of the parameters (or dependencies between them) will produce a pronounced inflection region.

The fit to experimental data using Equation 17 is shown in Figure 12 using the parameter values of Table 2 . The value of $r^{\text {sat }}$ was set equal to 1 for all temperatures, which in effect sets $C_{2}^{\text {sat }}=0$ and would appear to eliminate the possibility of an inflection region. Other parameter combination are still possible to give a better match. Neviertheless, the results are reasonably good. The fit at $140 \mathrm{C}$ is the poorest due to the large inflection region. The model was also fit to the desorption data shown in Figure 13. A different value for $C_{1}^{\text {sat }}=0.5$ was used to best match * the resulting capacities. We could argue that such flexibility in choosing $C_{1}^{\text {sat }}$ is acceptable since we do not known the actual composition of the as received / milled material. 

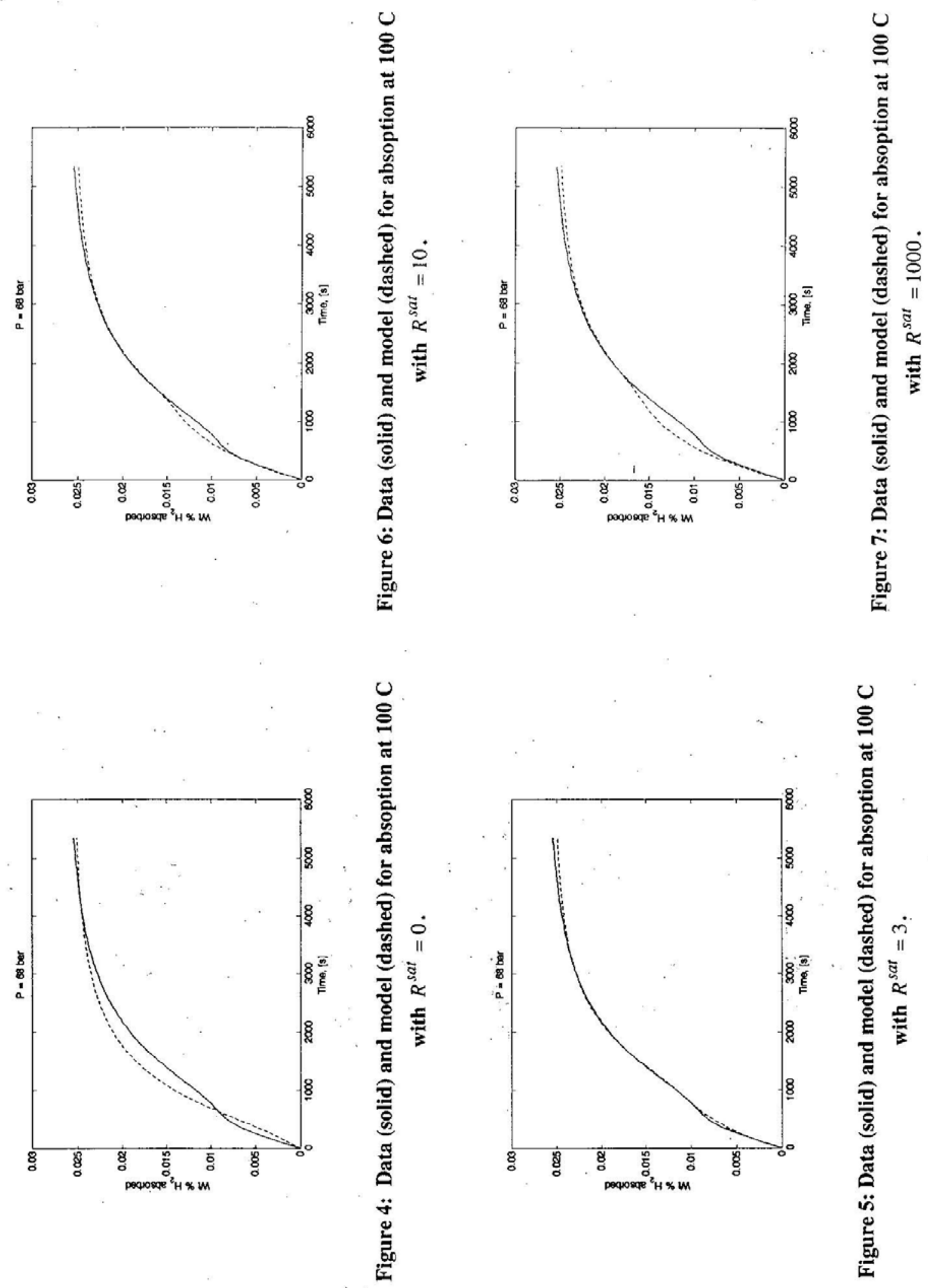

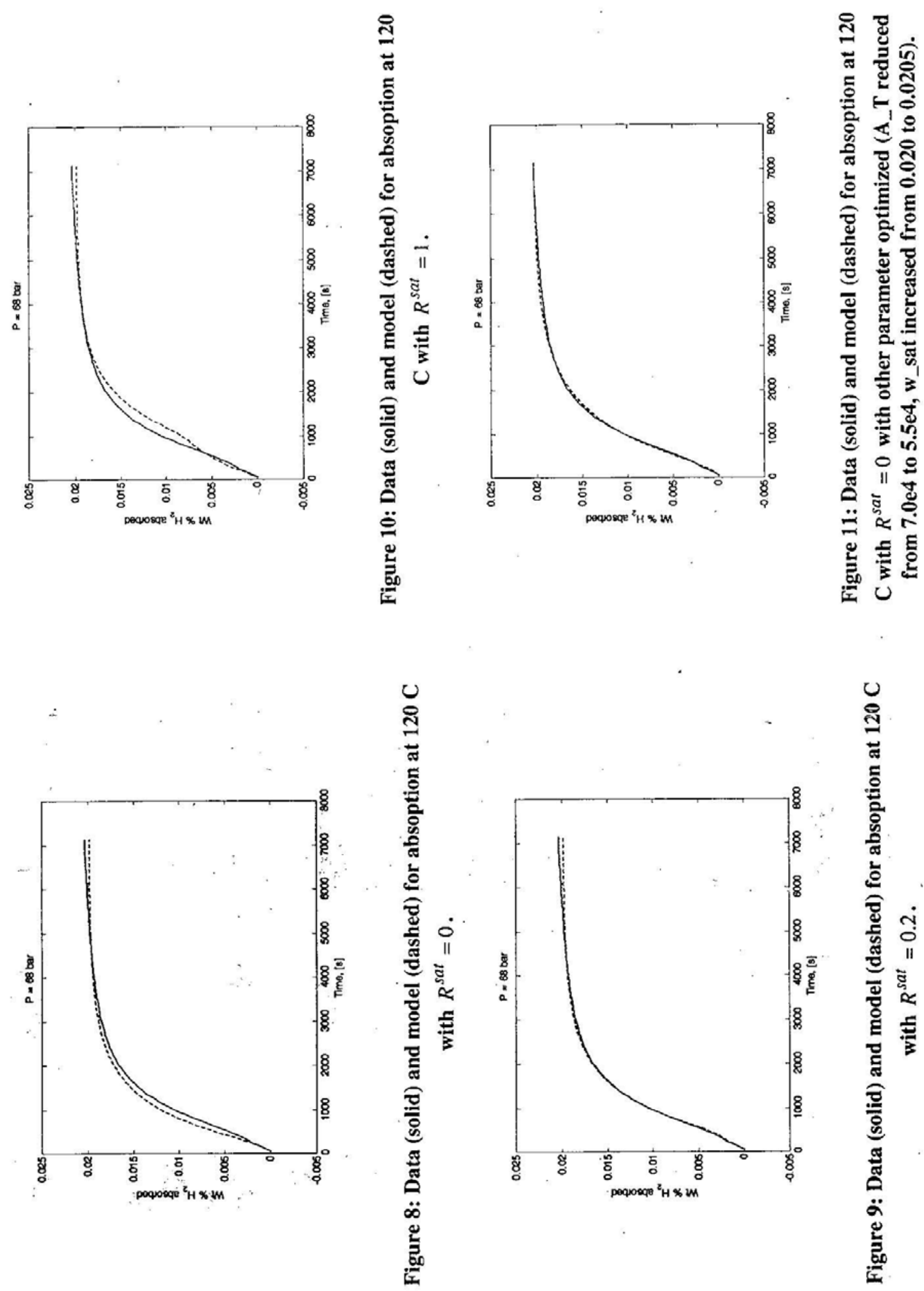
WSRC-TR-2007-00439

Revision 0

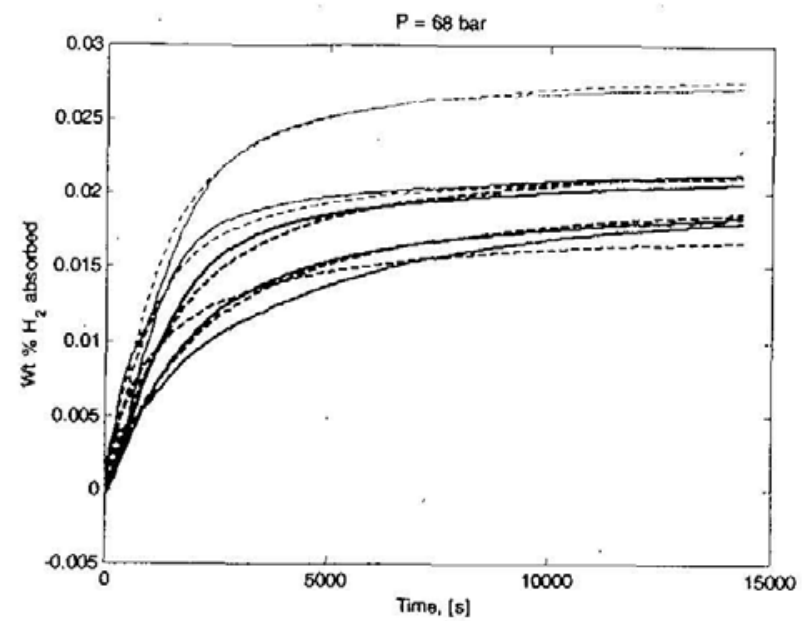

Figure 12: Absorption with starting $C_{-} 1=1$ and $T$ dependent C_1_sat $\left(r_{-}\right.$sat $(T)=1$ so $\left.C \_2 \_s a t=0\right)$. The dashed lines are the model with red $=80 \mathrm{C}$; blue $=90 \mathrm{C}$; cyan $=100 \mathrm{C}$; green $=120 \mathrm{C}$; and magenta $=140 \mathrm{C}$.

Table 2: MATLAB coding giving model parameter values.

T_sat_C $=\left[\begin{array}{lllllll}0 & 80 & 90 & 100 & 120 & 140 & 300\end{array}\right] ; \quad \%$ temperatures associated with w_iso

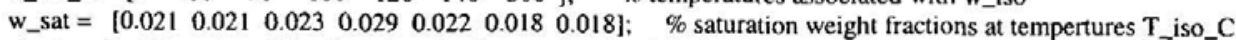
$r_{\text {_sat }}=\left[\begin{array}{llllllllll}1 & 1 & 1 & 1.0 & 1 & 1 & 1\end{array}\right]$; $\quad$ ratio of C_1_sat / C___sat_max

r_sat_threshold $=1-(0.056-0.0187) . /\left(0.056-\mathrm{w}_{\_}\right.$sat $) ; \%$ restriction level for $r_{-}$sat, $1-(0.056-0.0187) / 0.056=0.333$ $r_{\text {_sat }}=\max \left(r_{-}\right.$sat, r_sat_threshold); $\quad \%$ check for values of $r_{-}$sat that will maintain $\mathrm{C}_{2} 2$ sat $<1$.

T_sat_K $=$ T_sat_C +273

i_r = 1; \% directional reaction 1; dehydriding of $\mathrm{Na3AlH6}$ to $\mathrm{NaH}$ param $\left(i_{i} r, 1\right)=-6150 ; \quad \%$ A or delta $H / R$, stope in van't Hoff plot param $\left(i_{-} r, 2\right)=16.22 ; \quad \%$ B or -delta $S / R$, intercept in van't Hoff plot

param $\left(i_{1} r, 3\right)=6.0 \mathrm{e} 12 ; \quad \%$ A_ $\Upsilon$, lcading coefficient in temperature factor, time unit of seconds param $\left(\mathrm{i} \_\mathrm{r}, 4\right)=110000 ; \quad \% \mathrm{E}$, thermal activation energy, $\mathrm{J} / \mathrm{mol}$ of $\mathrm{H}_{-} 2$ param $\left(i \_r, 5\right)=1.0 ; \quad \%$ chi, exponent on reactant weight fraetion.

$i_{-} r=2$; \% directional reaction 2, hydriding of $\mathrm{NaH}$ to Na3AlH6 $\left(-r_{2}\right)$ param $\left(i \_r, 1\right)=-6150 ; \quad \% A$, not used, value for $i \_r=1$ used.

param $\left(i_{i} r, 2\right)=16.22 ; \quad \% B$, not used, value for $i_{-} r=1$ used param(i_r,3) $=1.5 \mathrm{e} 5: \quad \%$ A_T . param $\left(i_{-} r .4\right)=70000 ; \quad \% \mathrm{E}$ param $(i, r, 5)=1.0 ; \quad \%$ chi

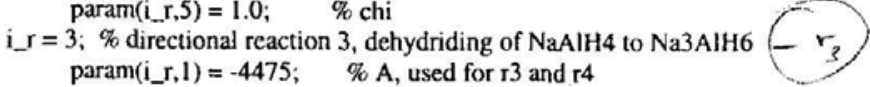
param $\left(i \_r, 2\right)=14.83 ; \quad \% B$, used for $r 3$ and $r 4(14.83)$

param $\left(i_{1} r, 3\right)=4.0 \mathrm{e} 12 ; \quad$ \% A_T param $\left(i \_r, 4\right)=110000 ; \quad \% \mathrm{E}$ param(i_r.5) $=2.0 ; \quad \%$ chi

i_r $=4$ : \% directional reaction 4, hydriding of Na3AlH6 to NaAlH4 - $r_{2}$ param $\left(i \_r, 1\right)=-4475 ; \quad \% A$, not used, value for $i \_r=3$ used param $\left(i_{\_} r, 2\right)=14.83 ; \quad \% B$, not used, value for $i_{-} r=3$ used (14.83) param(i_r.3) $=1.0 \mathrm{e} 8 ; \quad \%$ A_T param $\left(i_{1} r, 4\right)=80000 ; \quad \% \mathrm{E}$ param(i_r. 5$)=2 ; \quad \%$ chi

$\Delta H / R$ $-\Delta S / R$ A.

$\stackrel{E}{x}$ 
WSRC-TR-2007-00439

Revision 0

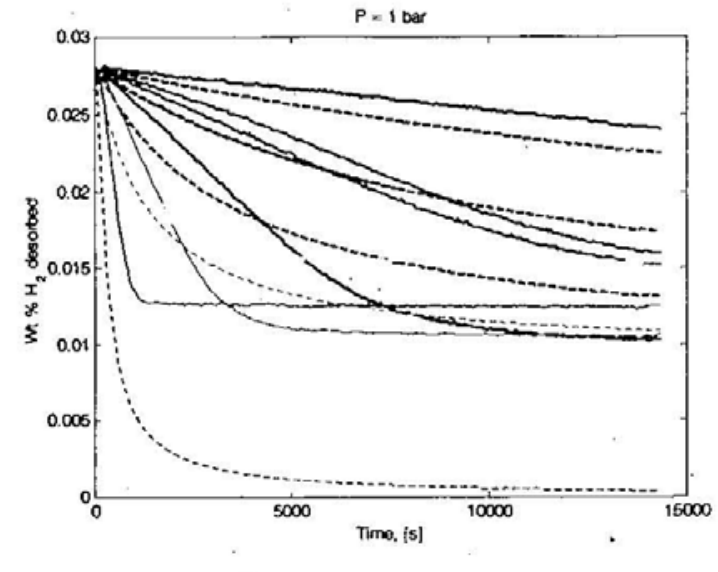

Figure 13: Desorption from as milled condition (assume C_1_sat $=0.5$ ). Dashed lines are model. Temperatures are black $=70 \mathrm{C} ;$ red $=80 \mathrm{C}$ (two experiments); blue $=90 \mathrm{C}$; cyan $=100 \mathrm{C}$; yellow $=110 \mathrm{C}$; green $=120 \mathrm{C}$;

Note that the equilibrium pressure for the lower van't Hoff line using a modified Equation 20 and parameters in Table 2 is

$$
P_{e}(T)=\exp \left(\frac{A}{T}+B\right)=\exp \left(\frac{-6150}{T}+16.22\right)
$$

Solving for the transition temperature for the desorption pressure of $1 \mathrm{~atm}$,

$$
T=\frac{-6150}{\ln \left(P_{e}(T)\right)-16.22}=\frac{-6150}{\ln (1 \mathrm{~atm})-16.22}=379 \mathrm{~K}=106 \mathrm{C}
$$

Thus, we would expect significant differences in capacity for temperatures above $106 \mathrm{C}$ versus those below it. This is reflected in the model predictions of Figure 13 (yellow and green lines) but not in the experimental data. In fact, after $8,000 \mathrm{~s}$, the desorbed capacity at $90 \mathrm{C}$ is greater than at $120 \mathrm{C}$. Additional experimentation and modeling is required to understand this effect.

The modifications to the kinetics model were made to the ABAQUS subroutines and check with a simple isothermal test problem. The user subroutine "powder_user2.for" was developed from the previous "powder_user.for" file based on additional modeling and parameter estimation in MATLAB. The implementation of changes required adding parameters to calculate saturation compositions and also the addition of these saturation levels to the hydriding reaction rate equations. Simple simulations were conducted in ABAQUS to verify that the implementation was accurate. These were nearly isothermal simulations of a cube $0.1 \mathrm{~m}$ in size. A slight temperature difference was produced by imposing a convective boundary condition which was 1 degree $\mathrm{C}$ higher than the initial temperature to avoid numerical problems of taking to small of a time step in transient thermal analyses. Such a small time $(100 \mathrm{~s})$ is needed to integrate the reaction equations. 
WSRC-TR-2007-00439

Revision 0

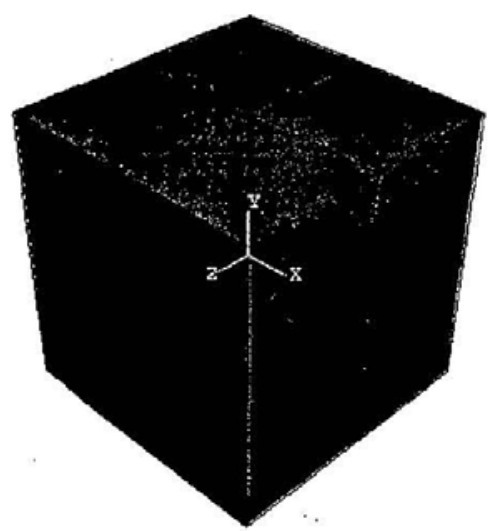

Figure 14: 0.1 meter cube used to test implementation of model in ABAQUS.

The results below are very similar to the comparison of data with the MATLAB implementation as expected. After these simulations were run, code was added to the user subroutine HETVAL to check whether the composition factors were positive. A simulation at $140 \mathrm{C}$ was then rerun and the results did not changed at all. This is expected since the value of $r_{-}$sat was 1 for all temperatures so that C_2_sat $=0$ and therefore there would not be any negative composition factors for an isothermal history starting with $C_{-} 1=1$. Note that the checks for negative composition factors were in the MATLAB code used to fit the parameters. Therefore, though the code was modified, it is expected that the results for the other temperatures besides $140 \mathrm{C}$ will also agree as in the figure.

The results in Figure 15 show good agreement with Figure 12 indicating the coditig of equations including their integration is accurate, at least for these conditions.

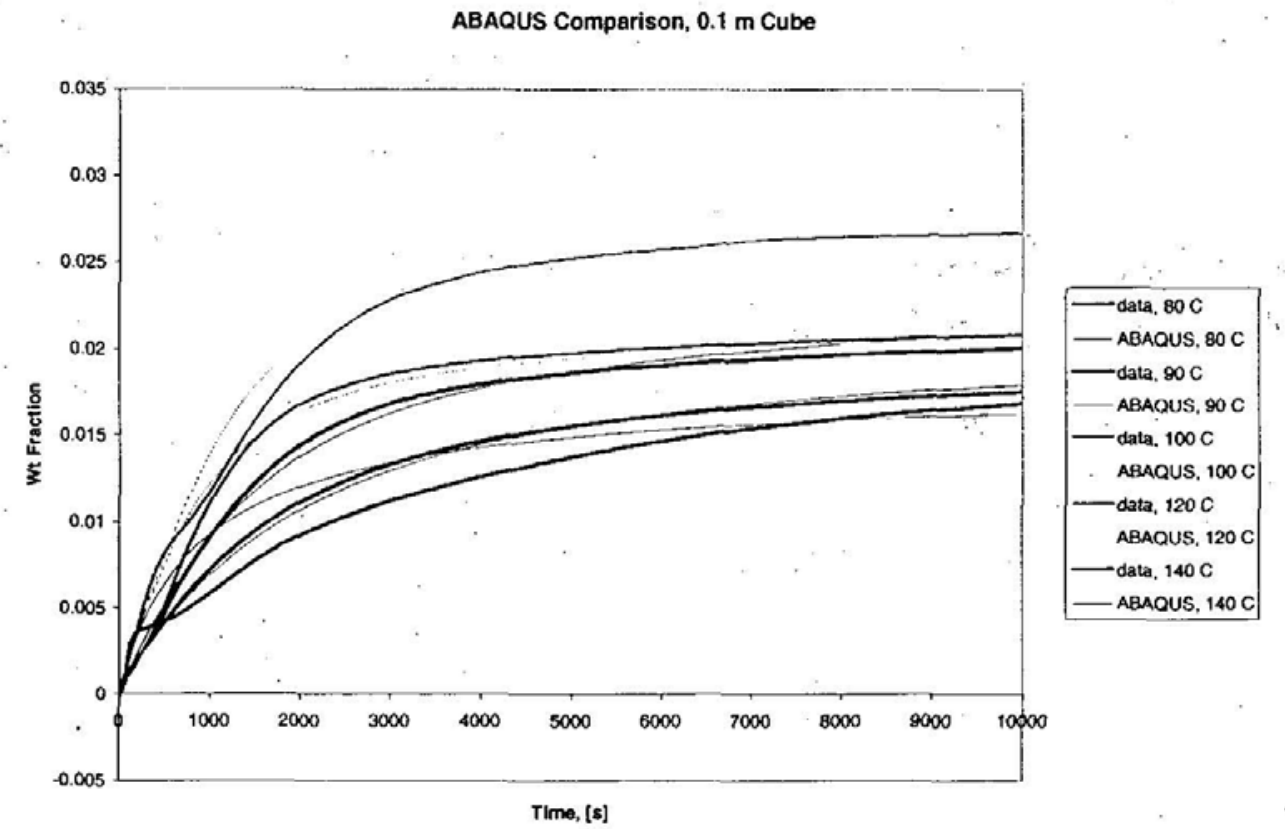

Figure 15: Results for absorption conditions. 